\title{
Electrophilic Fluorination of Secondary Phosphine Oxides and Its Application to $\mathbf{P}-\mathbf{O}$ Bond Construction
}

Qian Chen, * Jiekun Zeng, Xinxing Yan, Yulin Huang, Chunxiao Wen, Xingguo Liu, and Kun Zhang

School of Chemical Engineering and Light Industry, Guangdong University of

Technology, Guangzhou 510006, China

*E-mail: qianchen@gdut.edu.cn

\section{SUPPORTING INFORMATION}

\section{Content:}

1. Overview of substrates numbering ........................................ 2

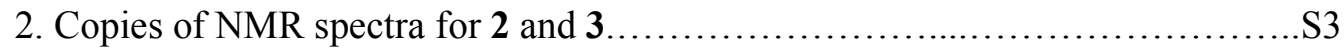




\section{Overview of substrates numbering}
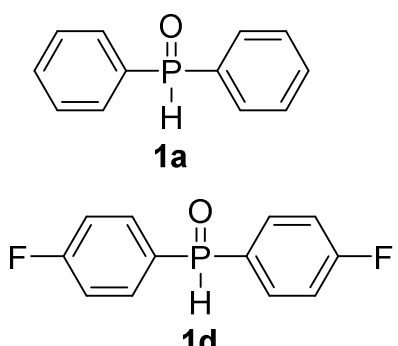

1d
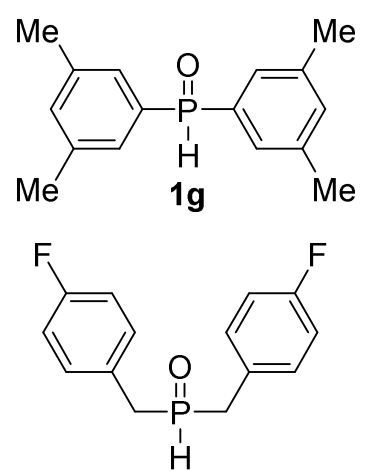

1j

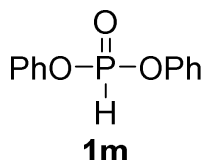

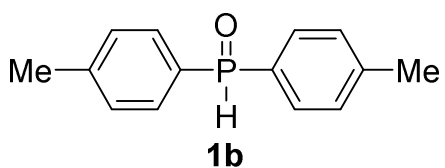
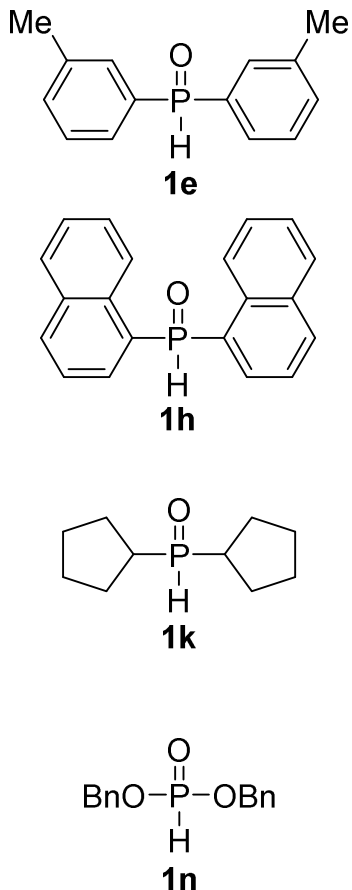
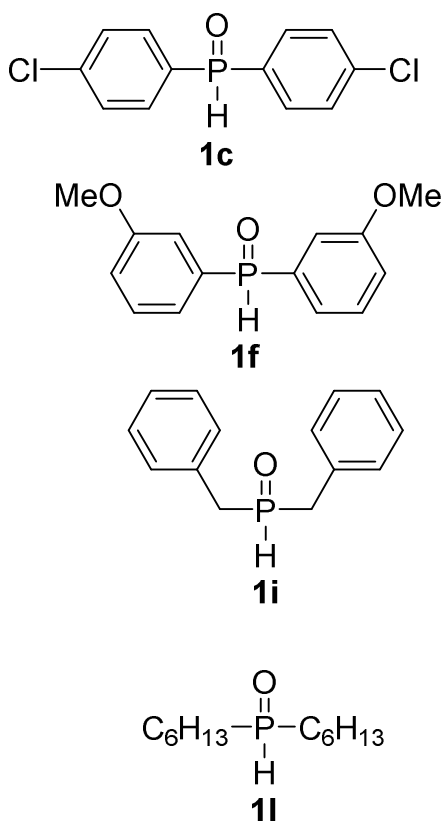

EtO-
PI
1
$H$
$\mathbf{1 0}$ 
2. Copies of NMR spectra for $\mathbf{2}$ and $\mathbf{3}$

万ृ

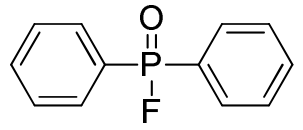

${ }^{1} \mathrm{H}$ NMR (400 MHz, $\mathrm{CDCl}_{3}$ )

$2 a$

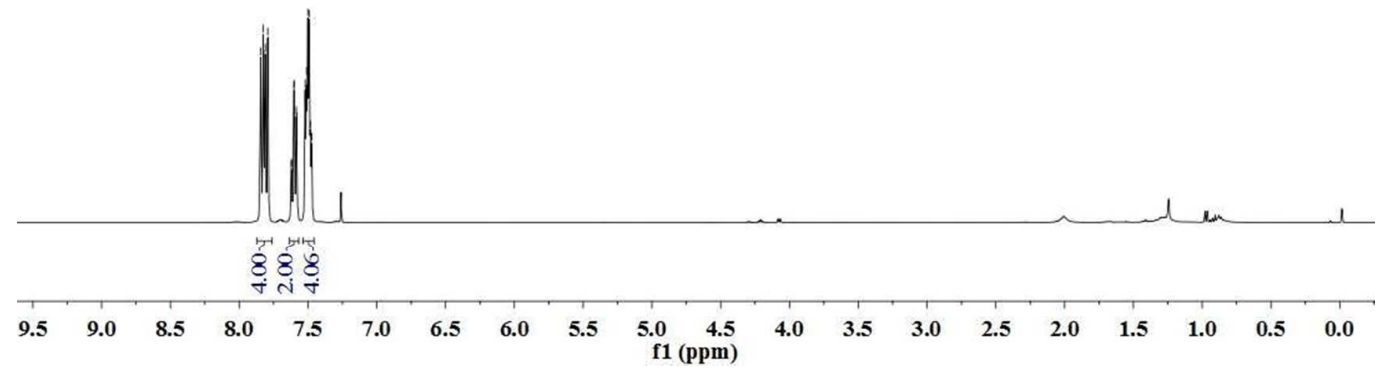

0
$\dot{0}$
$\dot{1}$

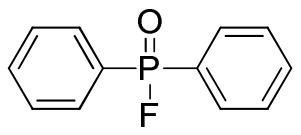

${ }^{31} \mathrm{P}$ NMR (162 MHz, $\mathrm{CDCl}_{3}$ )

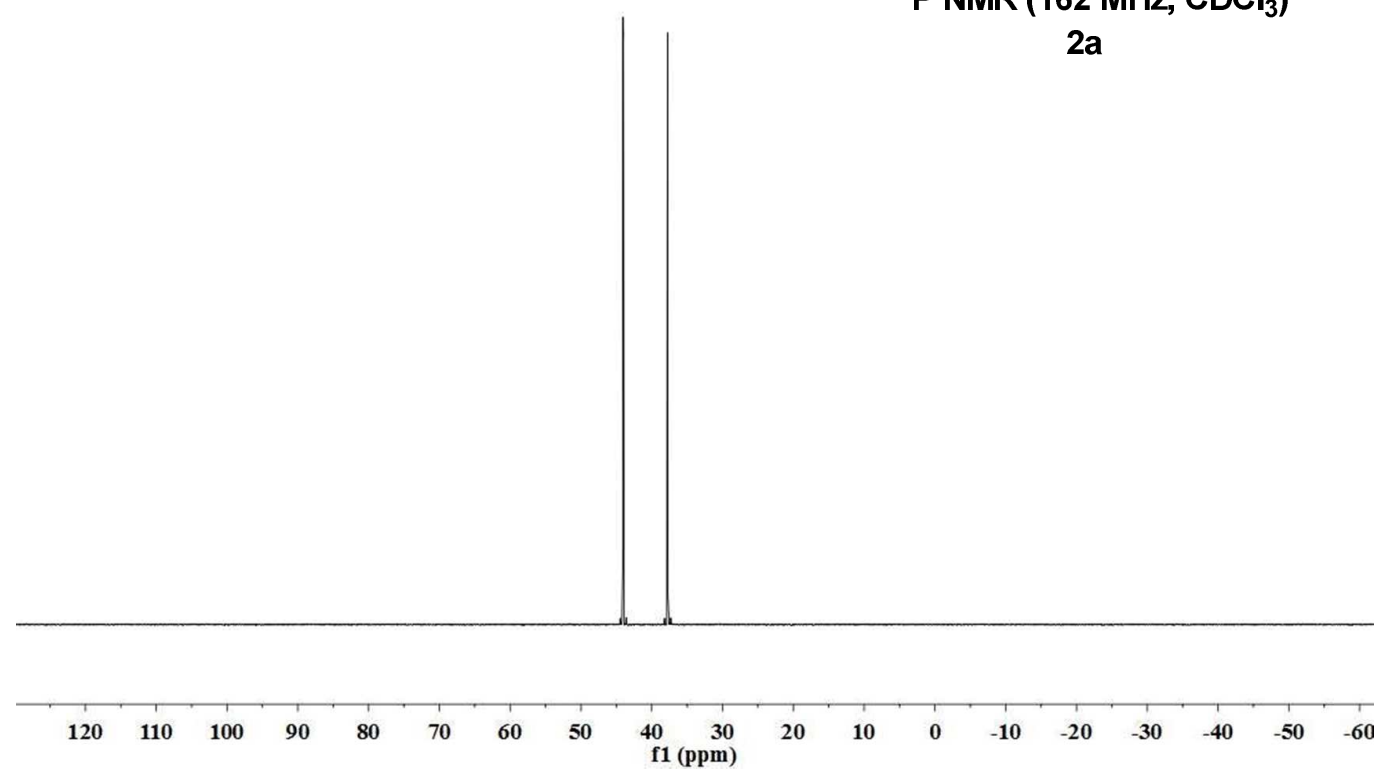




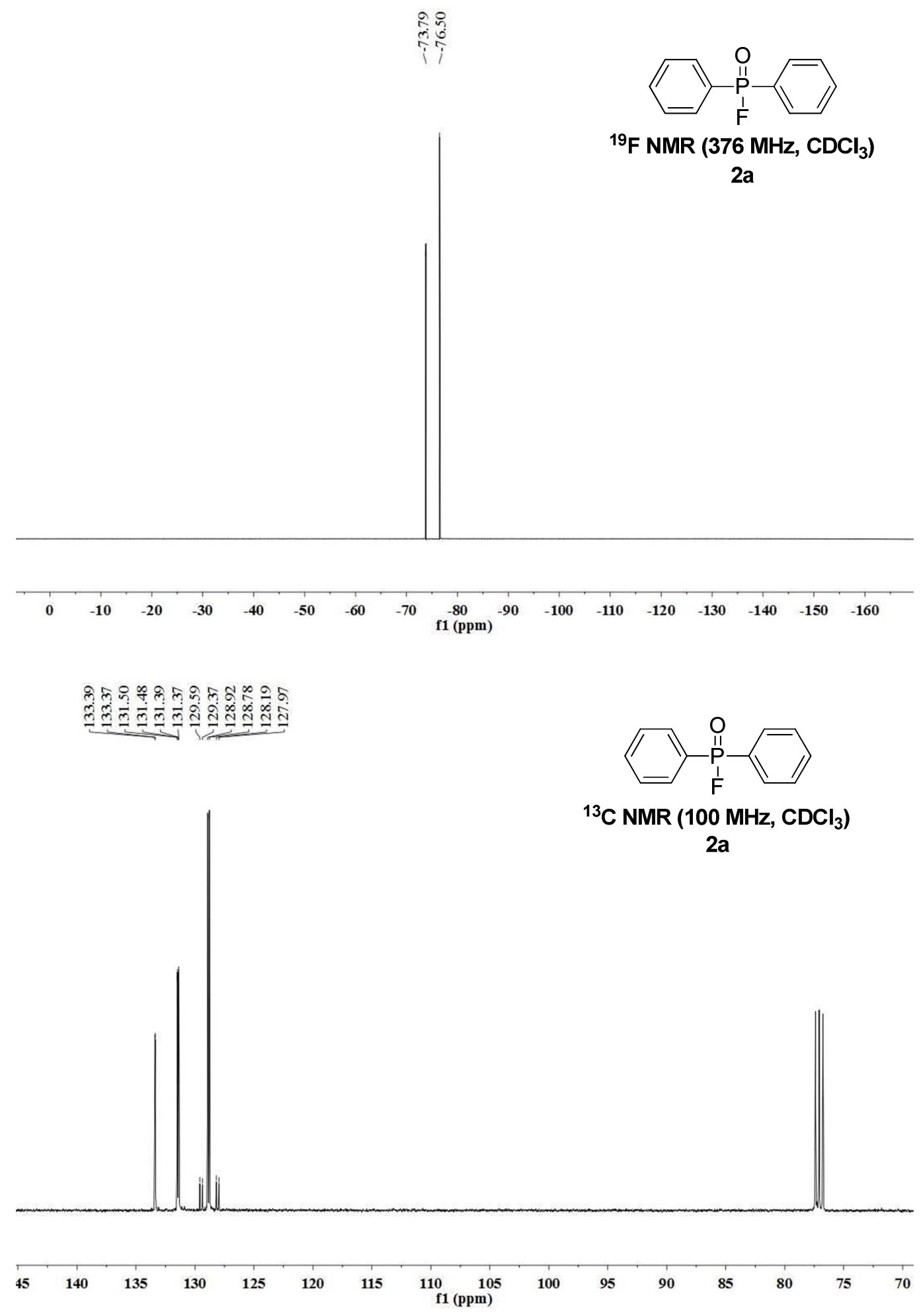




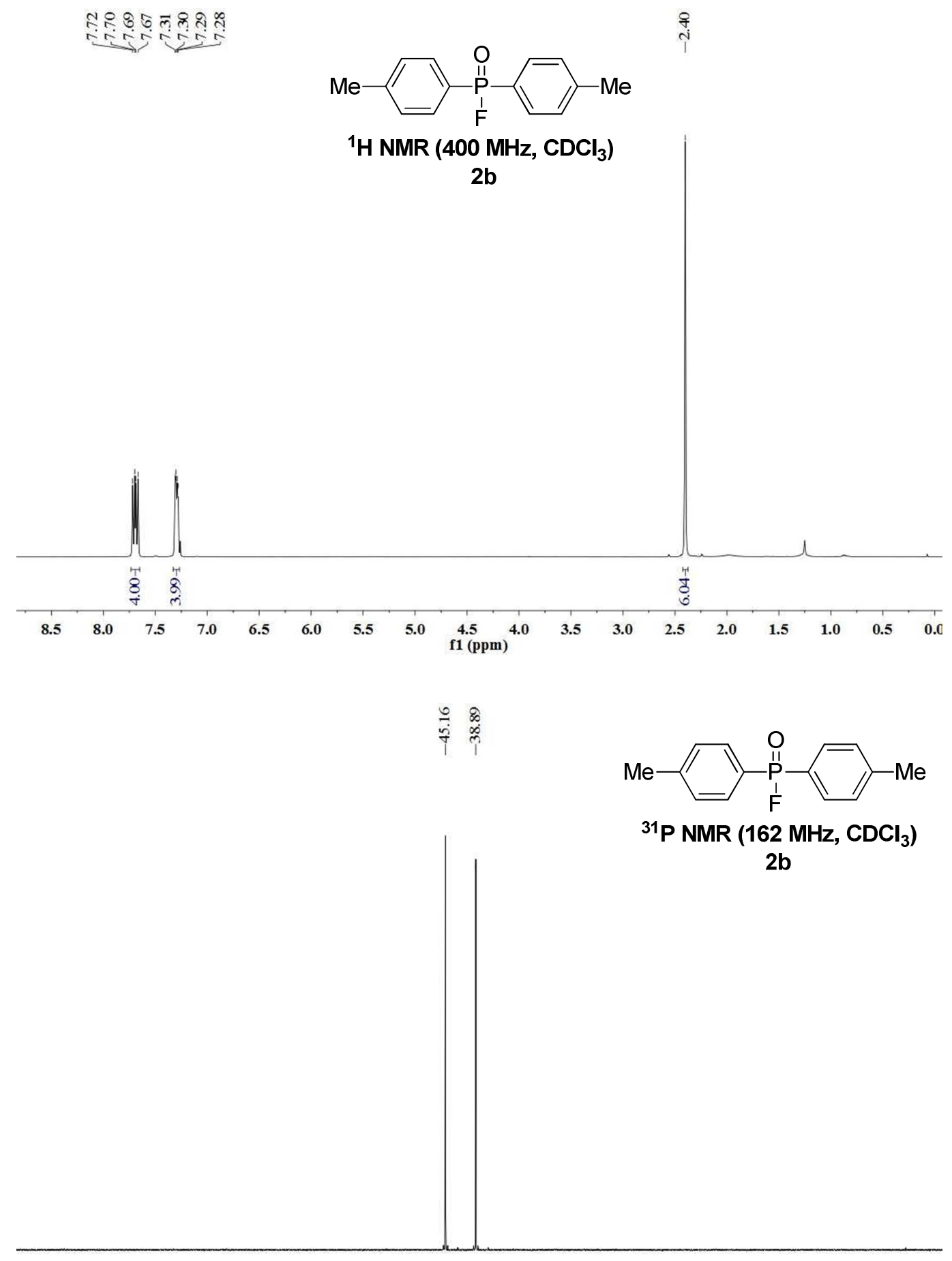

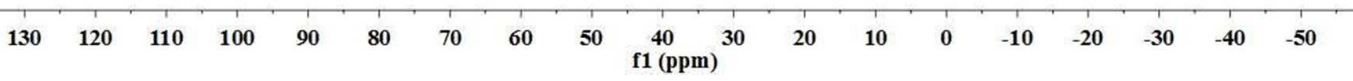




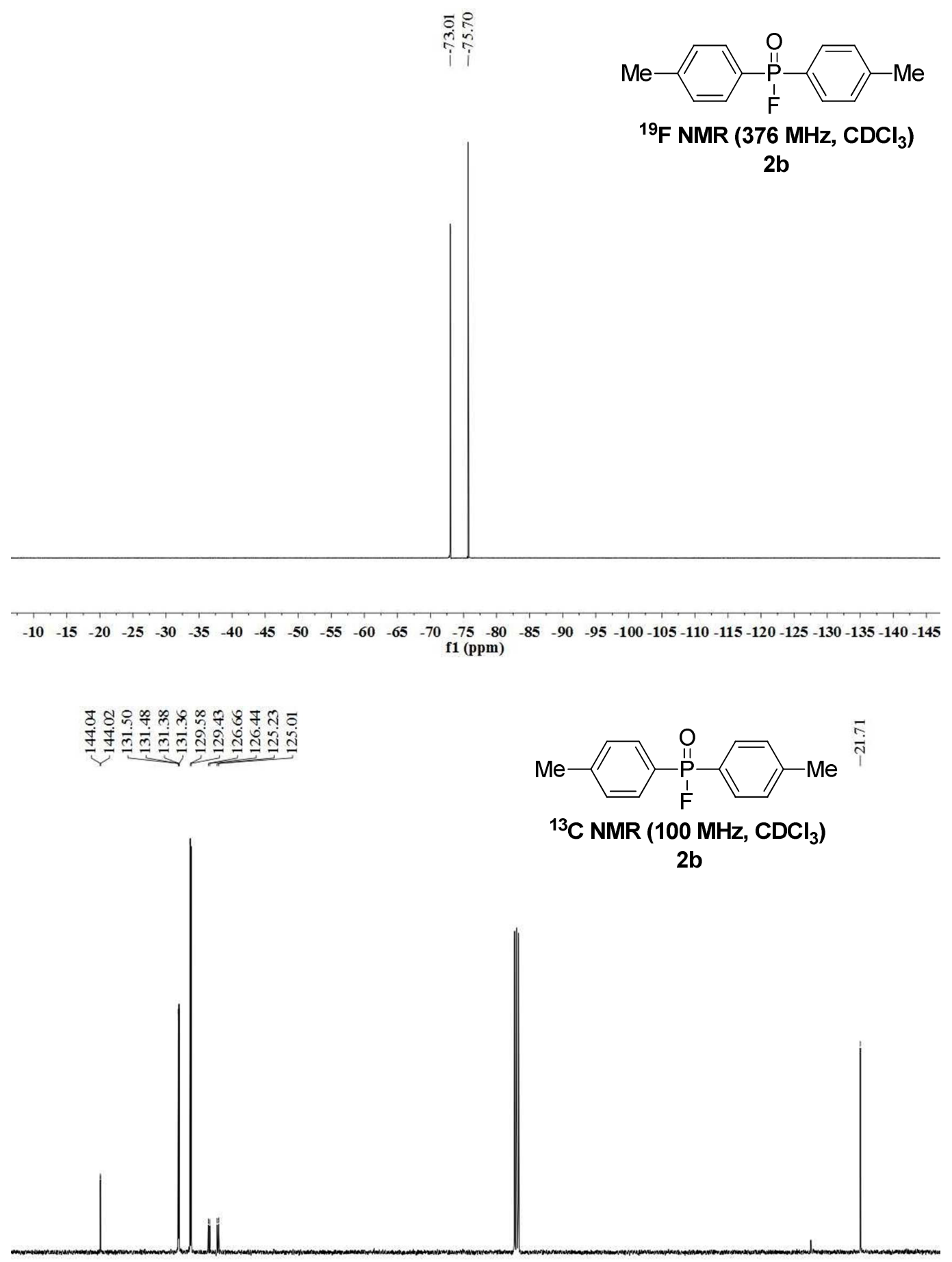

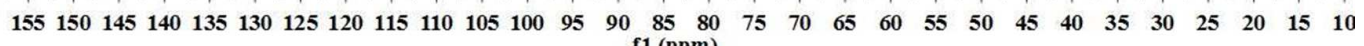
f1 (ppm) 

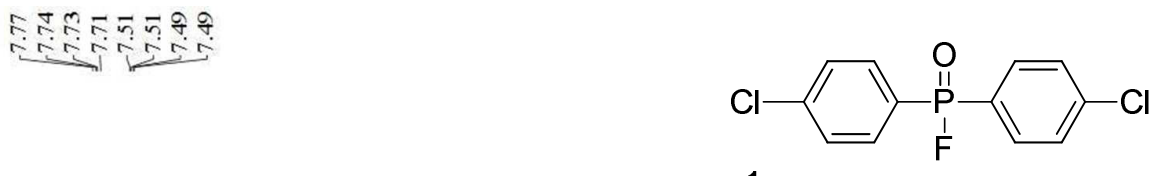

${ }^{1} \mathrm{H}$ NMR (400 MHz, $\mathrm{CDCl}_{3}$ )

2c

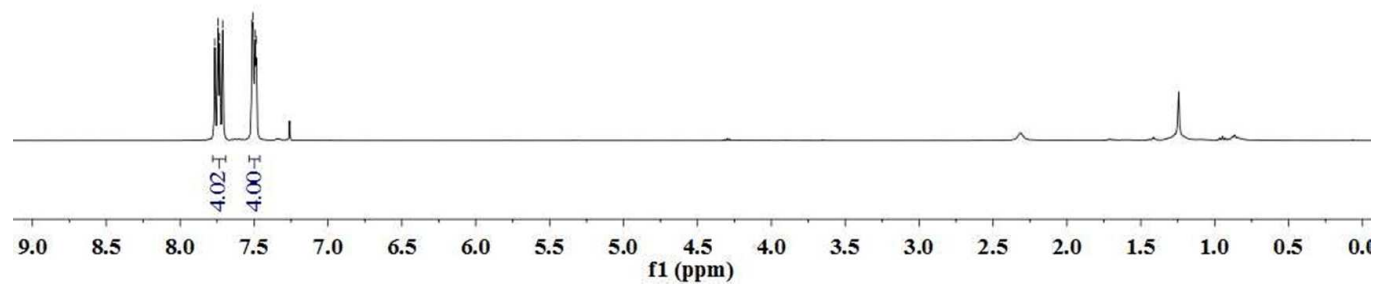

$\begin{array}{ll}\delta & \sigma \\ \overline{1} & m\end{array}$
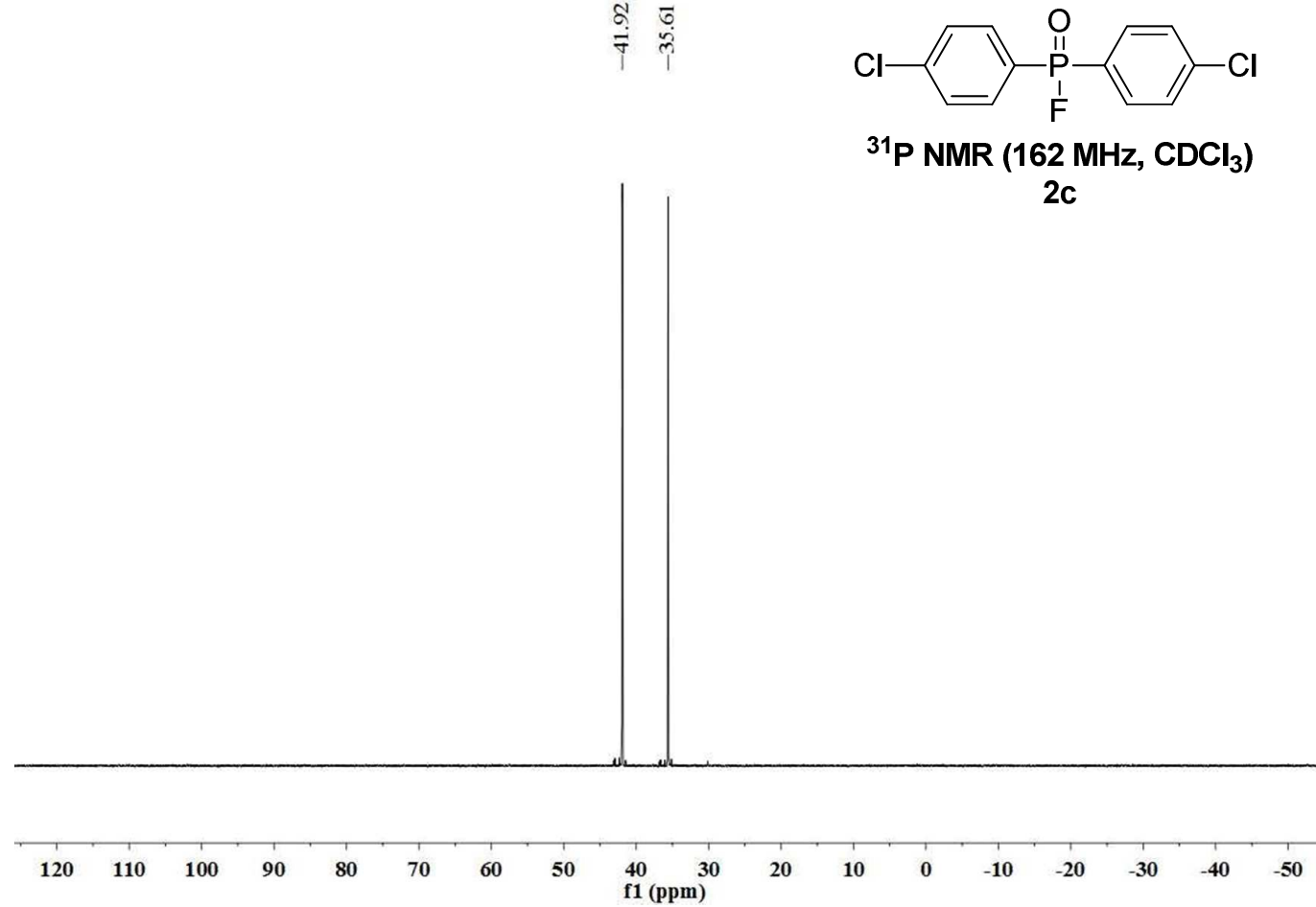

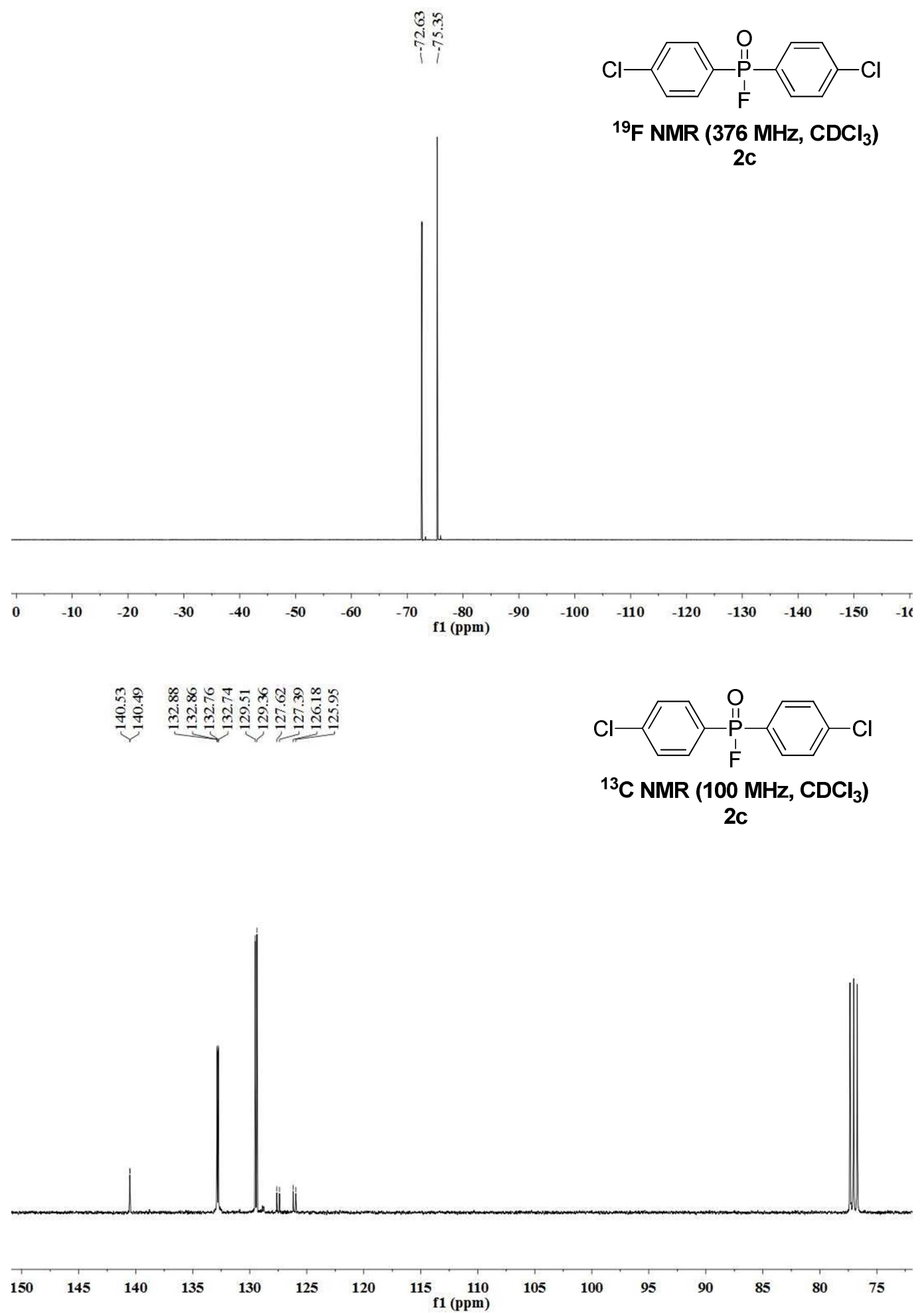


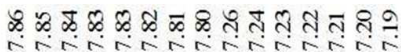

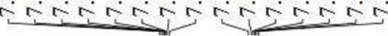

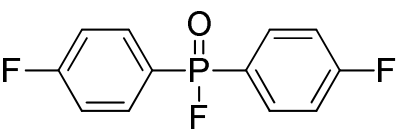

${ }^{1} \mathrm{H}$ NMR (400 MHz, $\mathrm{CDCl}_{3}$ )

2d

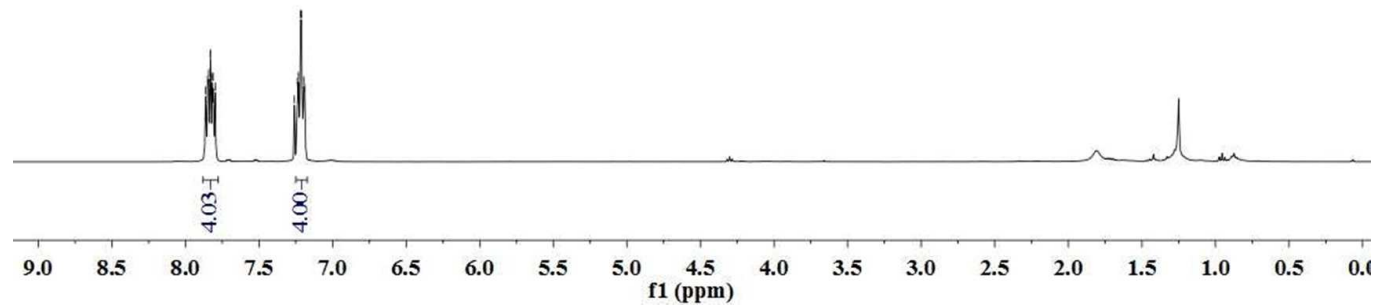

$\begin{array}{ll}5 & 0 \\ \bar{\gamma} & m\end{array}$

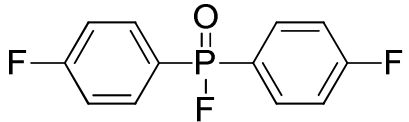

${ }^{31} \mathrm{P}$ NMR (162 MHz, $\mathrm{CDCl}_{3}$ )

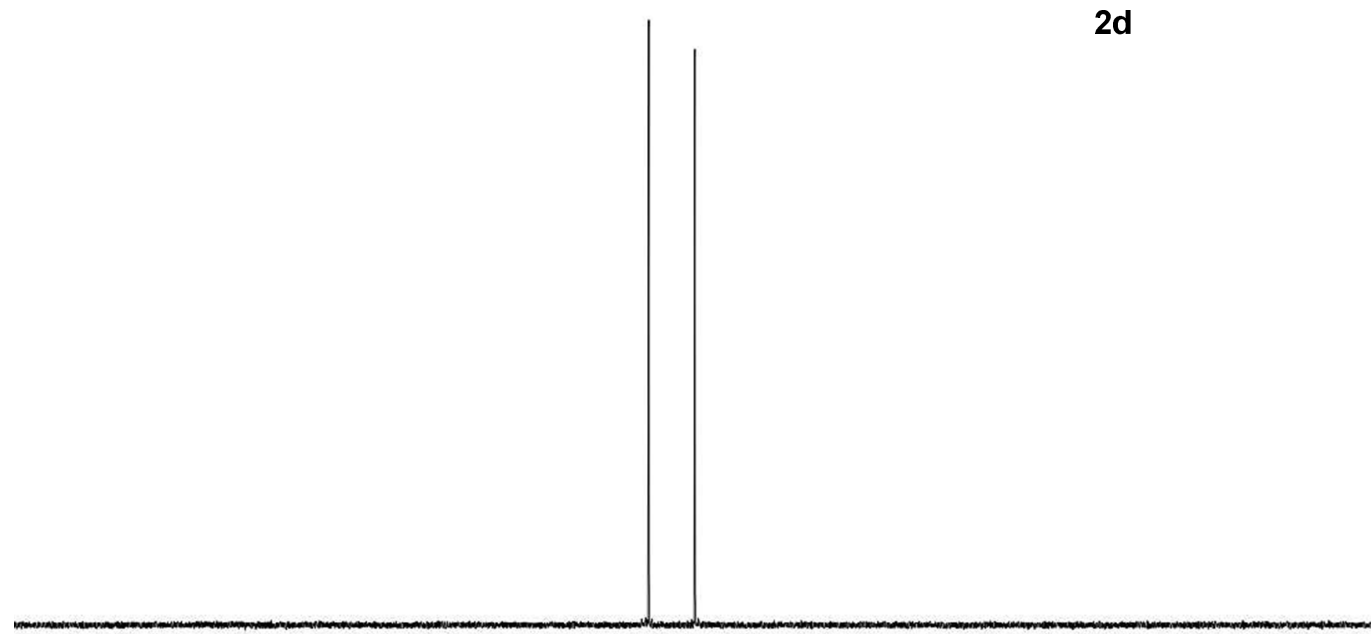

$\begin{array}{lllll}120 & 110 & 100 & 90 & 80\end{array}$

$\begin{array}{lll}60 & 50 & 40 \quad 30 \\ & & \text { f1 (ppm) }\end{array}$ 


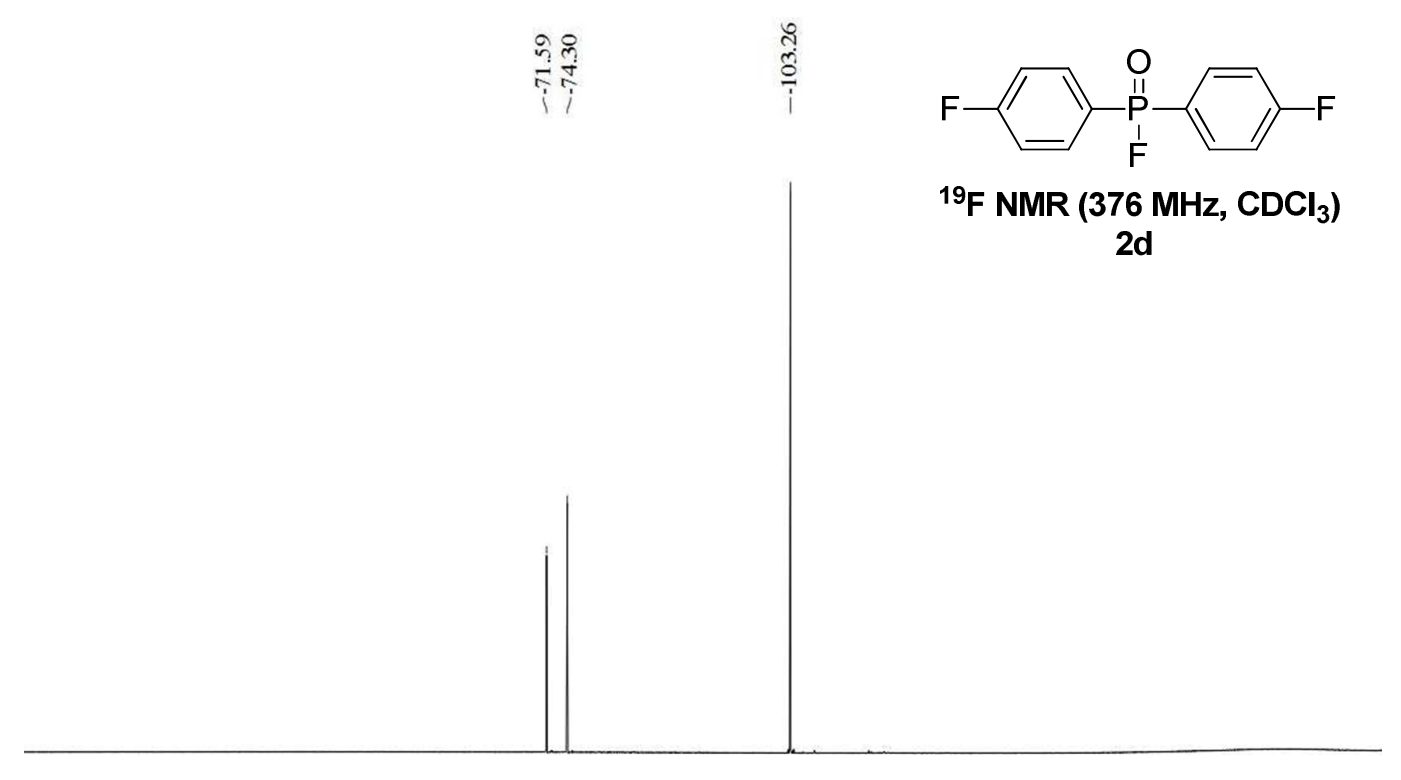

\begin{tabular}{|c|c|c|c|c|c|c|c|c|c|c|c|c|c|c|c|c|c|}
\hline-10 & -20 & -30 & -40 & -50 & -60 & -70 & -80 & $\begin{array}{c}-90 \\
\mathrm{f} 1(\mathrm{ppm}\end{array}$ & )$^{-100}$ & -110 & -120 & -130 & -140 & -150 & -160 & -170 & -1 \\
\hline
\end{tabular}

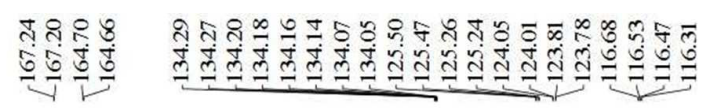

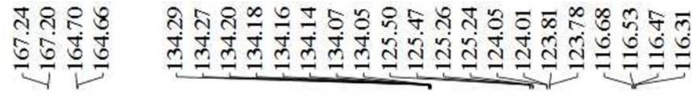

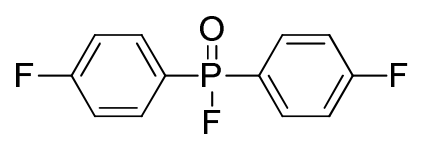

${ }^{13} \mathrm{C} \mathrm{NMR}\left(100 \mathrm{MHz}, \mathrm{CDCl}_{3}\right)$

2d

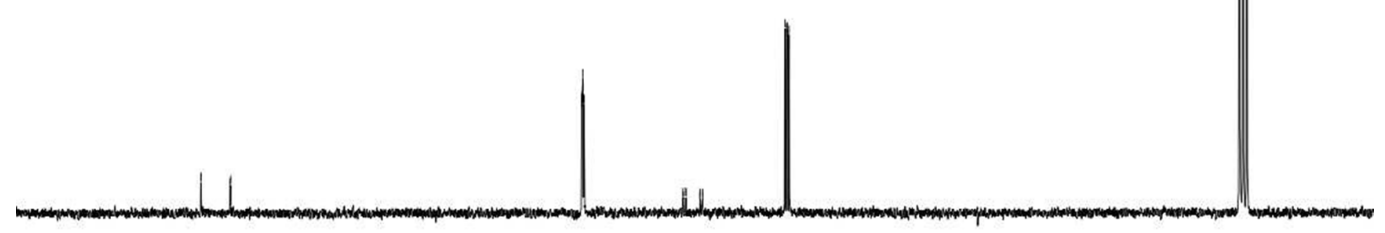

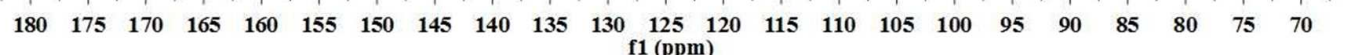




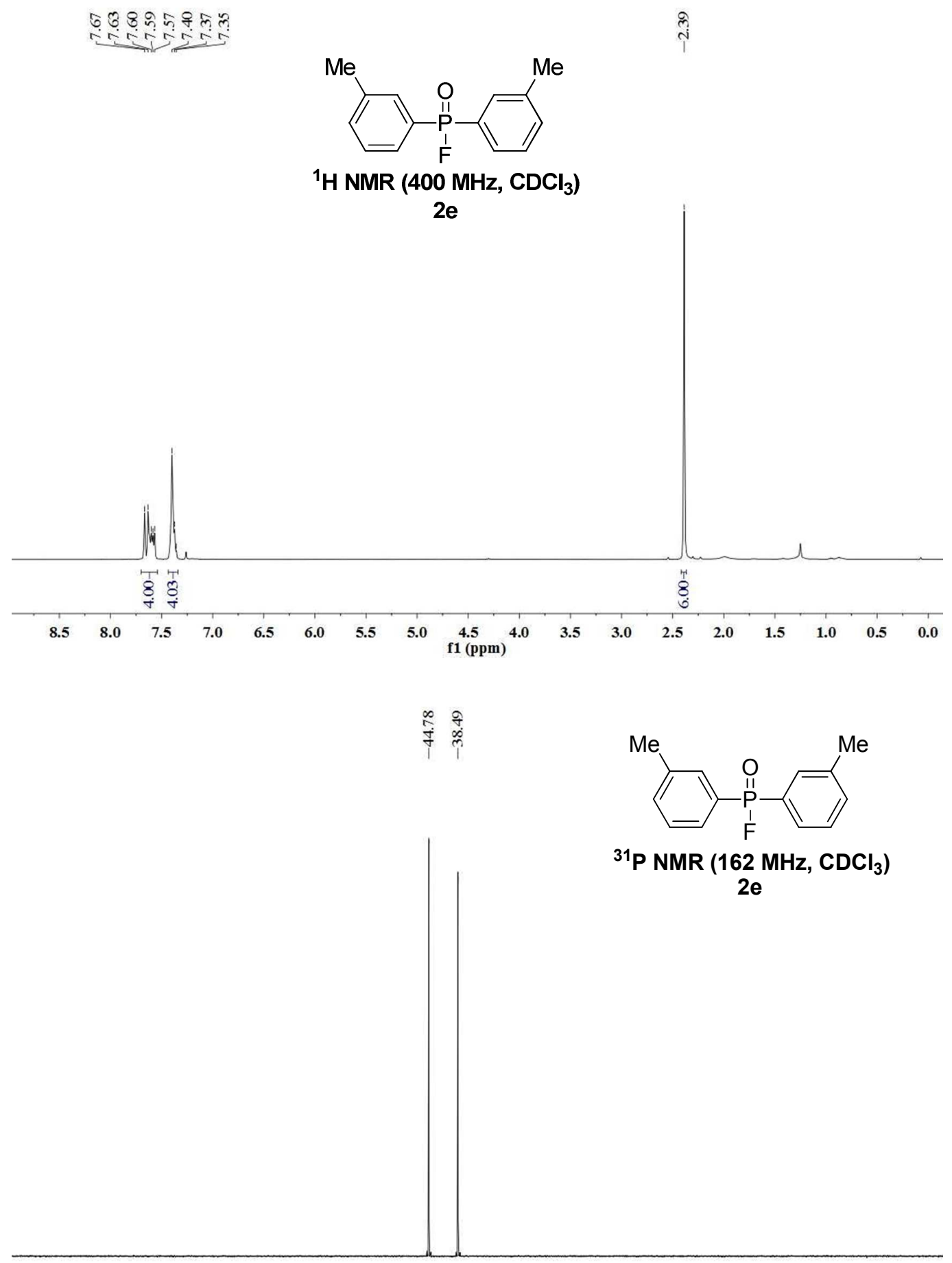

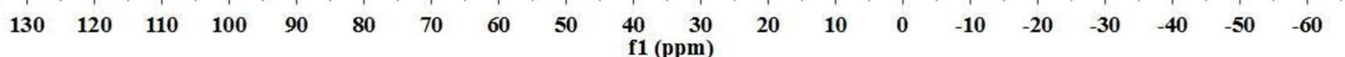




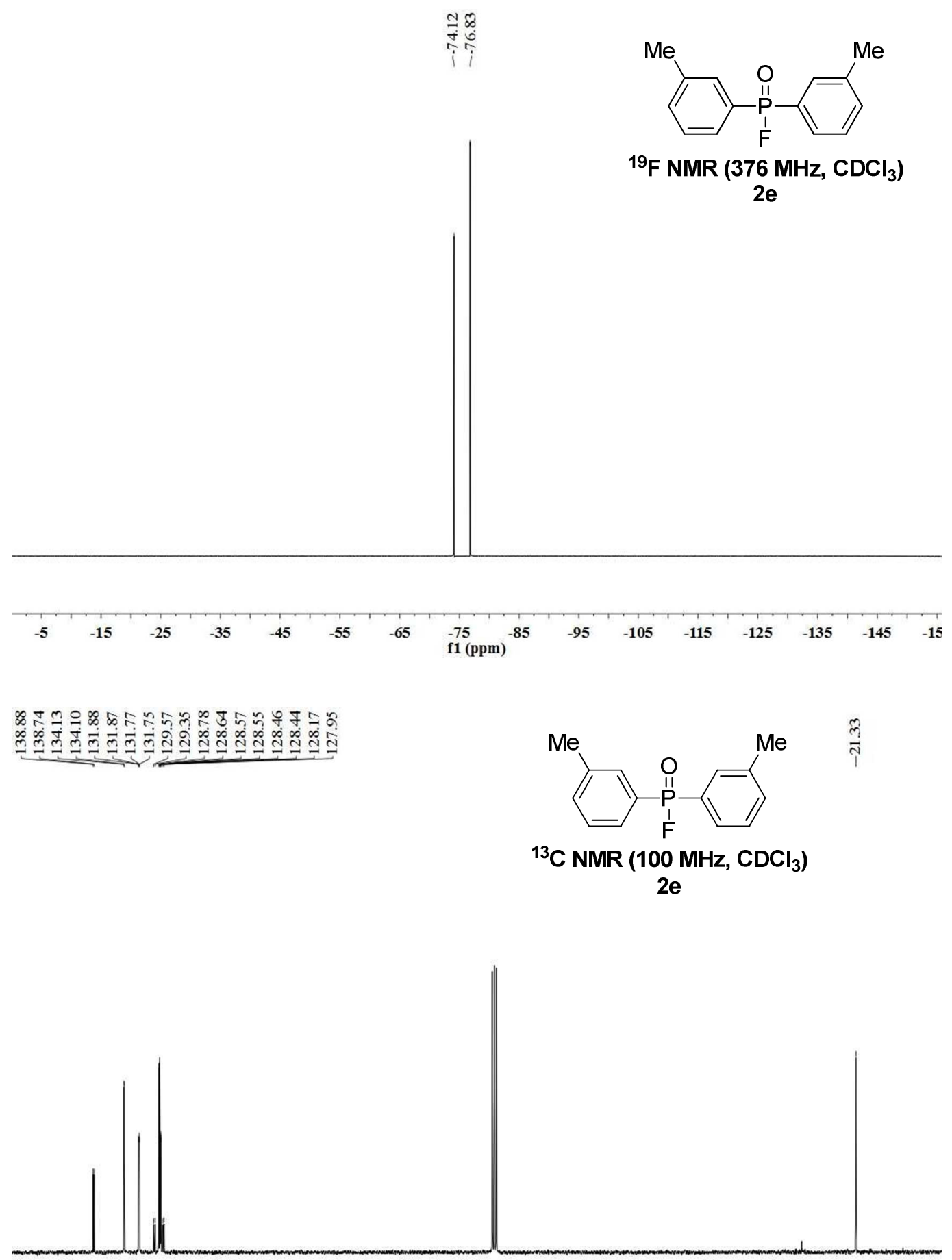

$\begin{array}{lllllllllllllllllllllllllllllllllllllllllllllllll}150 & 145 & 140 & 135 & 130 & 125 & 120 & 115 & 110 & 105 & 100 & 95 & 90 & 85 & 80 & 75 & 70 & 65 & 60 & 55 & 50 & 45 & 40 & 35 & 30 & 25 & 20 & 15 & 10\end{array}$ 

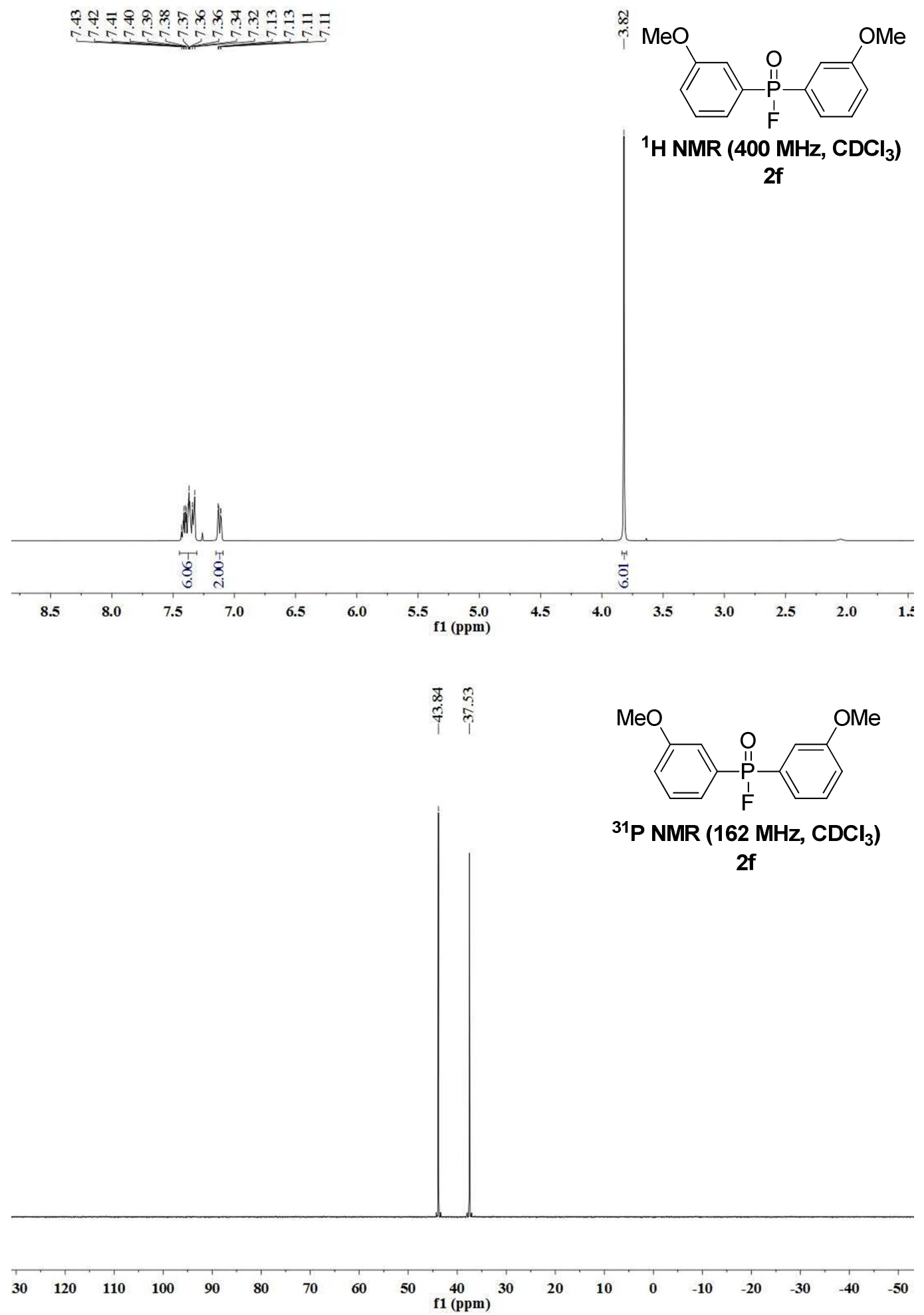


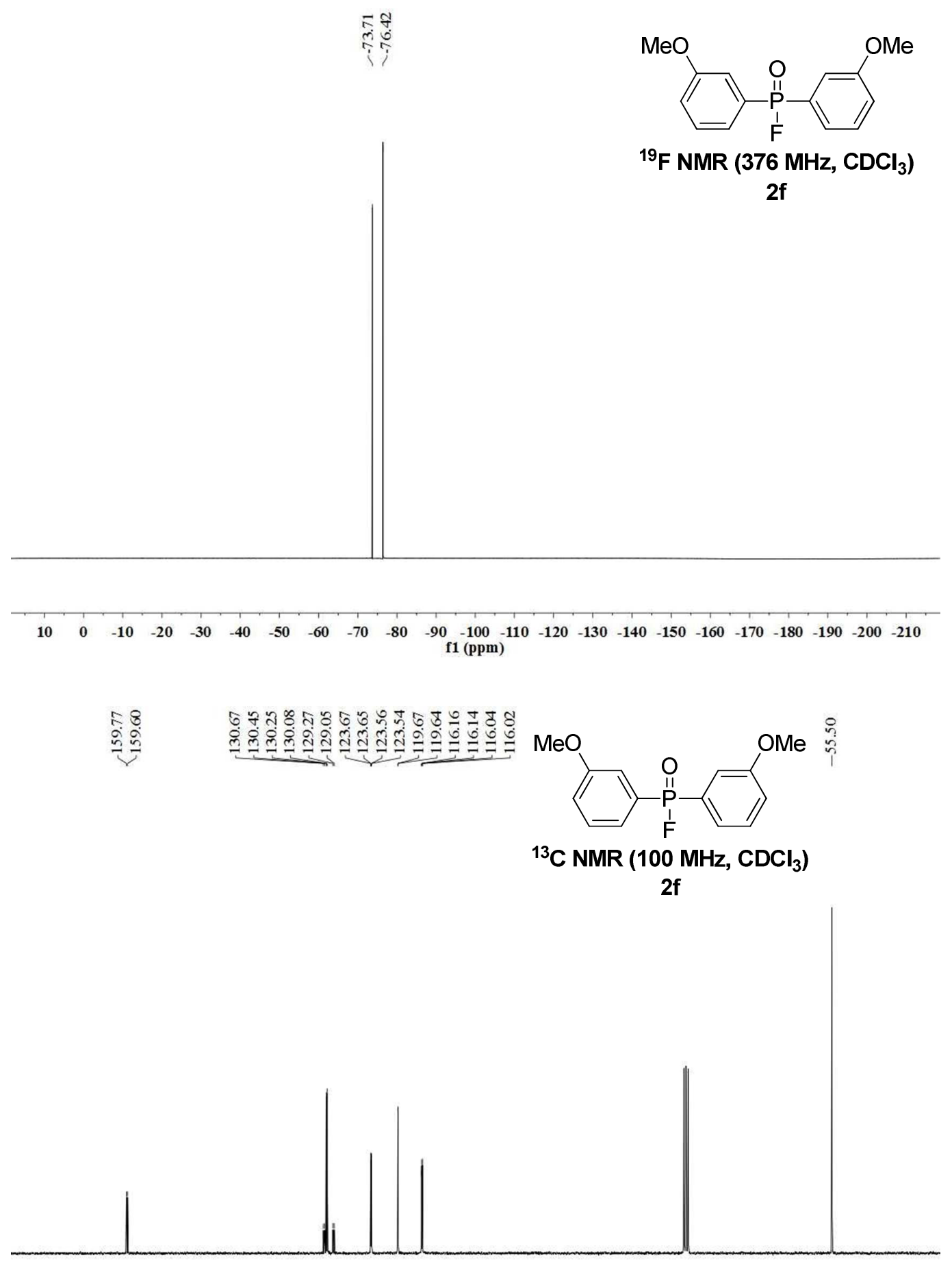

$\begin{array}{llllllllllllllllllllllllllllllllllllllllll}175 & 170 & 165 & 160 & 155 & 150 & 145 & 140 & 135 & 130 & 125 & 120 & 115 & 110 & 105 & 100 & 95 & 90 & 85 & 80 & 75 & 70 & 65 & 60 & 55 & 50 & 45 & 41\end{array}$ f1 (ppm) 


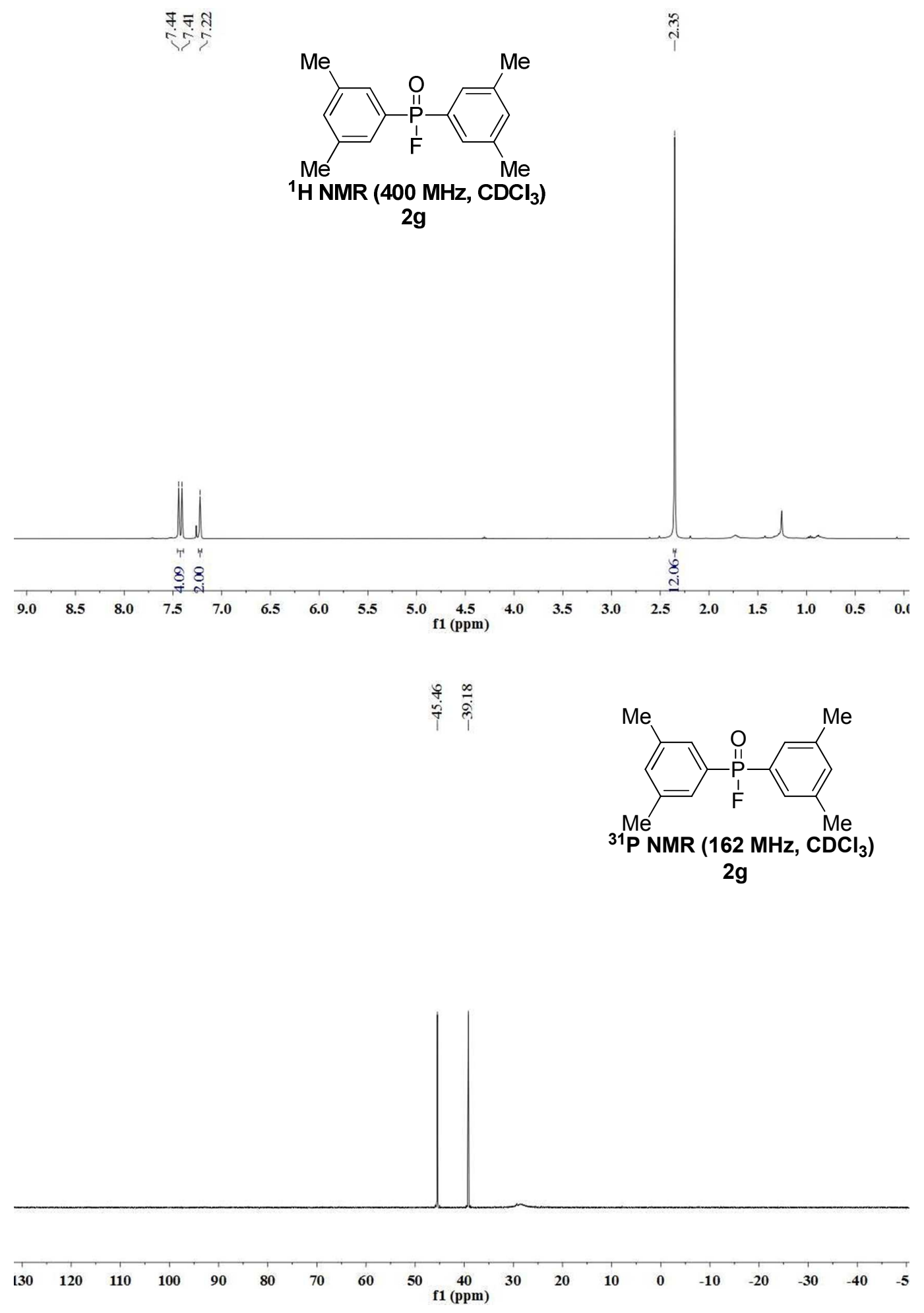




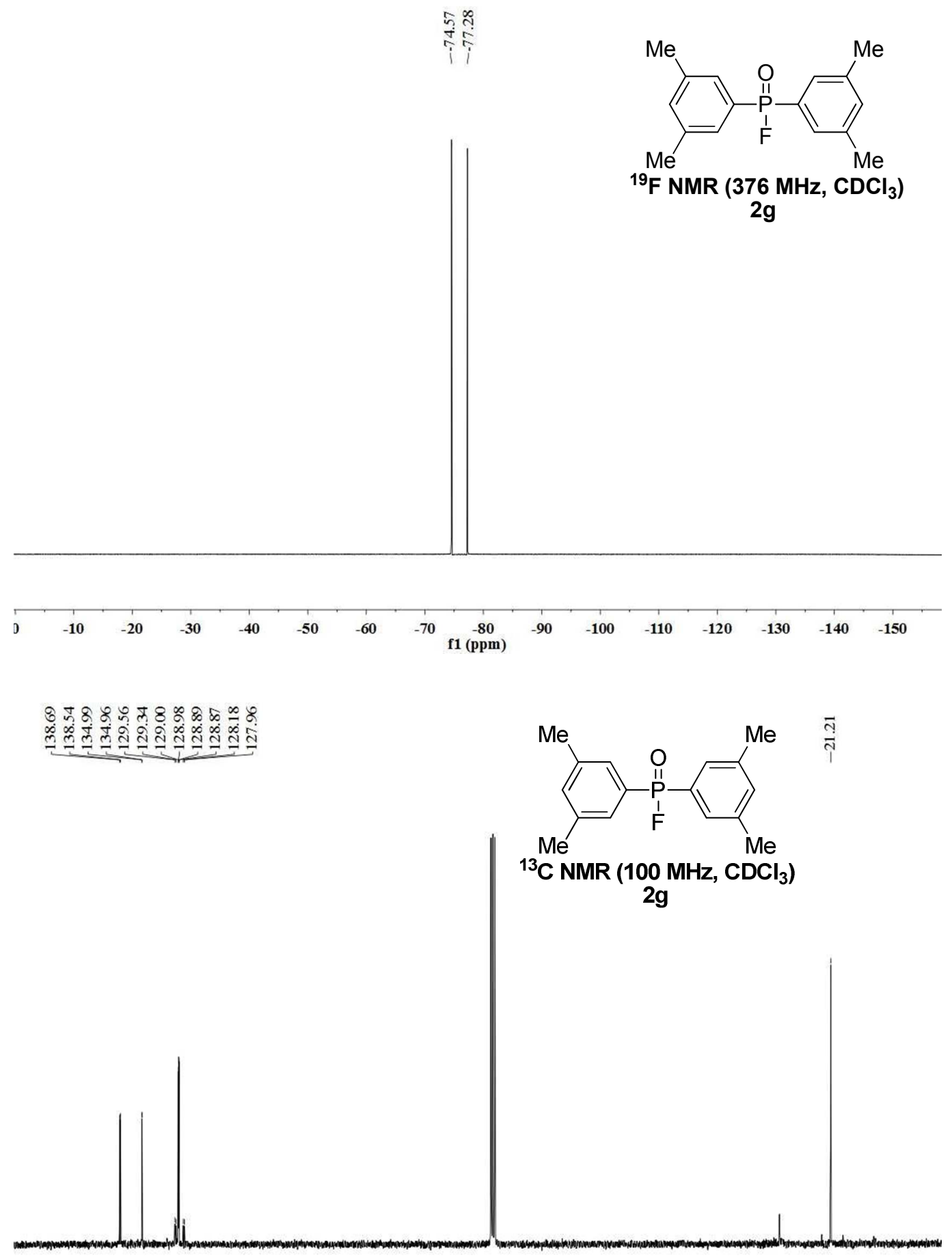

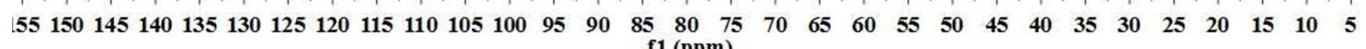




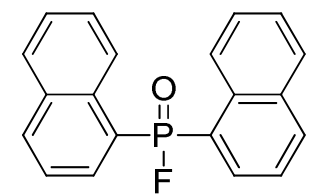

${ }^{1} \mathrm{H}$ NMR (400 MHz, $\mathrm{CDCl}_{3}$ )

2h

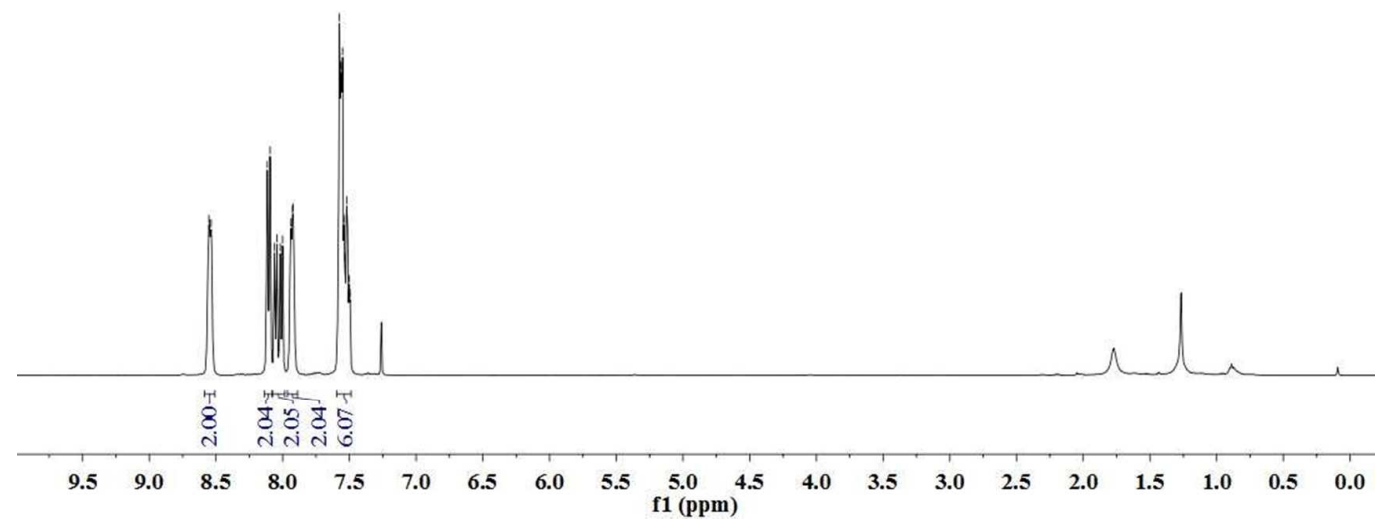

एँ ले
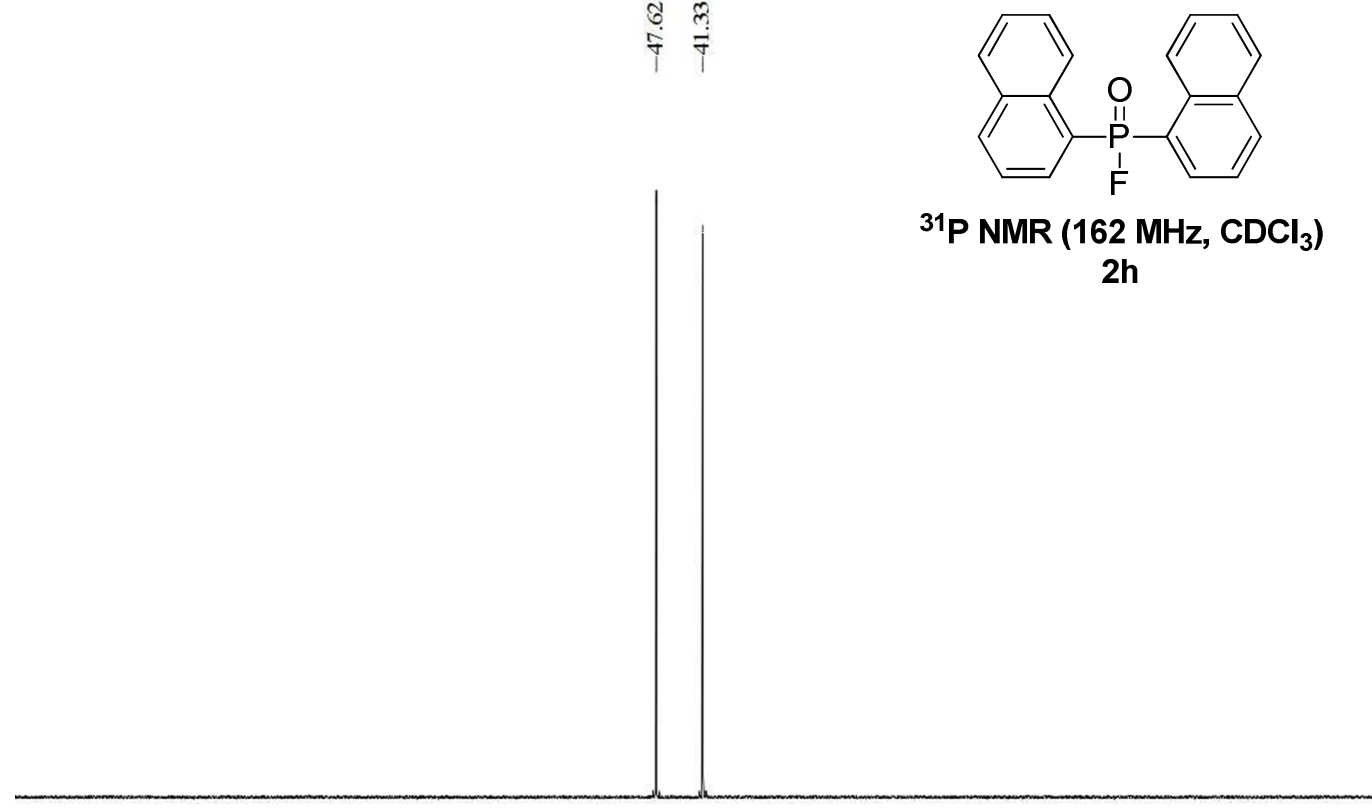

$\begin{array}{lllllllll}130 & 120 & 110 & 100 & 90 & 80 & 70 & 60 & 50 \underset{\text { f1 }(\mathrm{ppm})}{40}\end{array}$ 


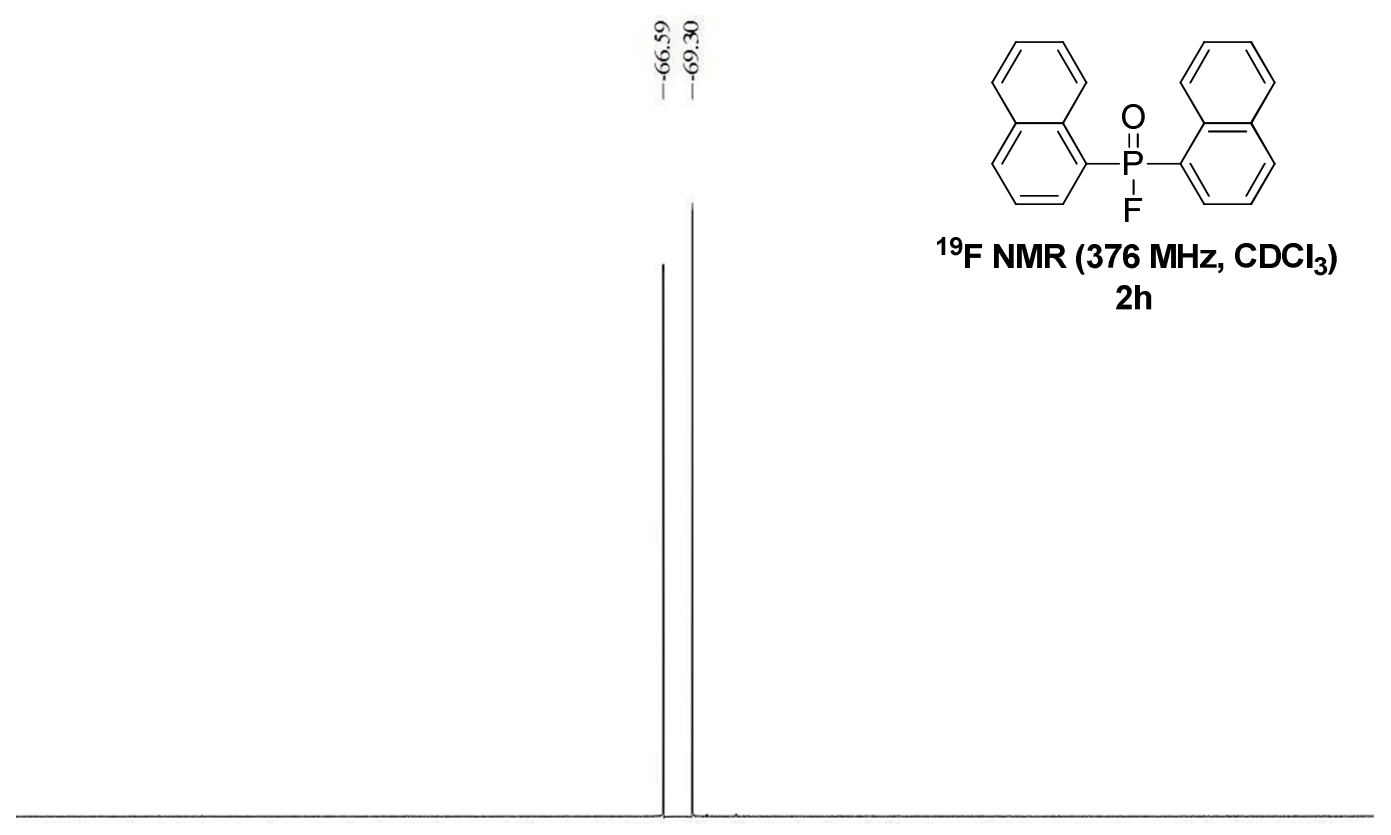

$\begin{array}{llllllllllllllllllllllllllllllll}-10 & -15 & -20 & -25 & -30 & -35 & -40 & -45 & -50 & -55 & -60 & -65 & -70 & -75 & -80 & -85 & -90 & -95 & -100 & -105 & -110 & -115 & -120 & -125 & -130\end{array}$

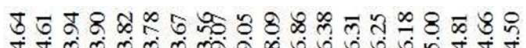

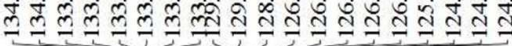

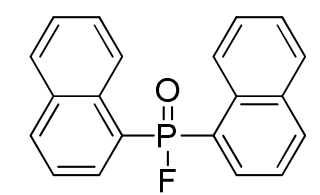

${ }^{13} \mathrm{C}$ NMR (100 MHz, $\left.\mathrm{CDCl}_{3}\right)$

2h

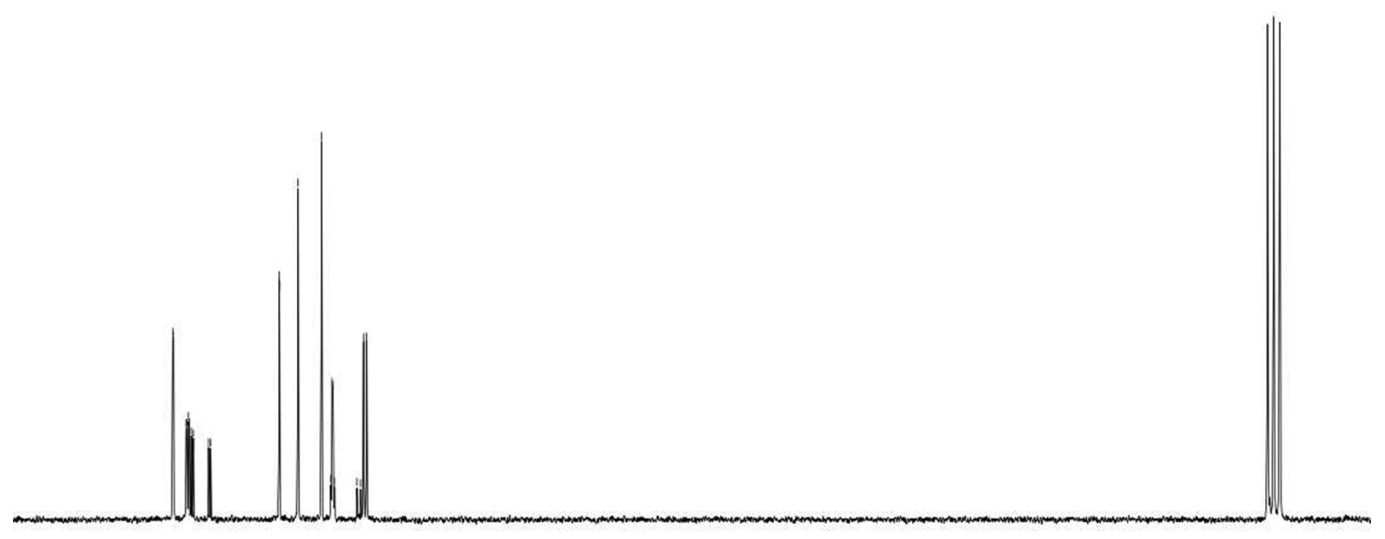

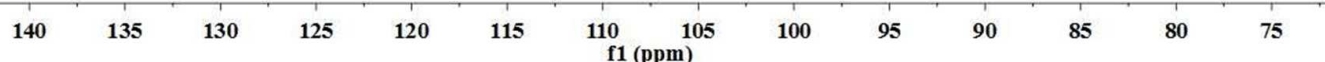



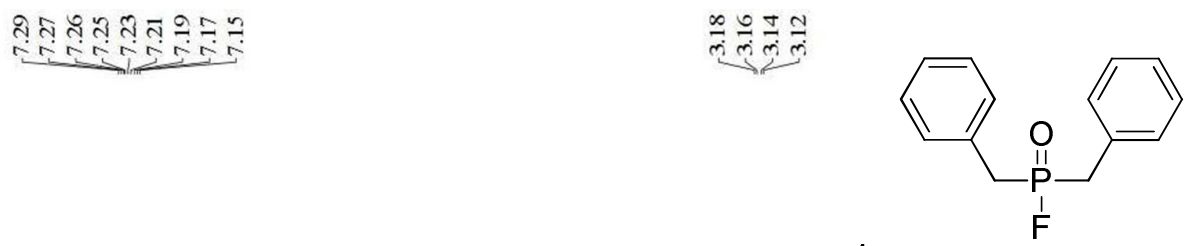

${ }^{1} \mathrm{H}$ NMR (400 MHz, $\left.\mathrm{CDCl}_{3}\right)$

2i
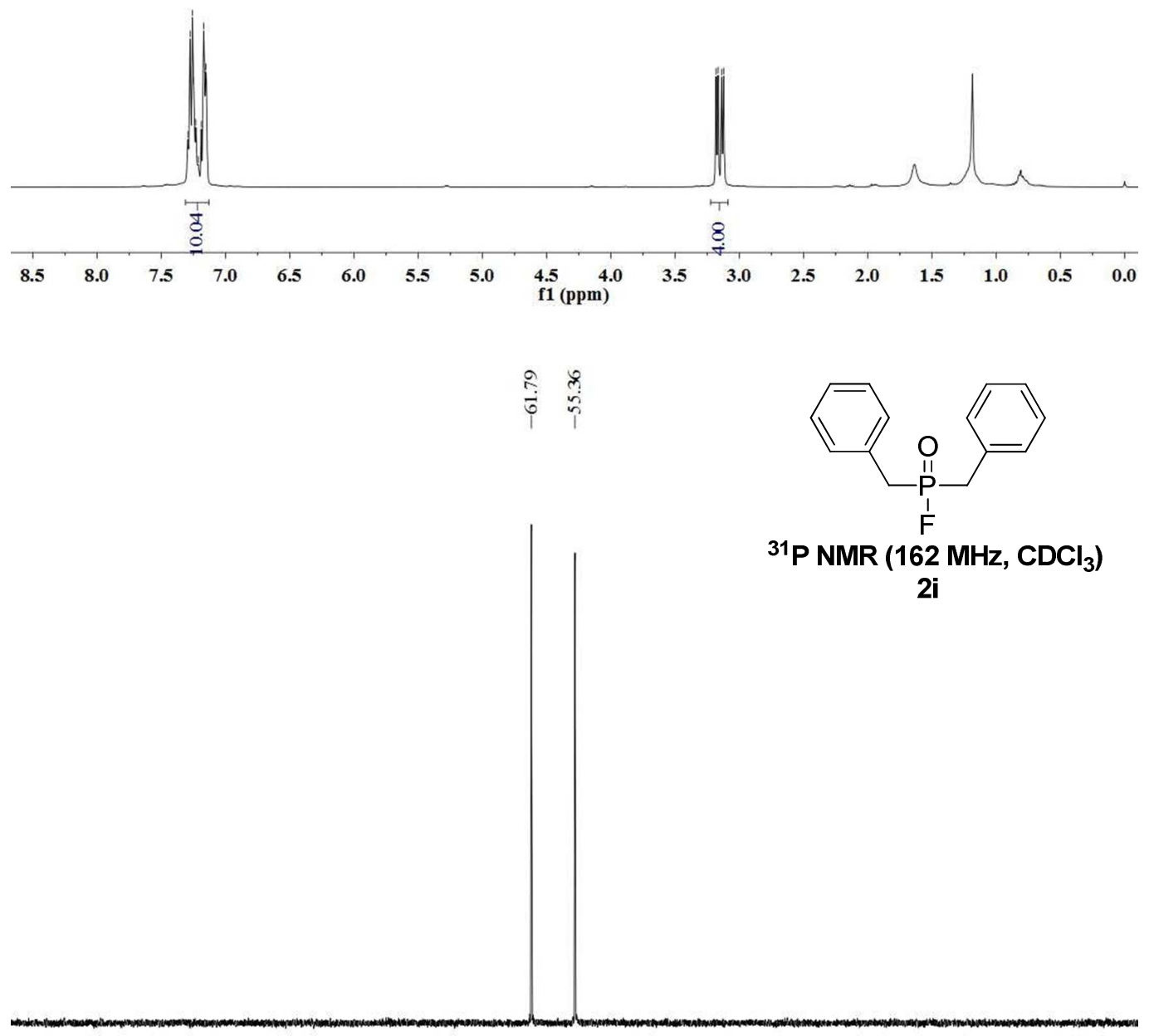

$\begin{array}{lllllllllllllll}130 & 120 & 110 & 100 & 90 & 80 & 70 & \underset{\mathrm{f} 1(\mathrm{ppm})}{60} & 40 & 30 & 20 & 10 & 0 & -10 & -20\end{array}$ 


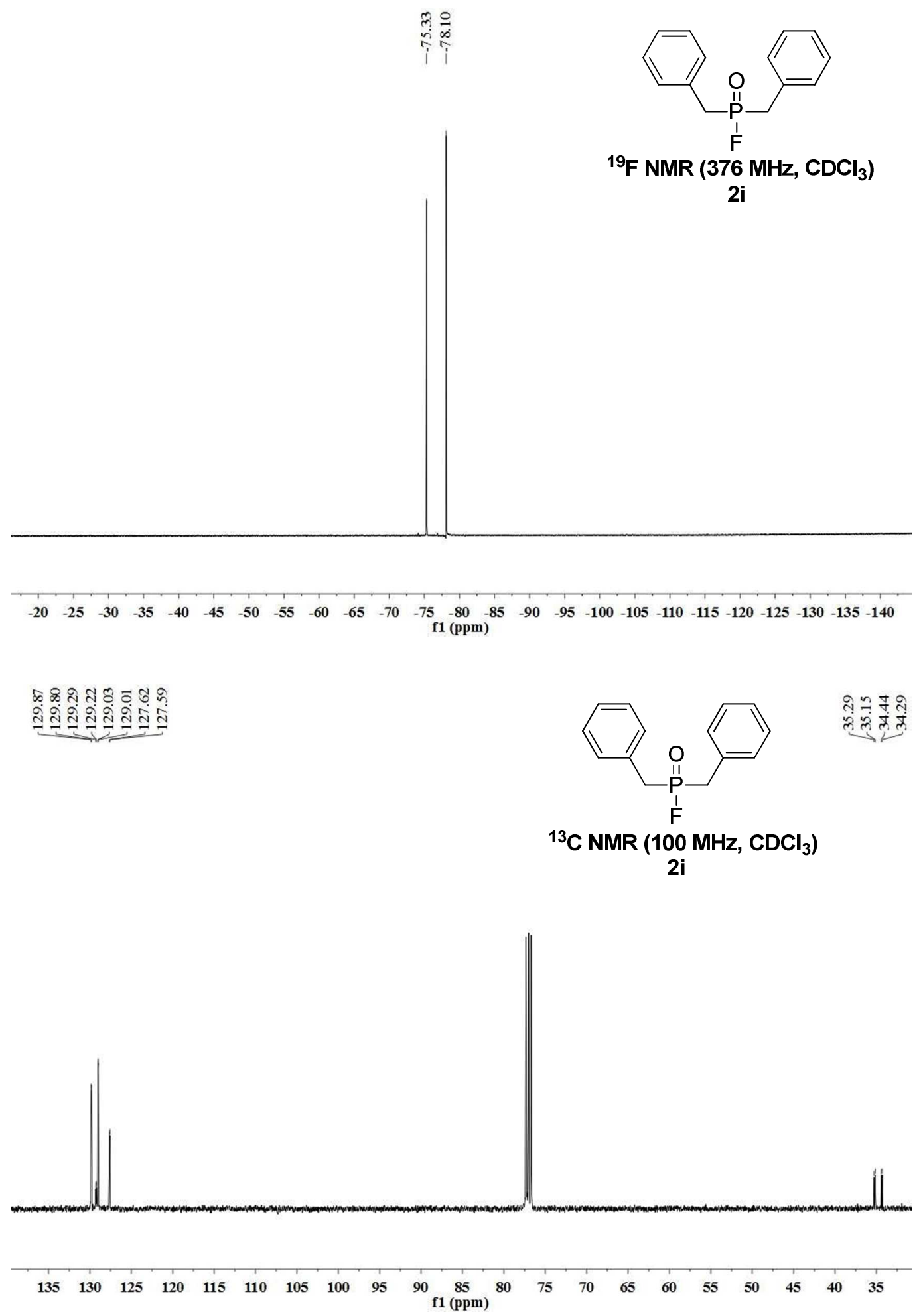



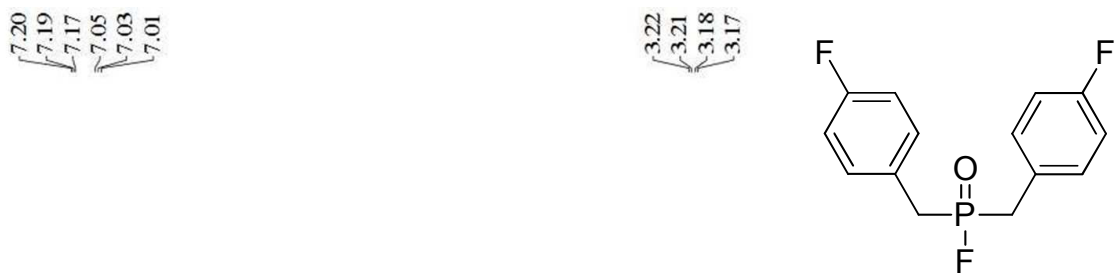

${ }^{1} \mathrm{H}$ NMR $\left(400 \mathrm{MHz}, \mathrm{CDCl}_{3}\right)$

2j

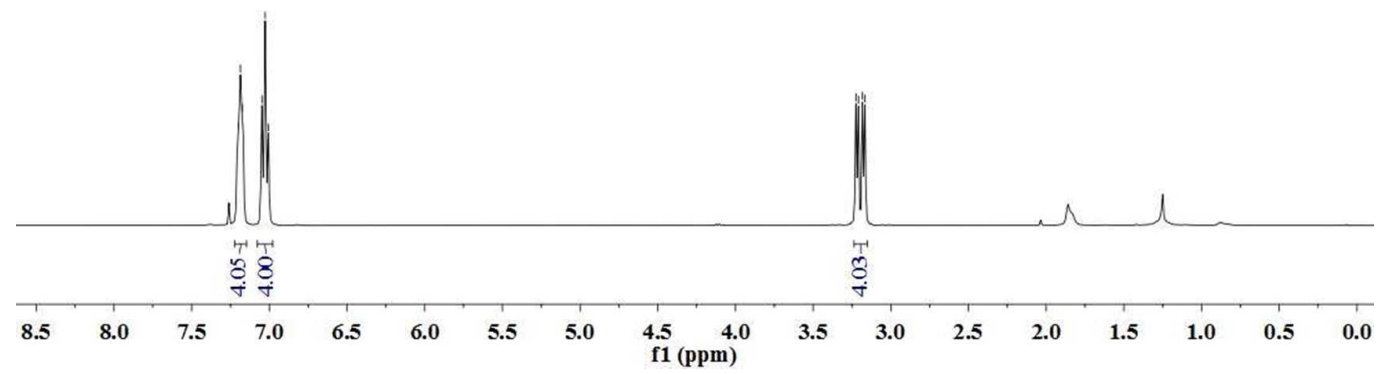

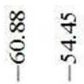
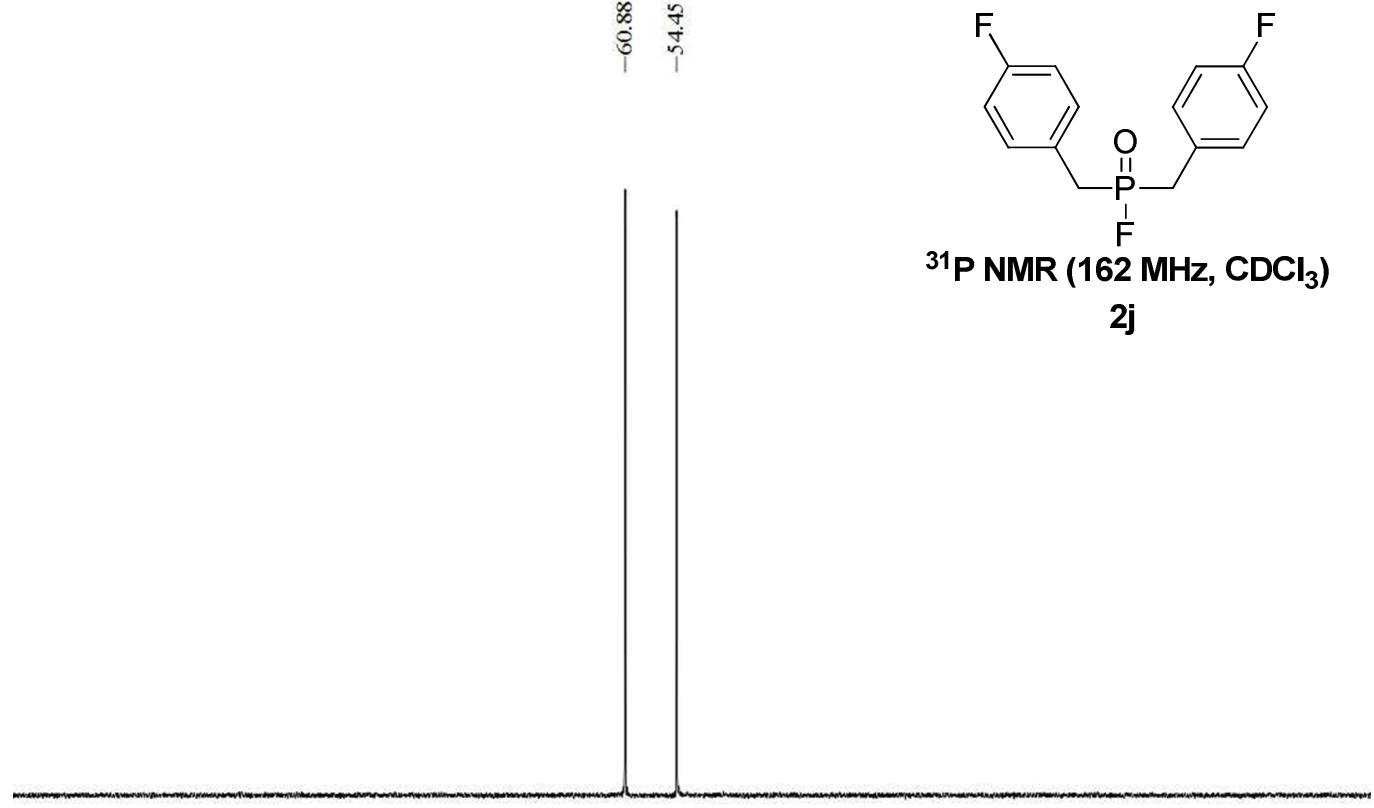

2j

$\begin{array}{lllllll}130 & 120 & 110 & 100 & 90 & 80 & 70\end{array}$

$60 \underset{f 1}{50}$

2010

$\begin{array}{llll}0 & -10 & -20 & -30\end{array}$ 


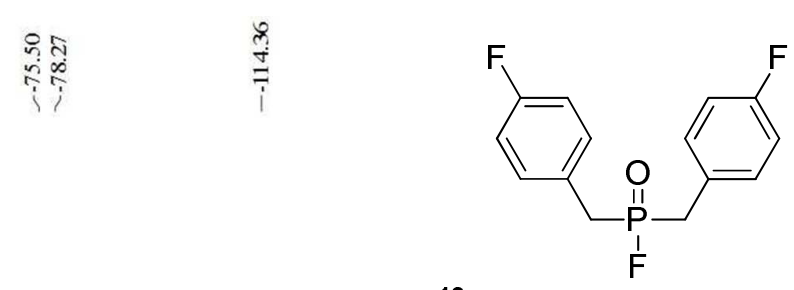

${ }^{19} \mathrm{~F}$ NMR (376 MHz, $\left.\mathrm{CDCl}_{3}\right)$

2j

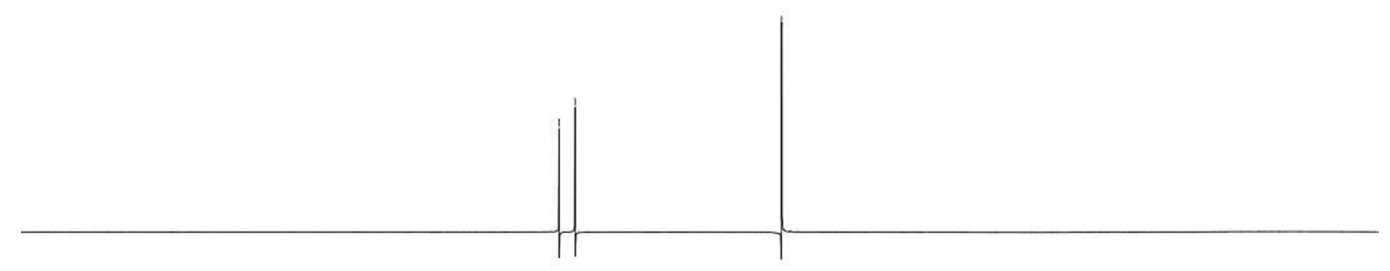

\begin{tabular}{llllllllllllllllllllllll}
\hline 10 & 0 & -10 & -20 & -30 & -40 & -50 & -60 & -70 & -80 & -90 & -100 & -110 & -120 & -130 & -140 & -150 & -160 & -170 & -180 & -190 & -200 & -210
\end{tabular}

क人

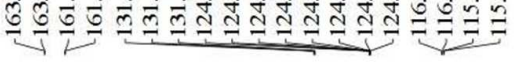

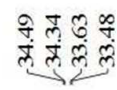

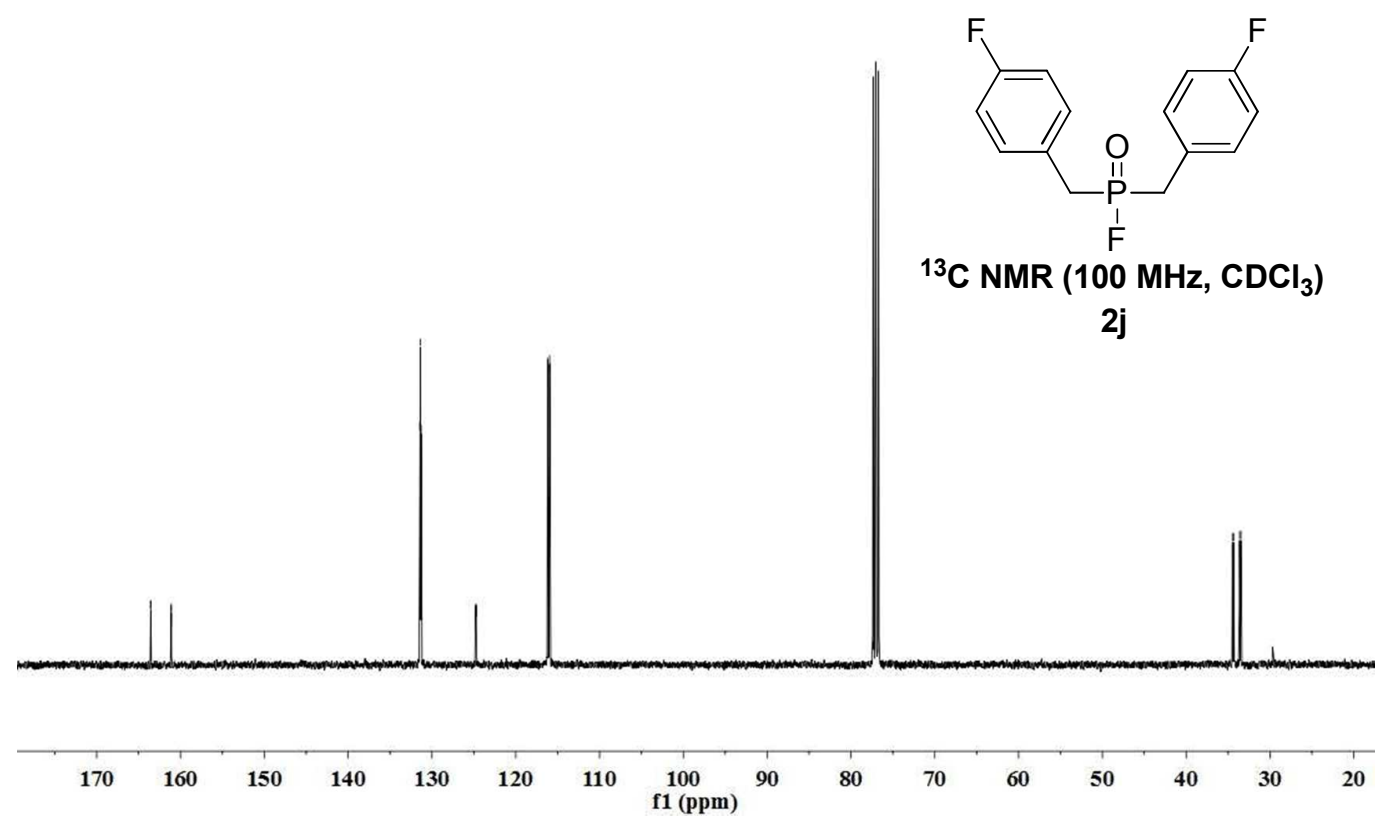




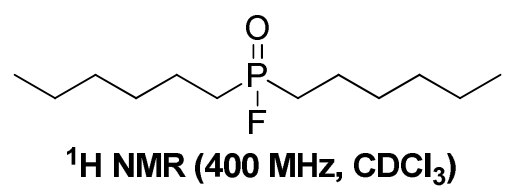

${ }^{1} \mathrm{H}$ NMR (400 MHz, $\mathrm{CDCl}_{3}$ )

2I
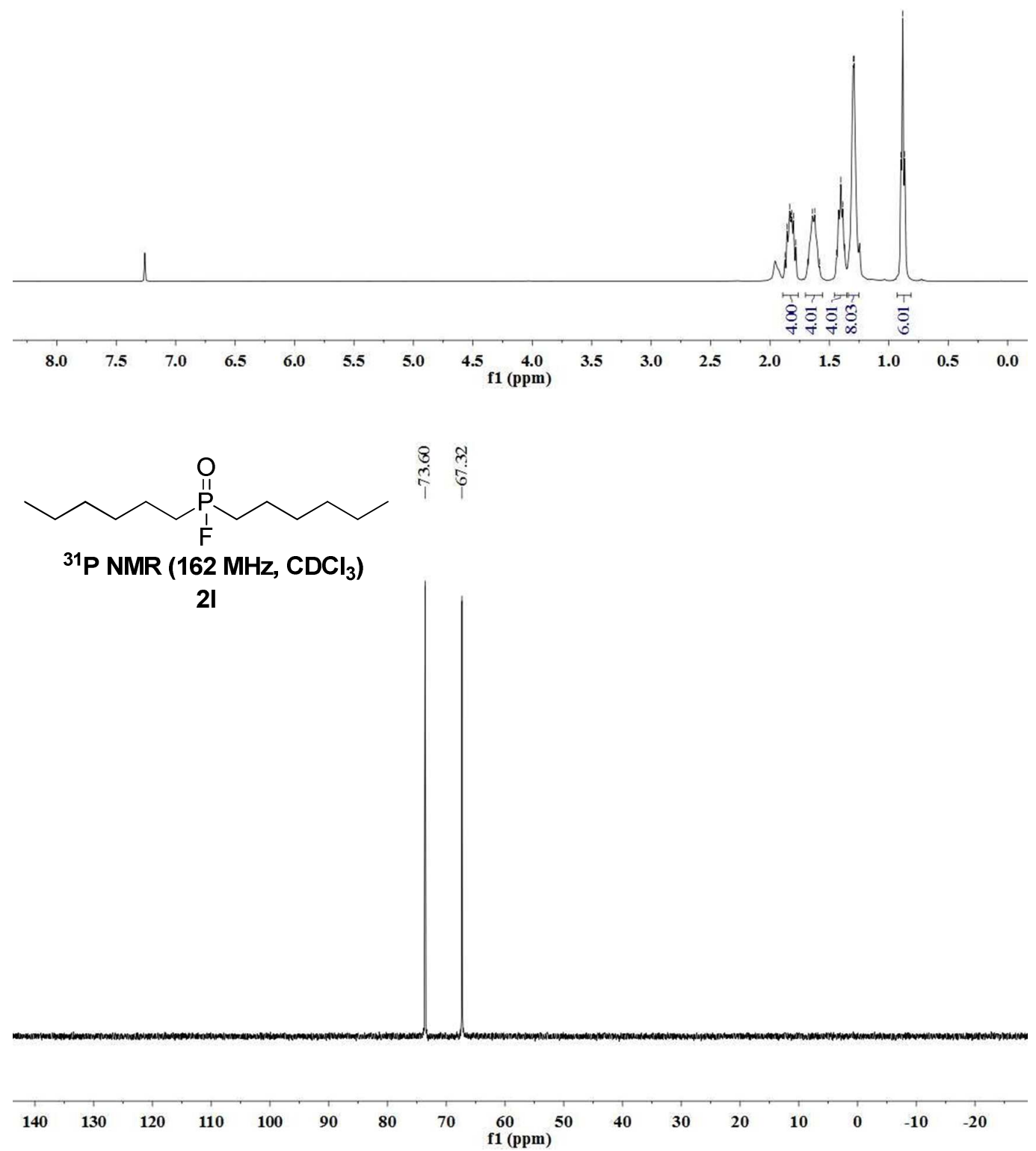


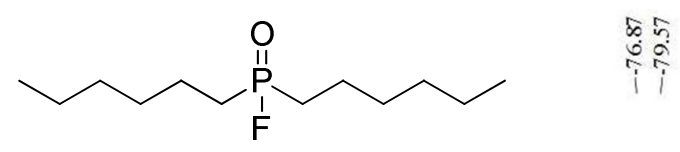

${ }^{19} \mathrm{~F} \mathrm{NMR}$ (376 MHz, $\left.\mathrm{CDCl}_{3}\right)$

2I

\begin{tabular}{|c|c|c|c|c|c|c|c|c|c|c|c|c|c|c|}
\hline-15 & -25 & -35 & -45 & -55 & -65 & ${ }^{-75}$ f & $\begin{array}{c}-85 \\
\text { pm) }\end{array}$ & -95 & -105 & -115 & -125 & -135 & -145 & -15 \\
\hline
\end{tabular}

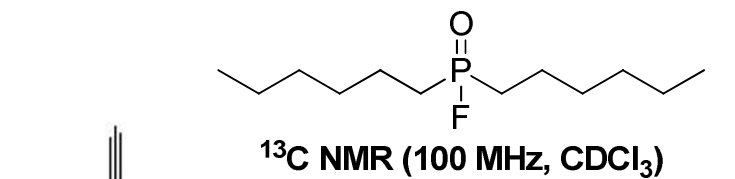

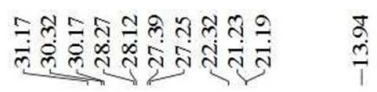

2I

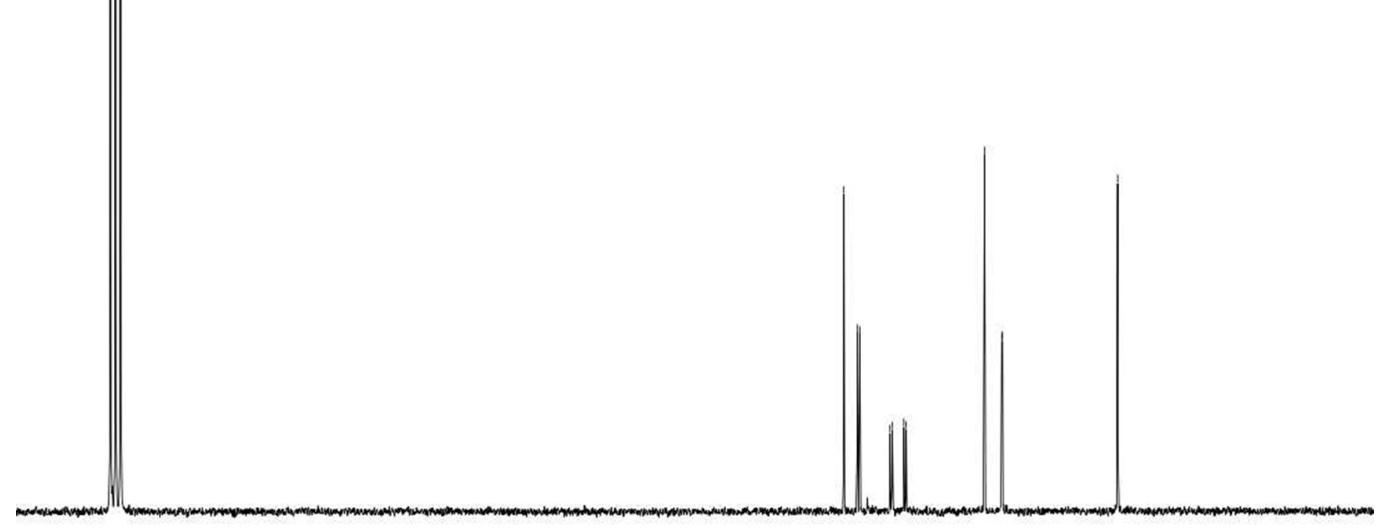

80

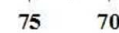

65

60

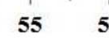

$45 \quad 40$
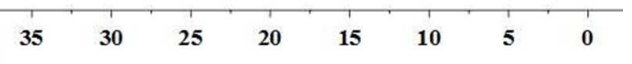

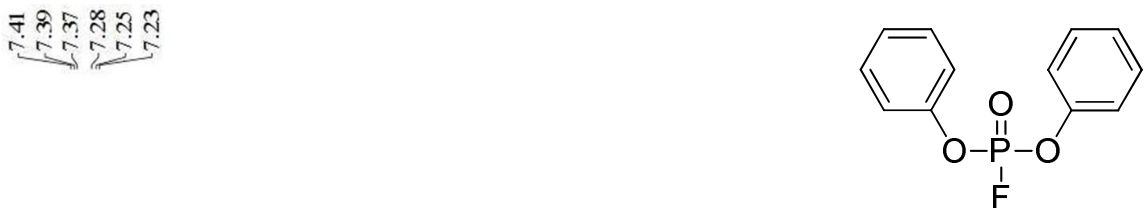

${ }^{1} \mathrm{H}$ NMR (400 MHz, $\mathrm{CDCl}_{3}$ )

$2 \mathrm{~m}$

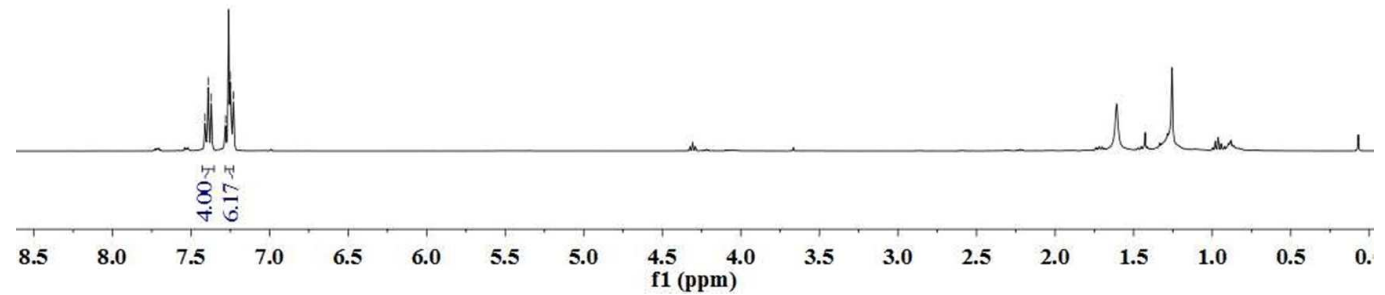

ले

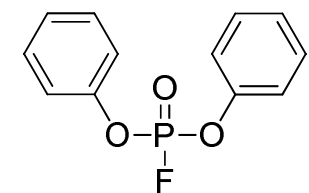

${ }^{31} \mathrm{P}$ NMR (162 $\left.\mathrm{MHz}, \mathrm{CDCl}_{3}\right)$ $2 \mathrm{~m}$

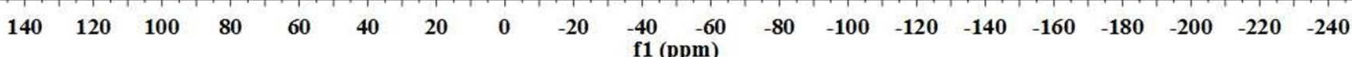




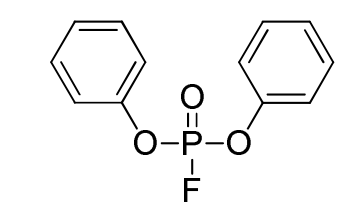

$\left.{ }^{19} \mathrm{~F} \mathrm{NMR} \mathrm{(376} \mathrm{MHz}, \mathrm{CDCl}_{3}\right)$ $2 \mathrm{~m}$

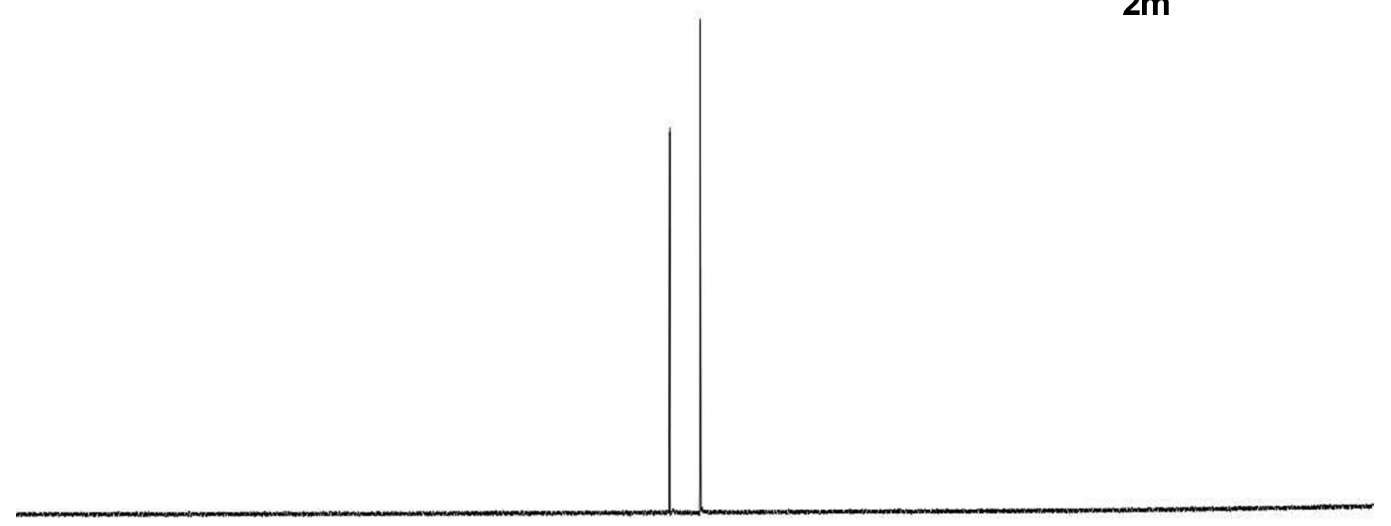

$\begin{array}{llllllllllllllllllllllllllllllllll}20 & -25 & -30 & -35 & -40 & -45 & -50 & -55 & -60 & -65 & -70 & -75 & -80 & -85 & -90 & -95 & -100 & -105 & -110 & -115 & -120 & -125 & -130 & -135\end{array}$

\begin{tabular}{|c|c|c|}
\hline 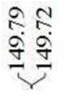 & 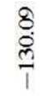 & సิ \\
\hline
\end{tabular}

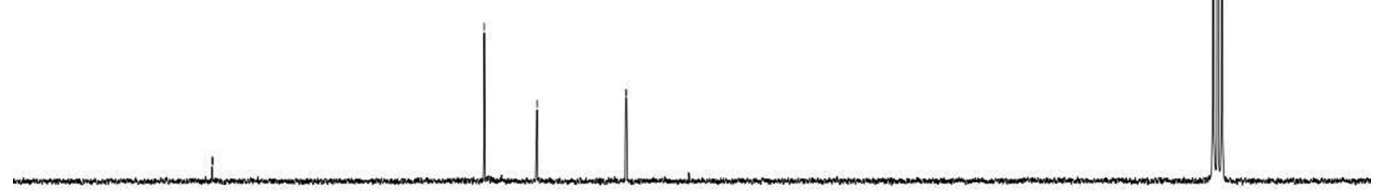

$\begin{array}{llllllllllllllllllll}160 & 155 & 150 & 145 & 140 & 135 & 130 & 125 & 120 & 115 & 110 & 105 & 100 & 95 & 90 & 85 & 80 & 75 & 70\end{array}$ 

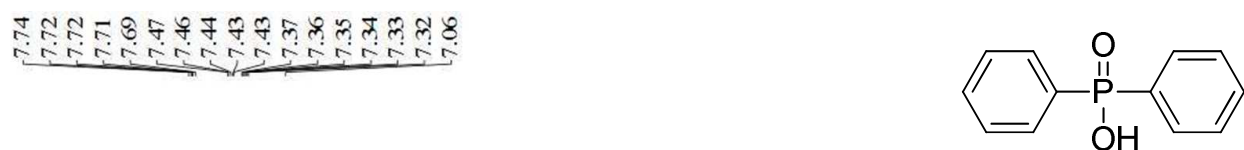

${ }^{1} \mathrm{H}$ NMR (400 MHz, $\mathrm{CDCl}_{3}$ )

$3 a$

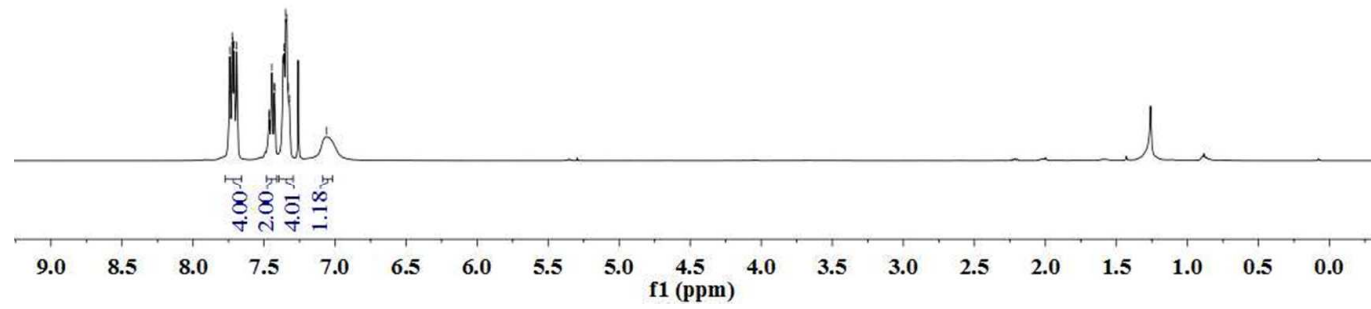

3
กं

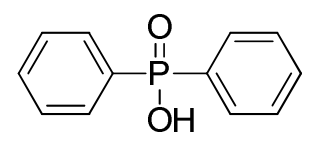

${ }^{31} \mathrm{P}$ NMR (162 MHz, $\mathrm{CDCl}_{3}$ )

$3 a$

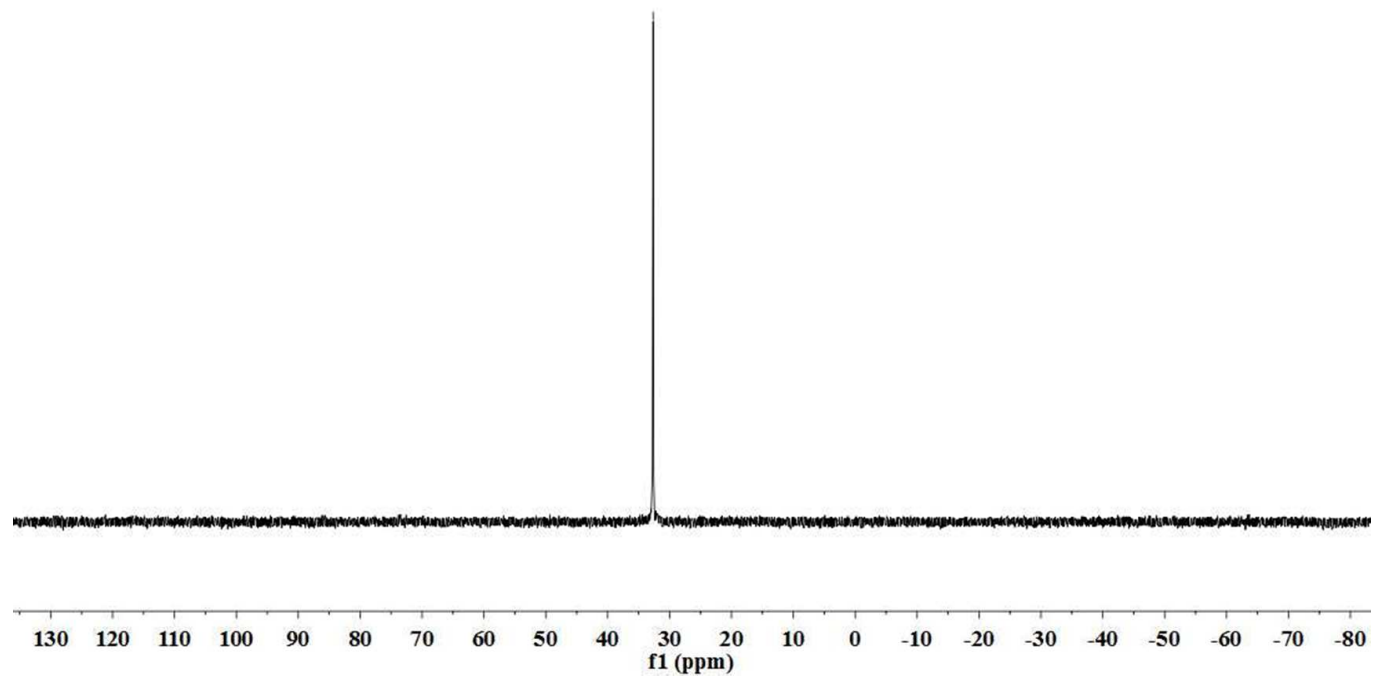




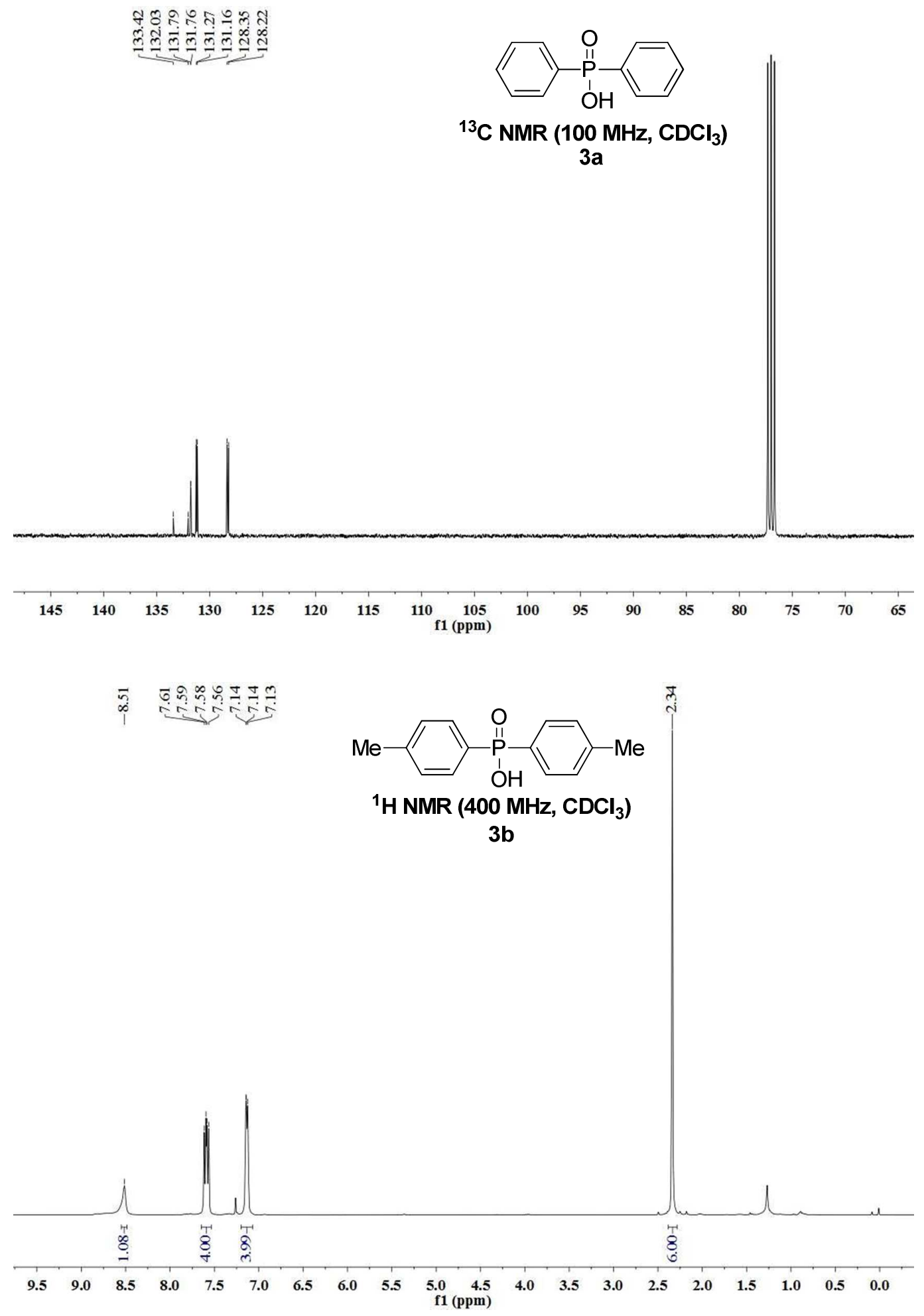



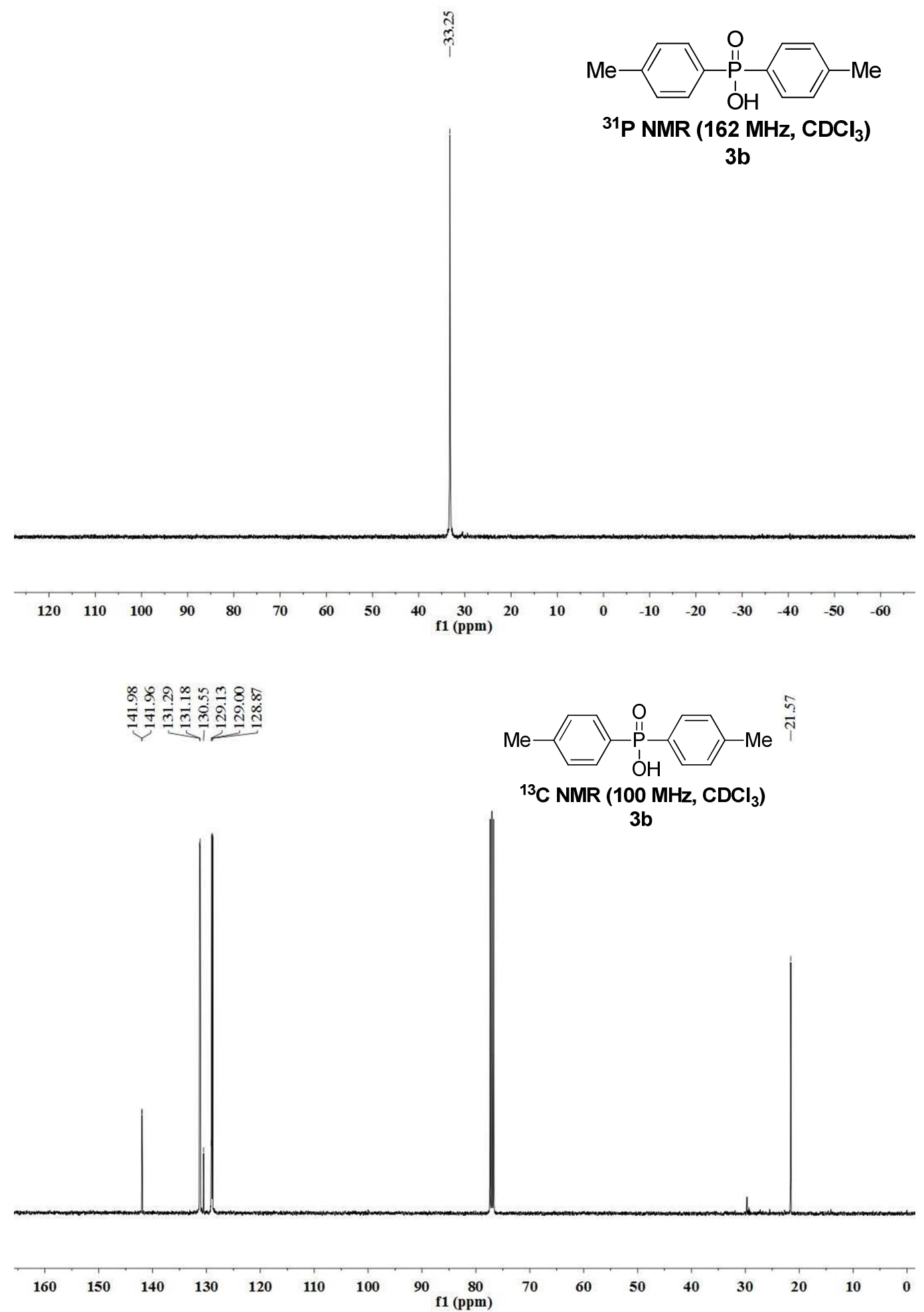
$\stackrel{\substack{1 \\ 1}}{8}$

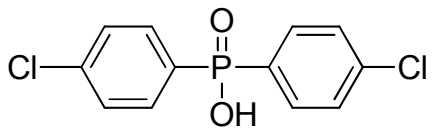

${ }^{1} \mathrm{H}$ NMR (400 MHz, $\left.\mathrm{CDCl}_{3}\right)$

$3 c$

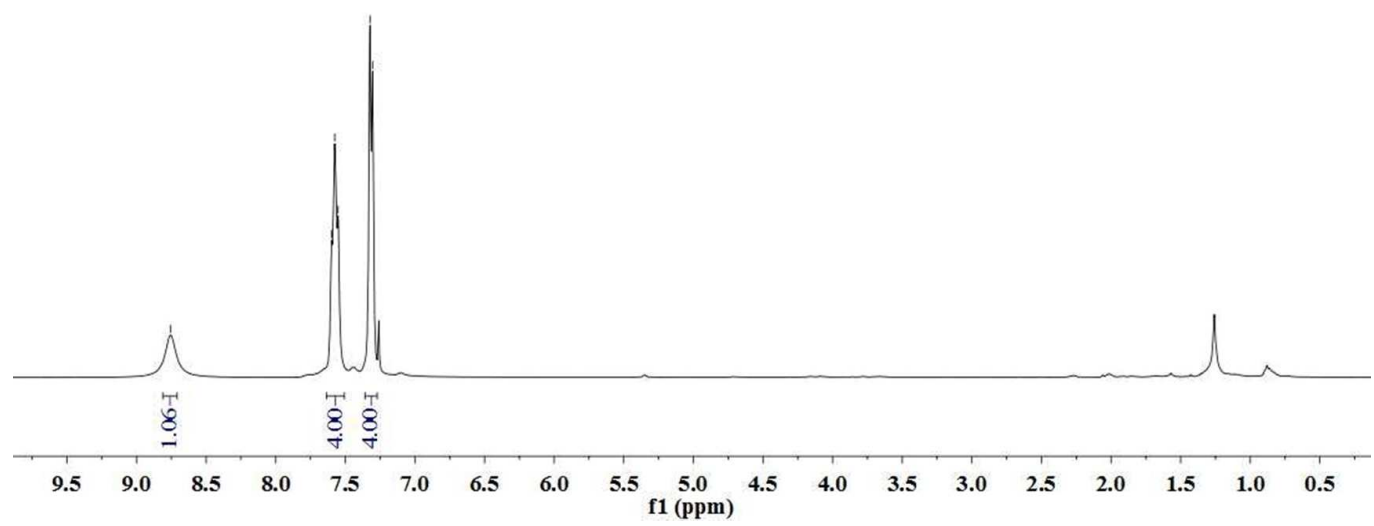

$\infty$
$\infty$
$i$

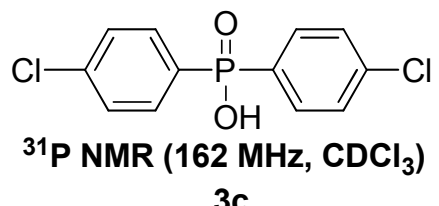

$3 c$

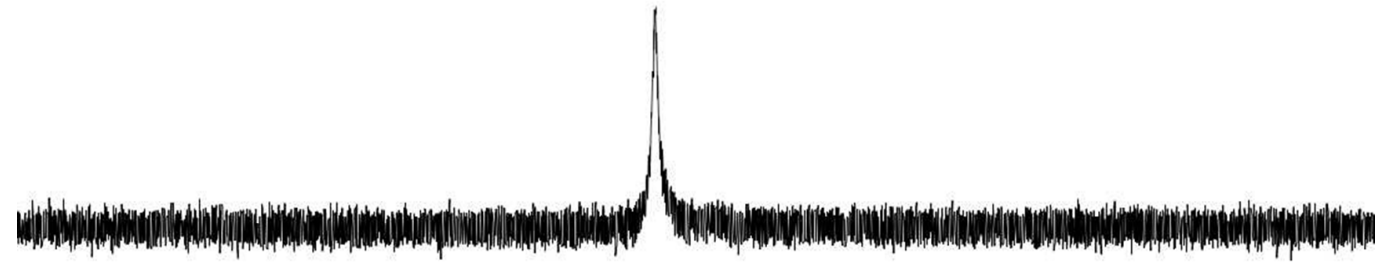

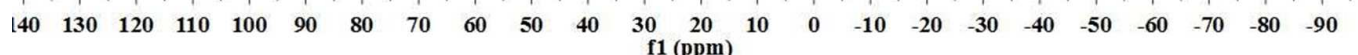




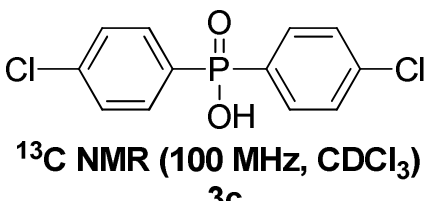

$3 \mathrm{c}$

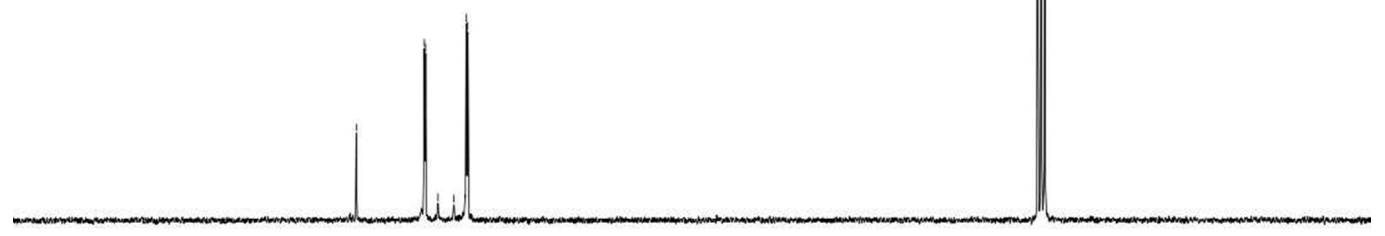

$\begin{array}{llllllllllllllllllllllll}165 & 160 & 155 & 150 & 145 & 140 & 135 & 130 & 125 & 120 & 115 & 110 & 105 & 100 & 95 & 90 & 85 & 80 & 75 & 70 & 65 & 60 & 55 & 50\end{array}$ ह

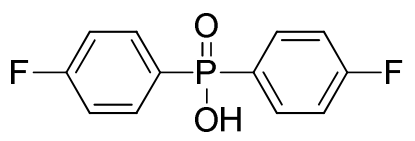

${ }^{1} \mathrm{H}$ NMR (400 MHz, $\mathrm{CDCl}_{3}$ )

3d

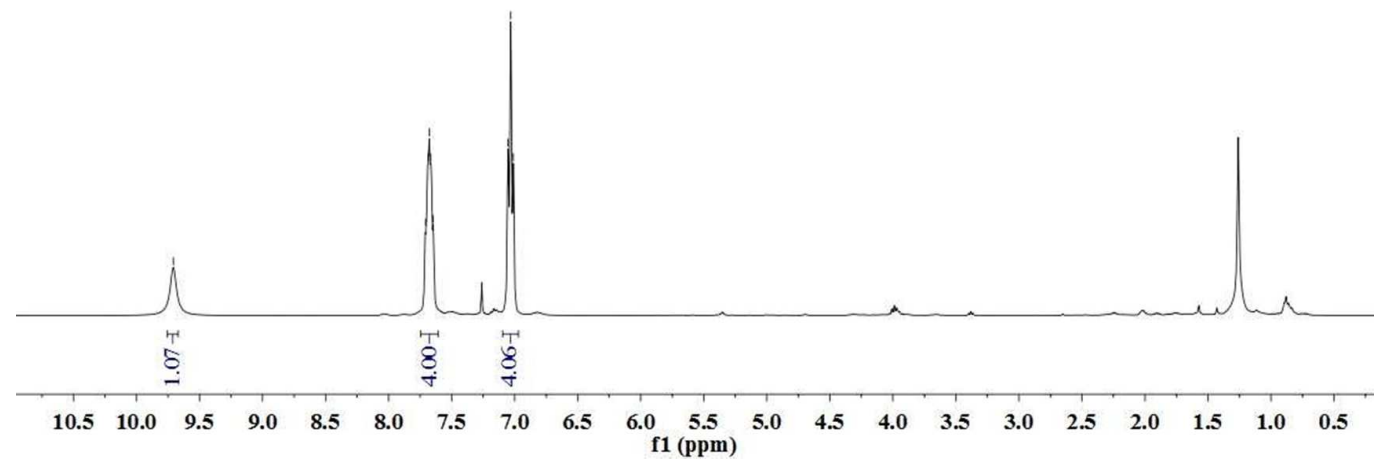




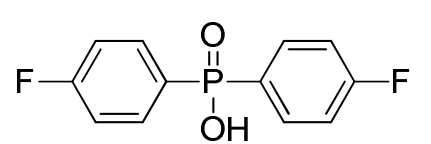

${ }^{31} \mathrm{P}$ NMR (162 $\left.\mathrm{MHz}, \mathrm{CDCl}_{3}\right)$

3d

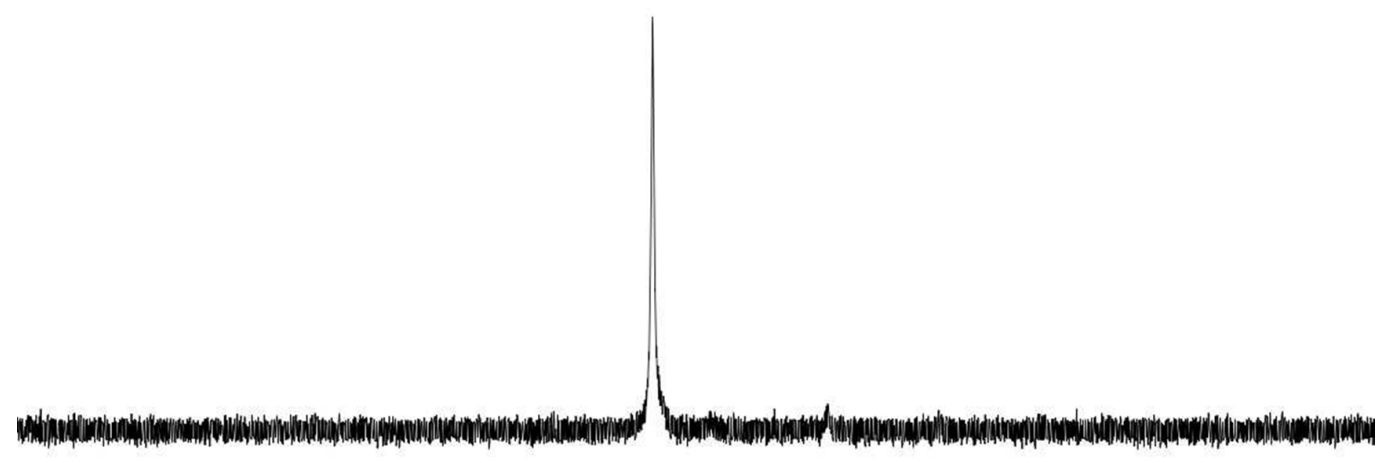

$\begin{array}{lllllllllllllllllllllllllll}130 & 120 & 110 & 100 & 90 & 80 & 70 & 60 & 50 & 40 & \underset{f 1}{\mathbf{f} 1} \underset{(\mathrm{ppm})}{20} & 10 & 0 & -10 & -20 & -30 & -40 & -50 & -60 & -70 & -80 & -90\end{array}$

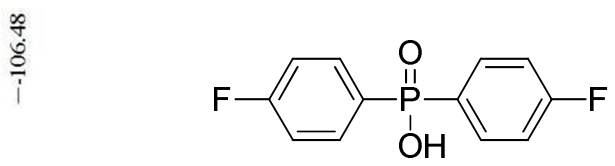

${ }^{19}$ F NMR (376 $\left.\mathrm{MHz}, \mathrm{CDCl}_{3}\right)$

3d

$\begin{array}{llllllllllllllllllllllllllllll}10 & 0 & -10 & -20 & -30 & -40 & -50 & -60 & -70 & -80 & -90 & -100 & -110 & -120 & -130 & -140 & -150 & -160 & -170 & -180 & -190 & -200 & -210\end{array}$ 


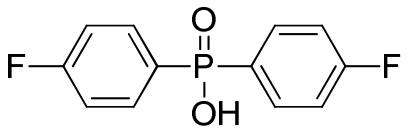

${ }^{13} \mathrm{C}$ NMR (100 MHz, $\left.\mathrm{CDCl}_{3}\right)$

3d

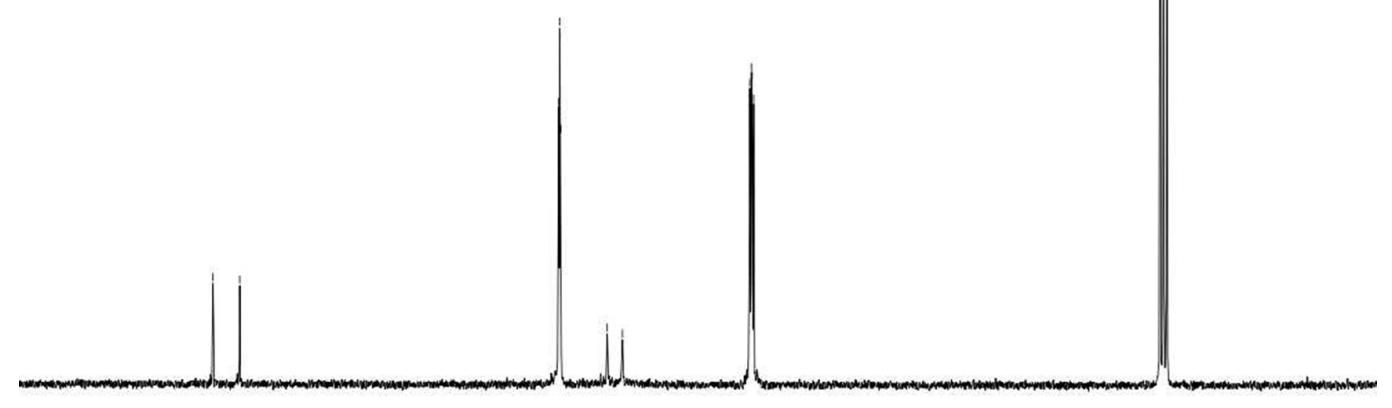

$\begin{array}{lllllllllllllllllllllllllll}180 & 175 & 170 & 165 & 160 & 155 & 150 & 145 & 140 & 135 & 130 & 125 & 120 & 115 & 110 & 105 & 100 & 95 & 90 & 85 & 80 & 75 & 70 & 65 & 60\end{array}$
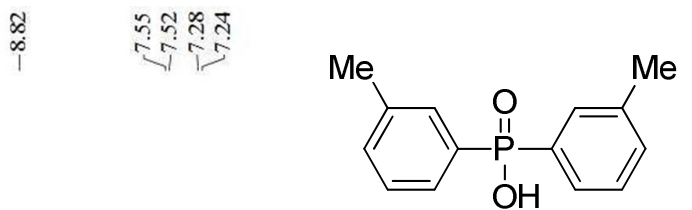

${ }^{1} \mathrm{H}$ NMR (400 MHz, $\mathrm{CDCl}_{3}$ )

$3 e$

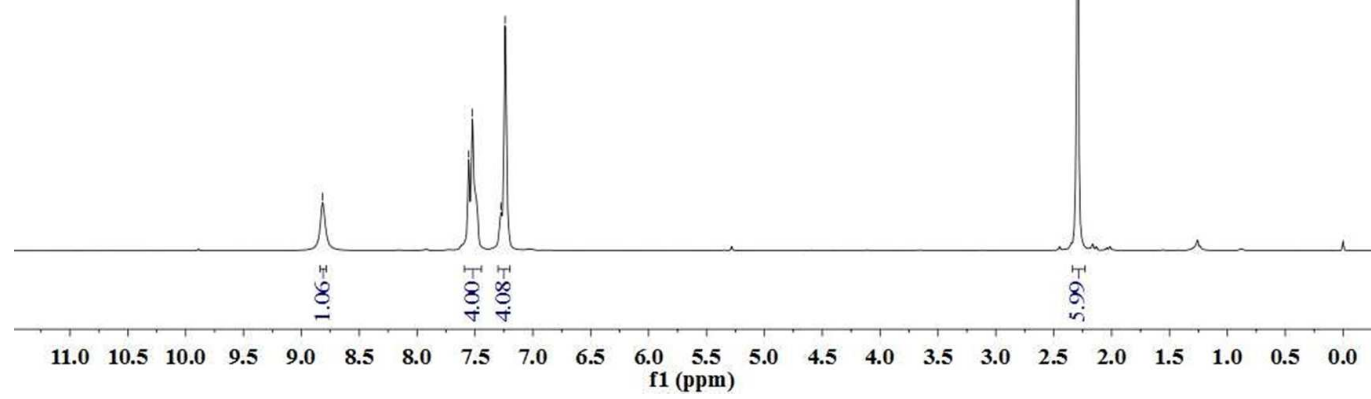




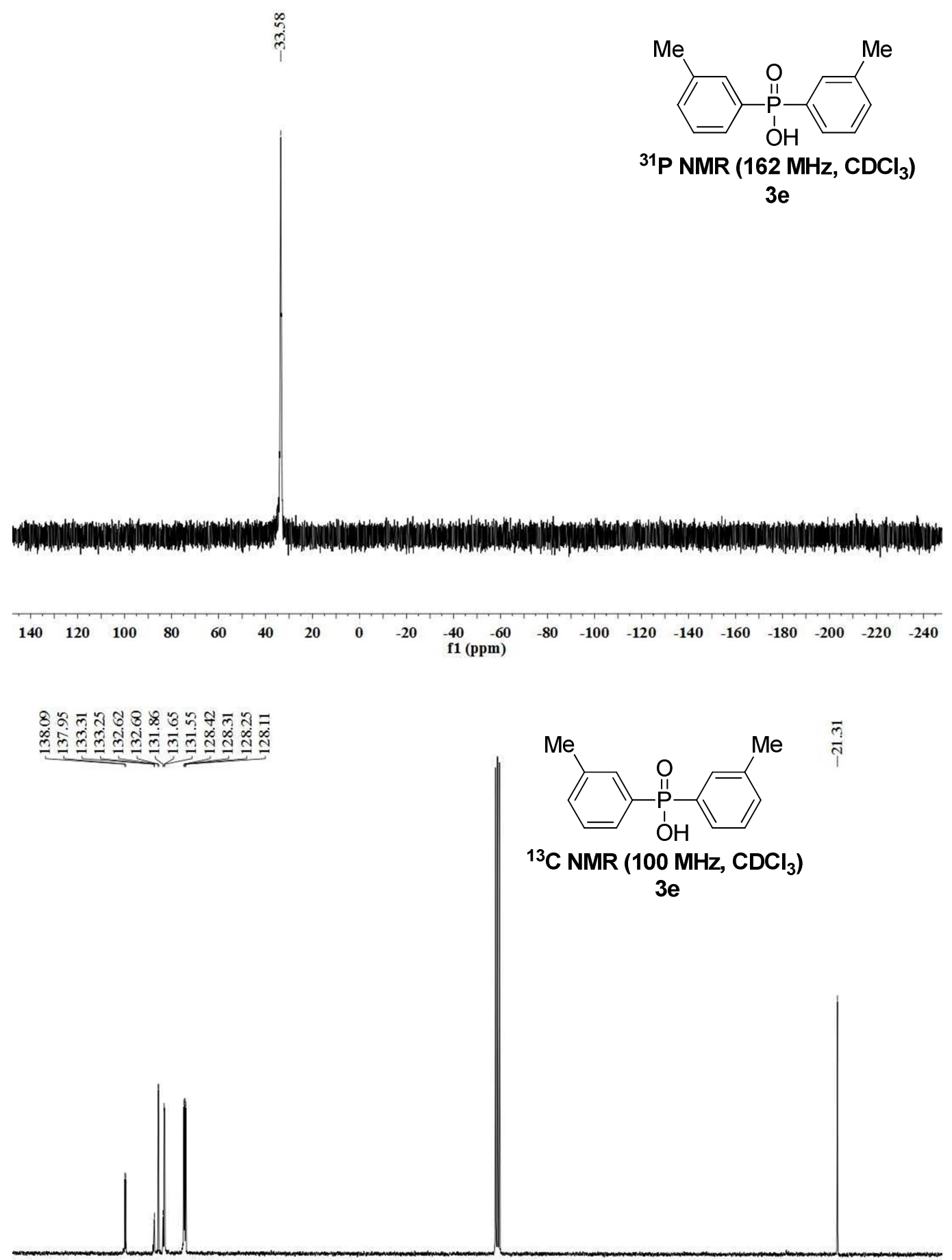

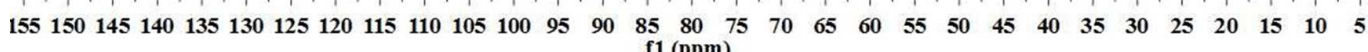




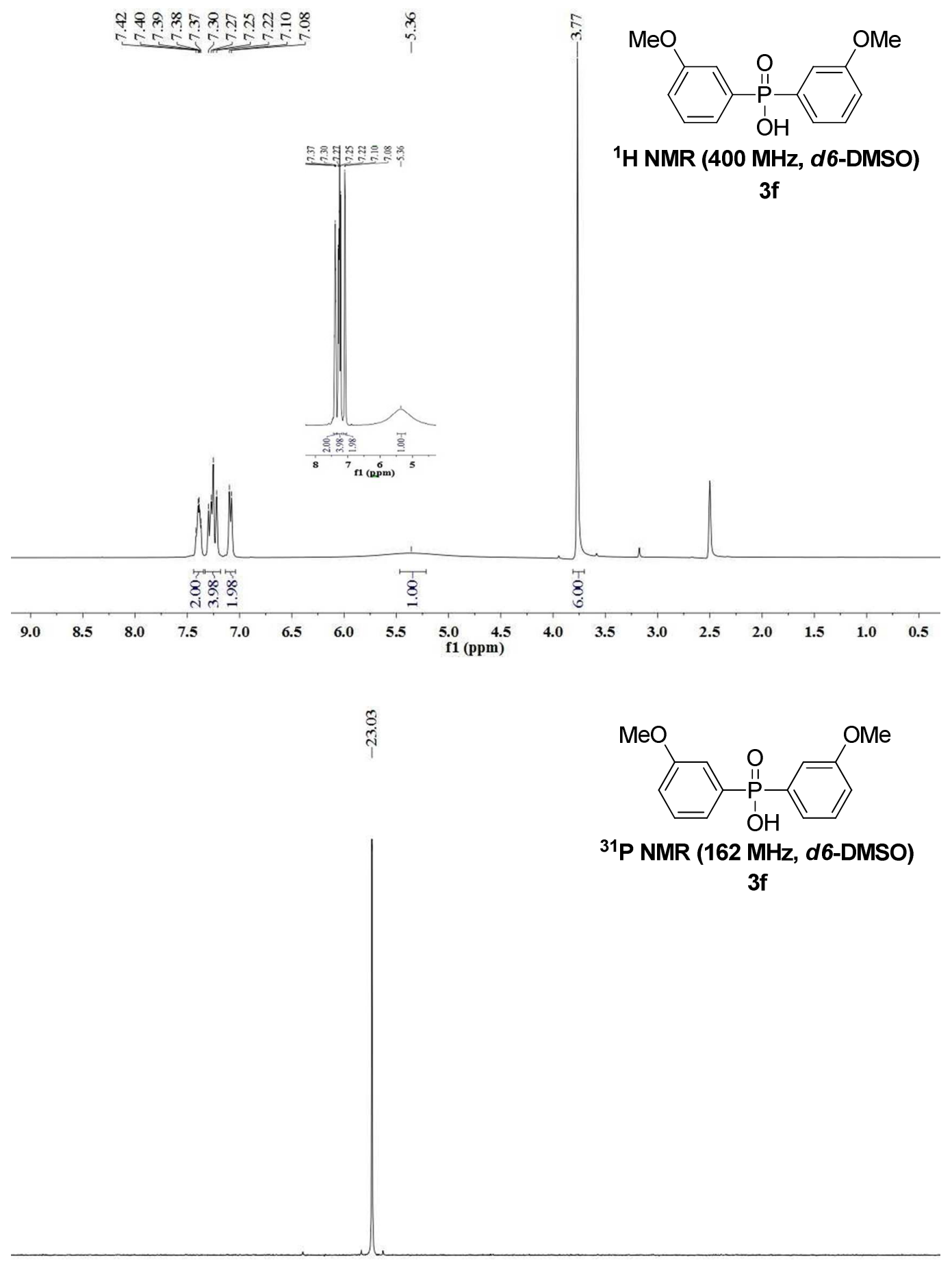

$\begin{array}{llllllllllllllllllllllllllllllllllll}36 & 35 & 34 & 33 & 32 & 31 & 30 & 29 & 28 & 27 & 26 & 25 & 24 & 23 & 22 & 21 & 20 & 19 & 18 & 17 & 16 & 15 & 14 & 13 & 12 & 11 & 10 & 9 & 8 & 7 & 6 & 5 & 4 & 3 & 2\end{array}$ f1 (ppm) 
$\mathrm{MeO}$<smiles>COc1cccc(P(=O)(O)c2cccc(O)c2)c1</smiles>

${ }^{13} \mathrm{C}$ NMR (100 MHz, d6-DMSO)

$3 f$

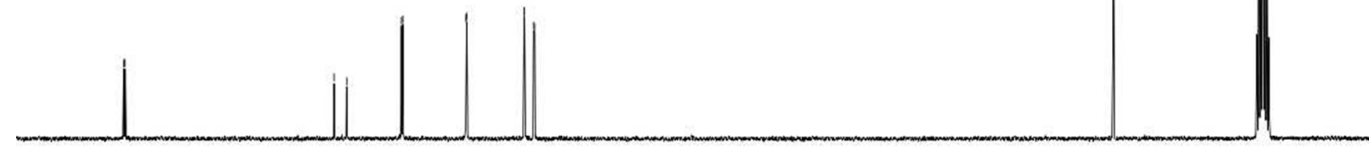

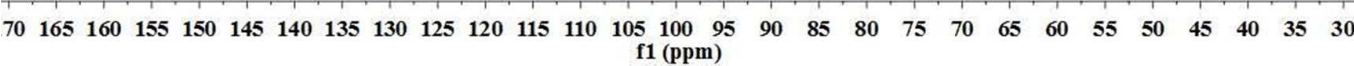
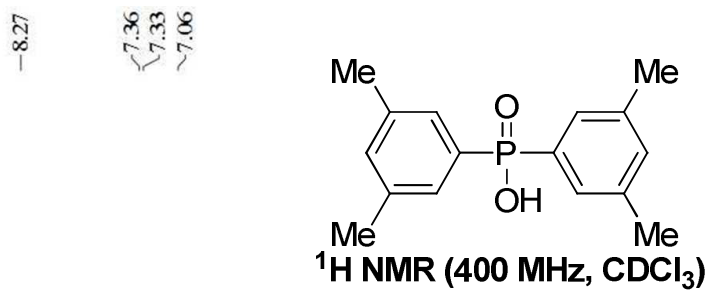

$\stackrel{\text { กิ }}{\text { i }}$

$3 g$

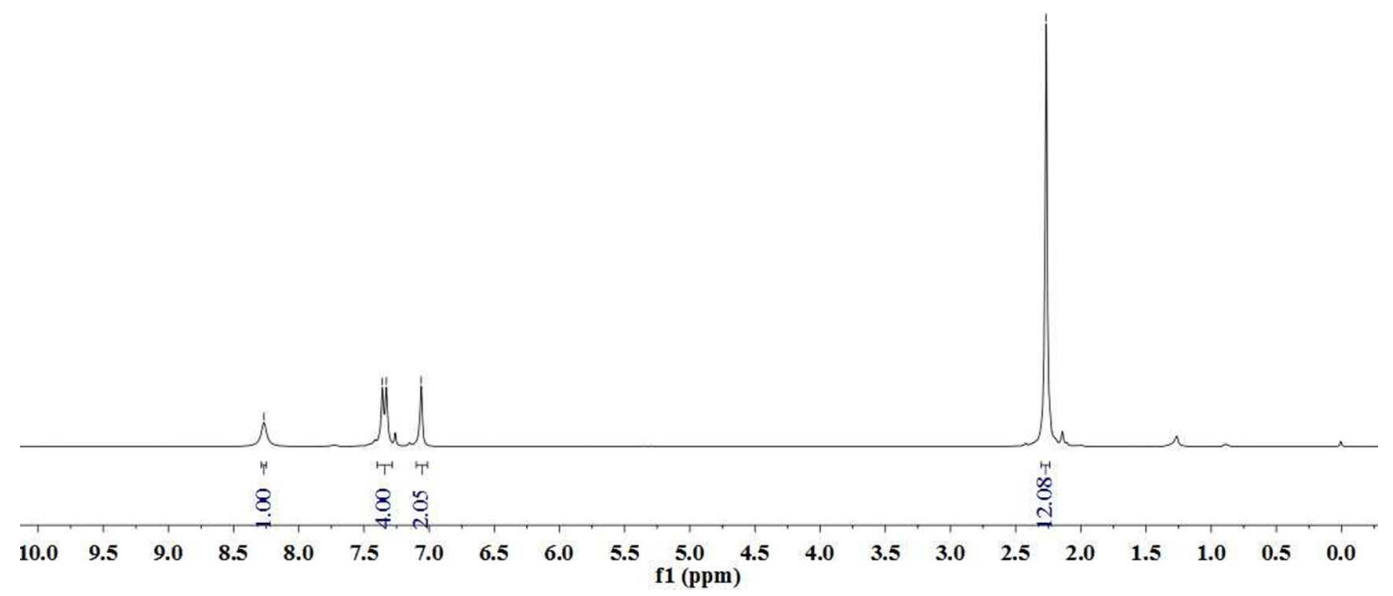




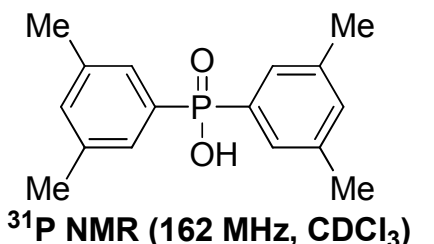

$3 g$

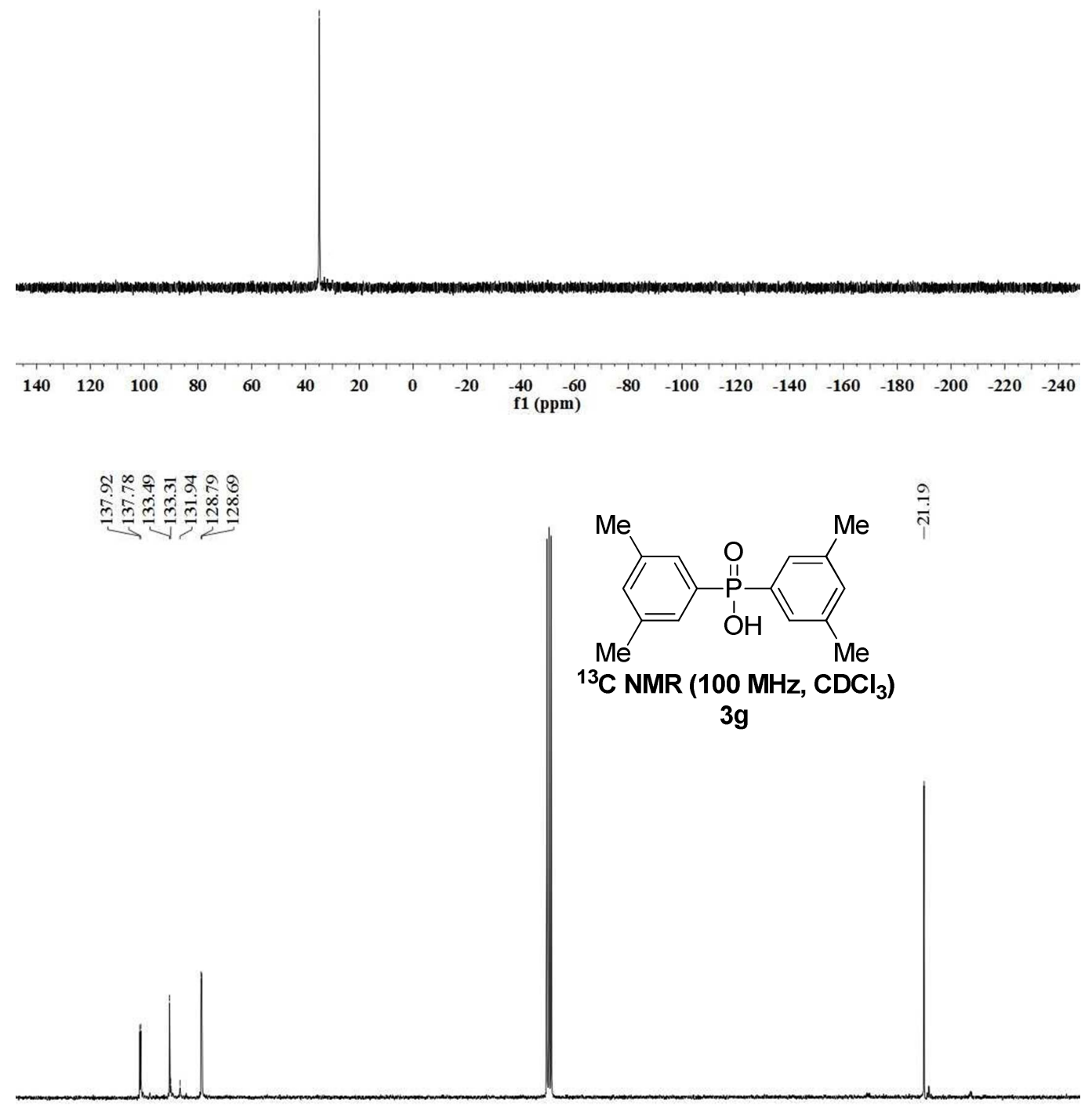

\begin{tabular}{|c|c|c|c|c|c|c|c|c|c|c|c|c|c|c|}
\hline 150 & 140 & 130 & 120 & 110 & 100 & 90 & $\begin{array}{l}80 \\
\mathrm{f} 1 \text { (ppm) }\end{array}$ & 70 & 60 & 50 & 40 & 30 & 20 & 10 \\
\hline
\end{tabular}




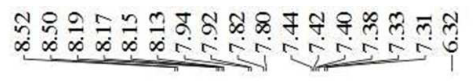

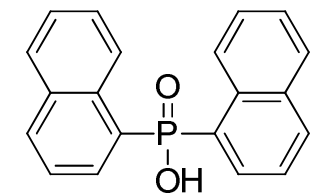

${ }^{1} \mathrm{H}$ NMR (400 MHz, $\mathrm{CDCl}_{3}$ )

$3 \mathrm{~h}$

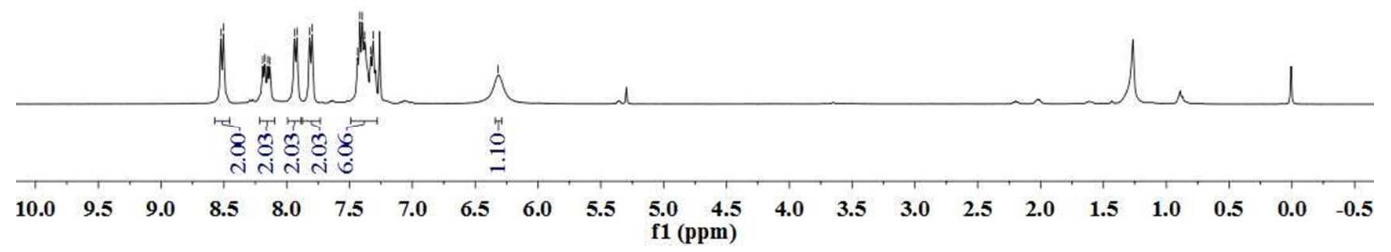

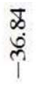

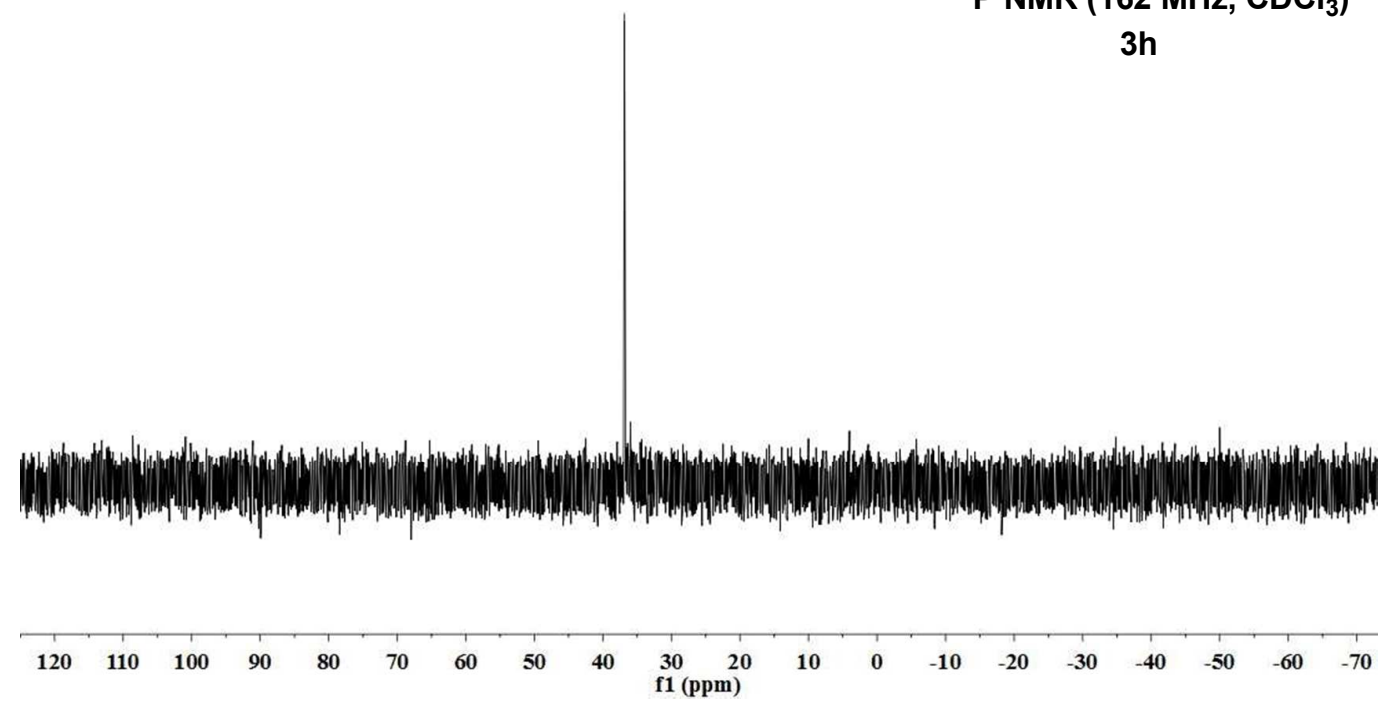




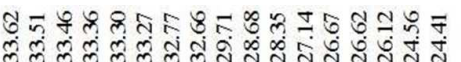

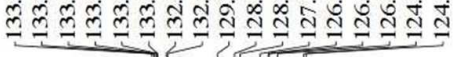

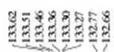

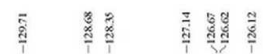

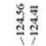

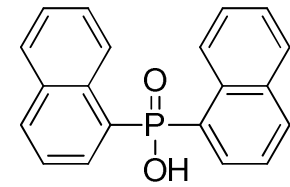

${ }^{13} \mathrm{C}$ NMR (100 MHz, $\mathrm{CDCl}_{3}$ )

3h

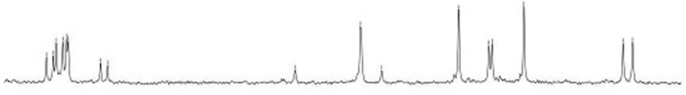

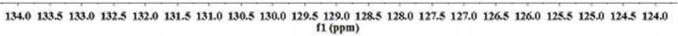

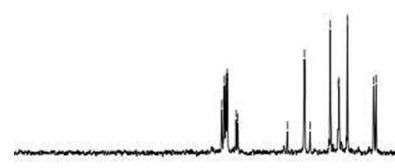

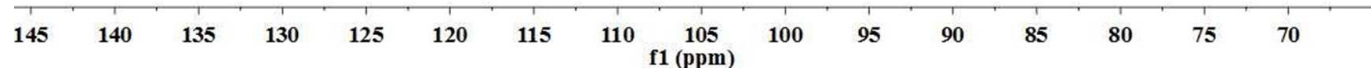

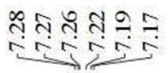

$\stackrel{\Xi}{i}$

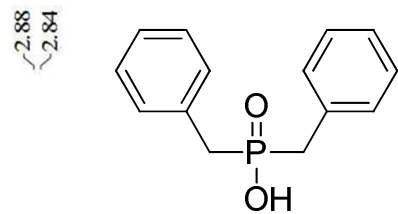

${ }^{1} \mathrm{H}$ NMR (400 MHz, $\mathrm{CDCl}_{3}$ )

3i

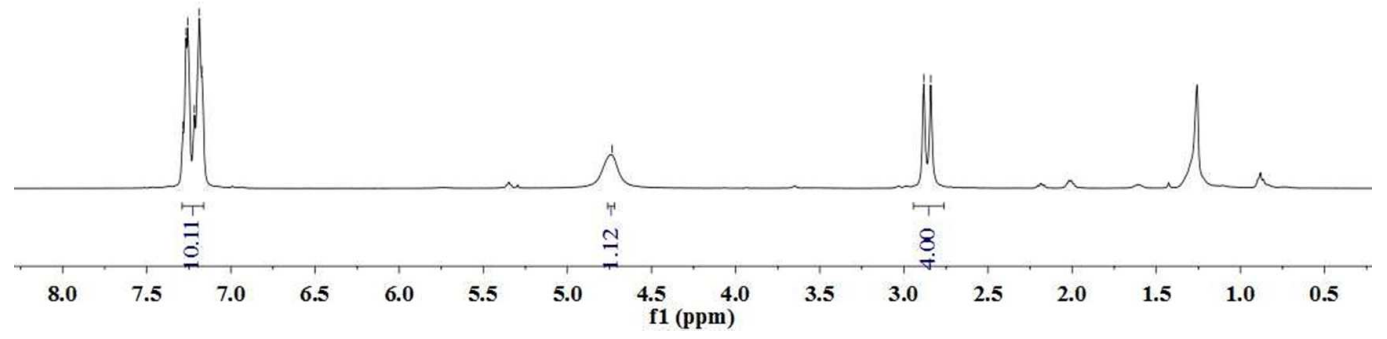




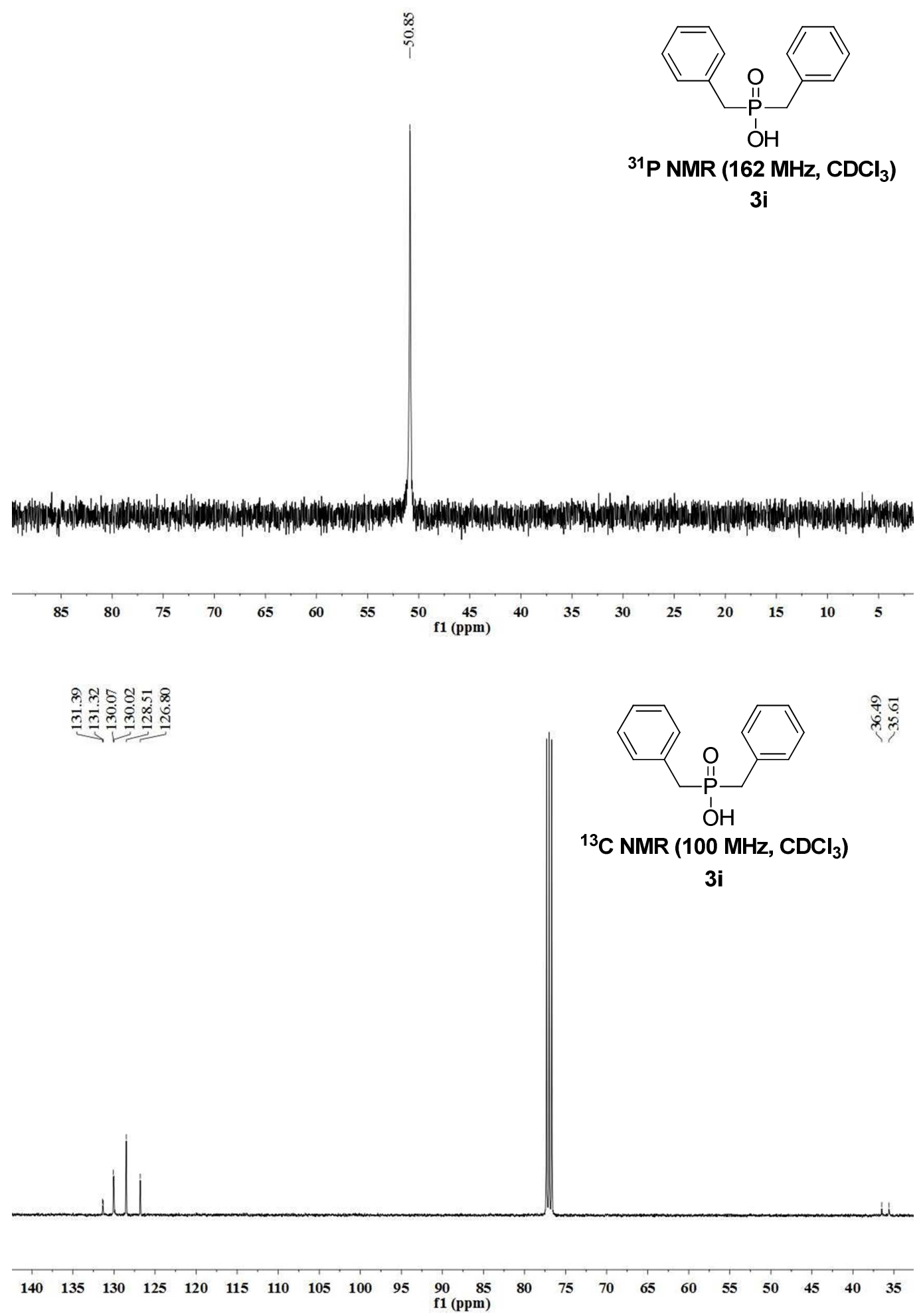




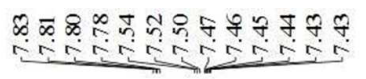

$\stackrel{2}{m}$

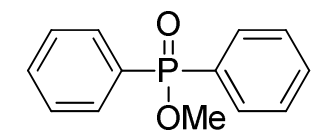

${ }^{1} \mathrm{H}$ NMR (400 MHz, $\left.\mathrm{CDCl}_{3}\right)$

3j

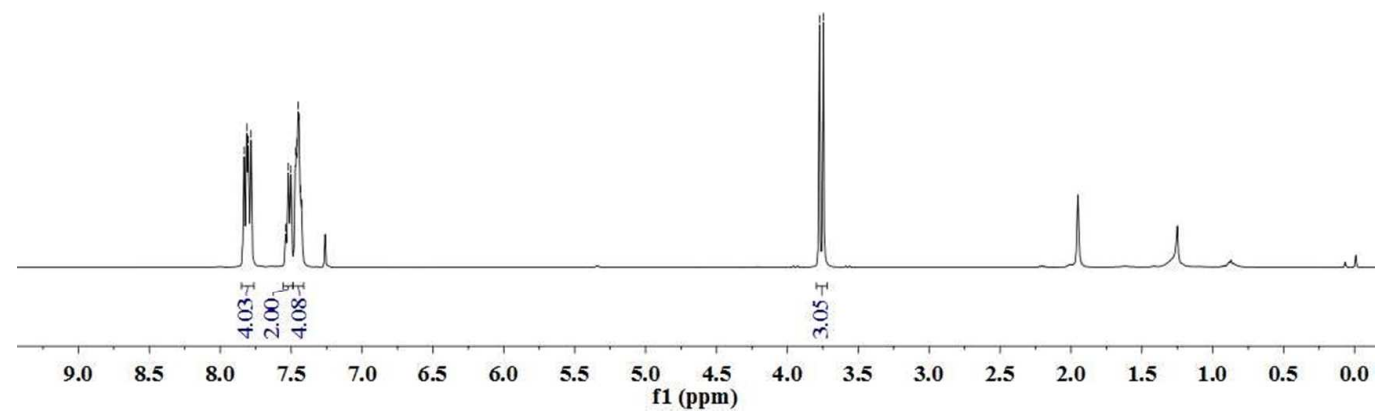

ले

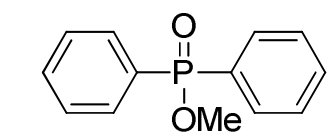

${ }^{31} \mathrm{P}$ NMR (162 MHz, $\mathrm{CDCl}_{3}$ )

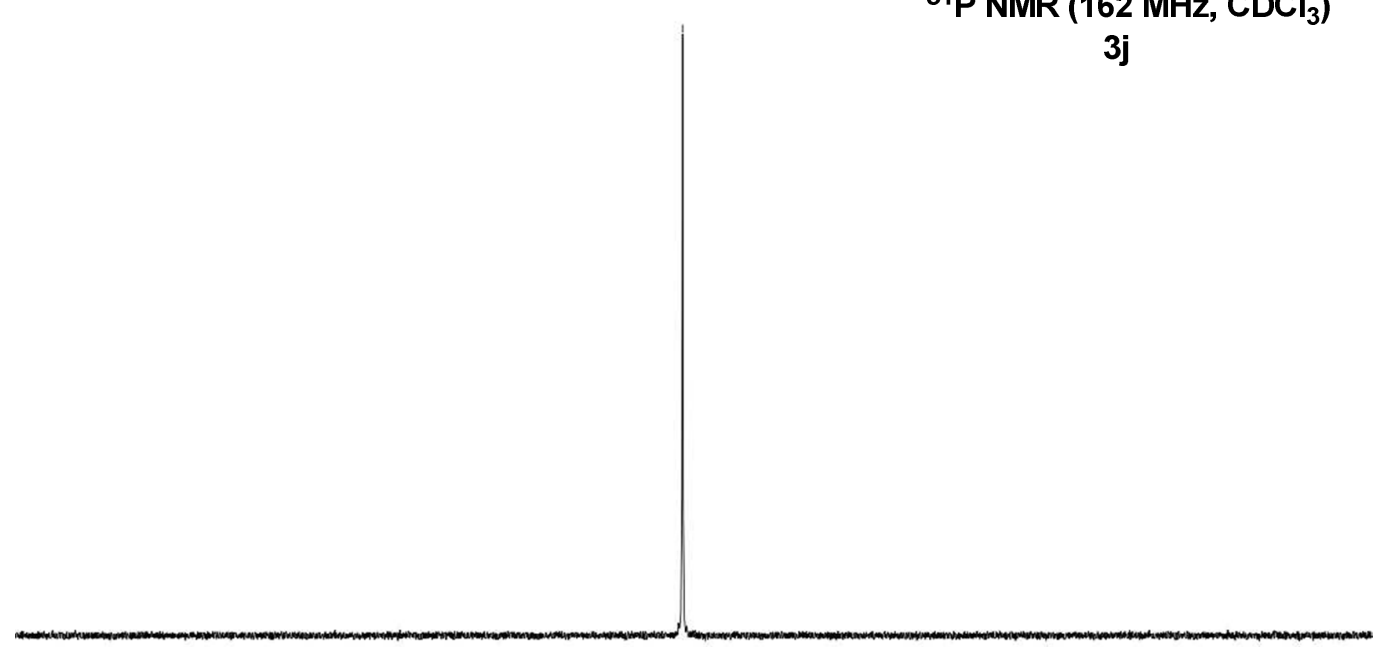

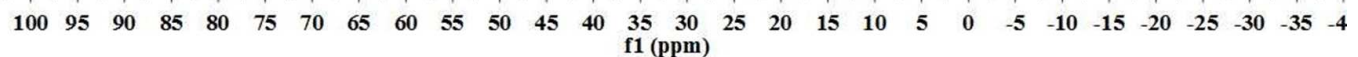



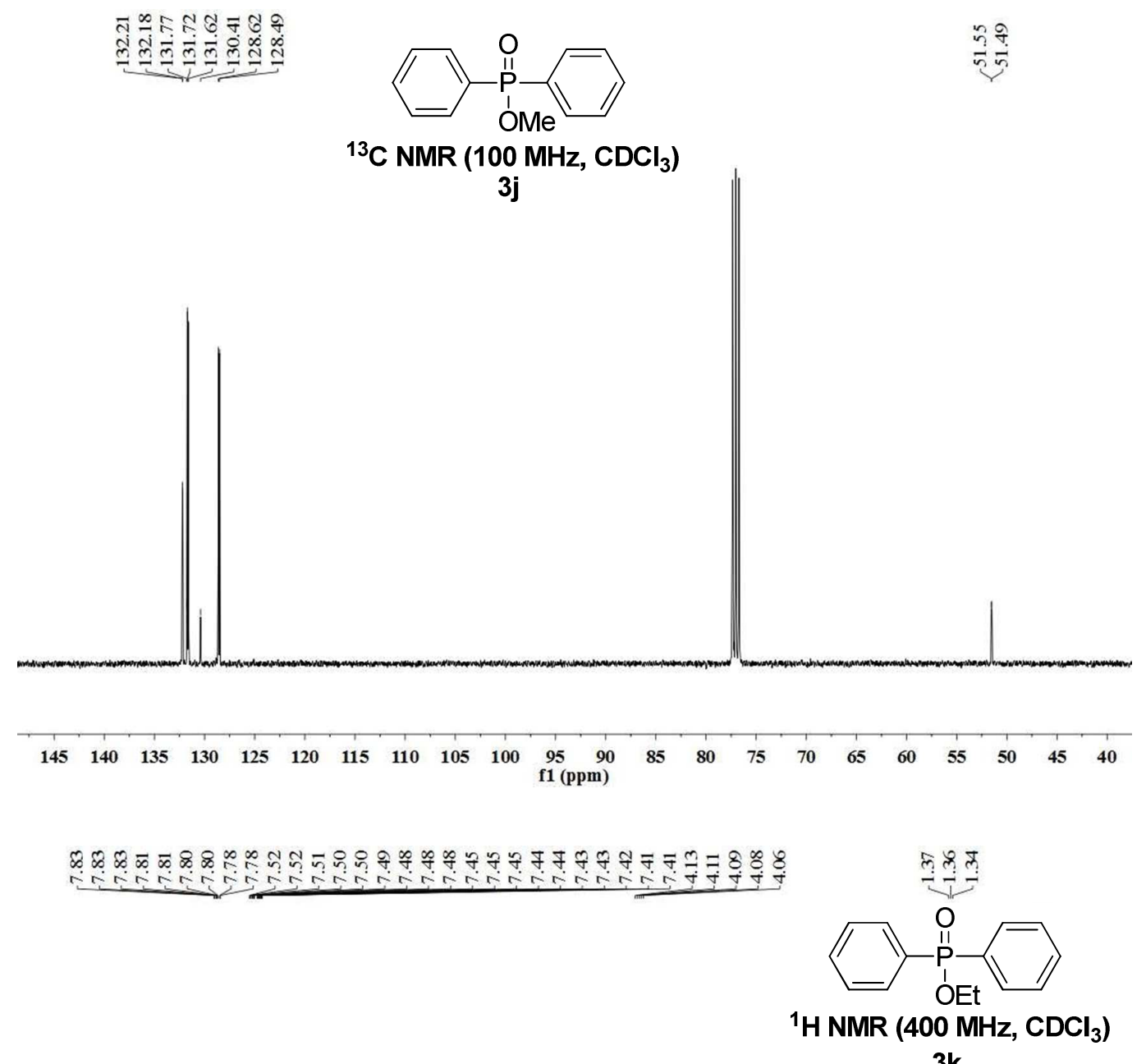

3k

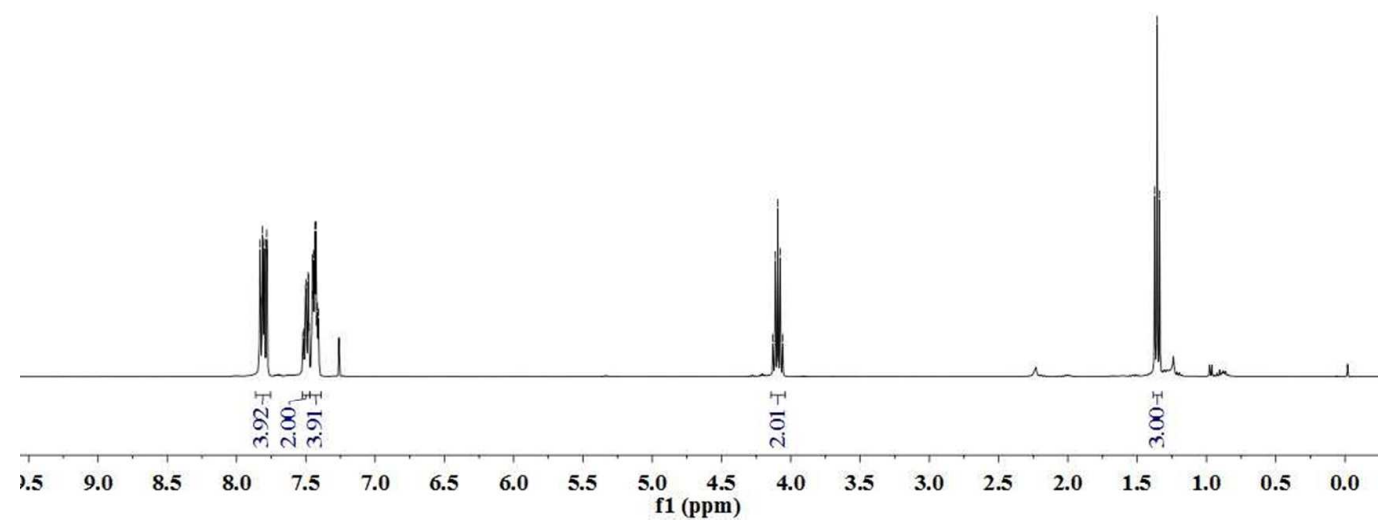



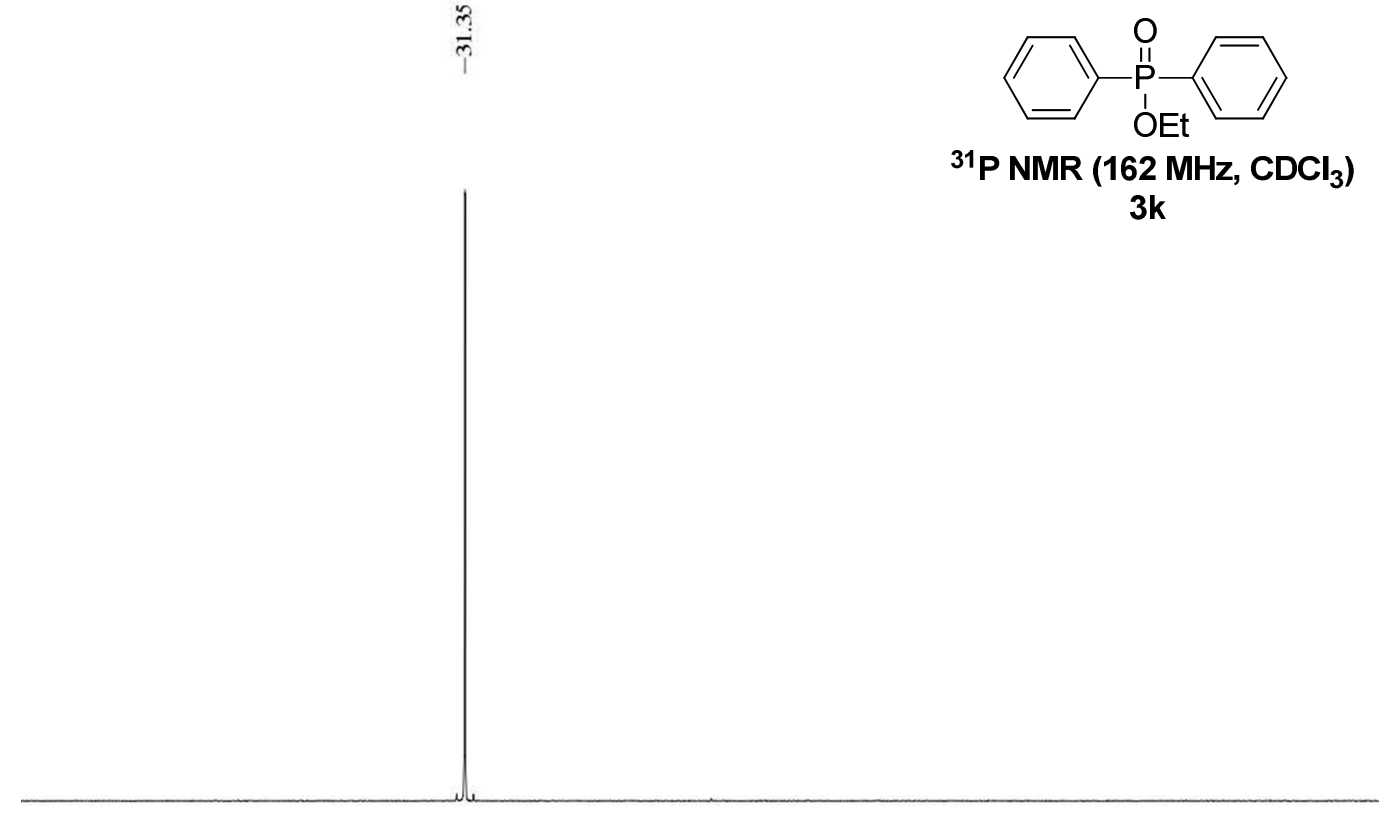

${ }^{31} \mathrm{P}$ NMR (162 MHz, $\left.\mathrm{CDCl}_{3}\right)$

3k

$\begin{array}{llllllllllllllllllllllllllllllllllllll}52 & 50 & 48 & 46 & 44 & 42 & 40 & 38 & 36 & 34 & 32 & 30 & 28 & 26 & 24 & 22 & 20 & 18 & 16 & 14 & 12 & 10 & 8 & 6 & 4 & 2 & 0 & -2 & -4 & -6 & -8 & -10 & -12 & -14\end{array}$ f1 (ppm)
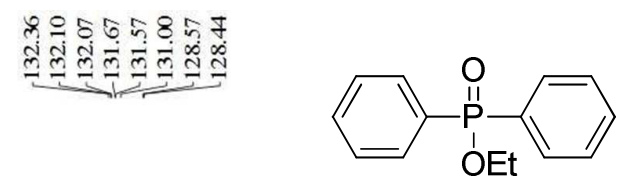

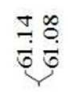

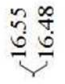

${ }^{13} \mathrm{C}$ NMR (100 MHz, $\left.\mathrm{CDCl}_{3}\right)$

$3 k$

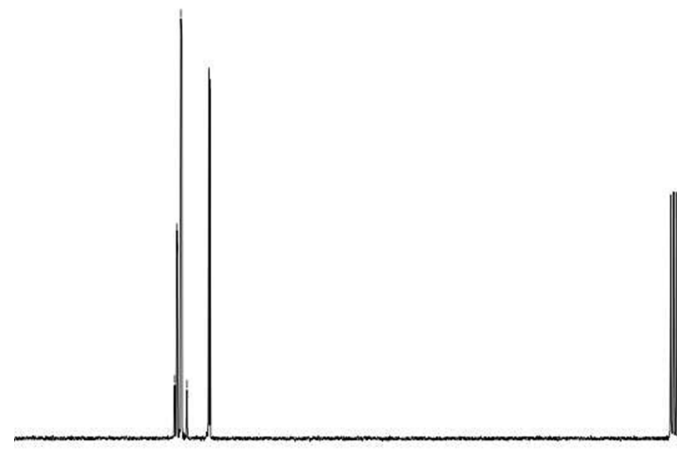

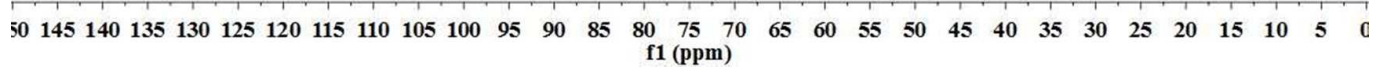




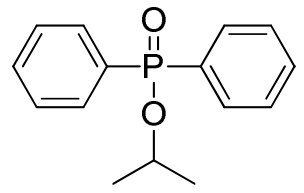

${ }^{1} \mathrm{H}$ NMR $\left(400 \mathrm{MHz}, \mathrm{CDCl}_{3}\right)$

3I

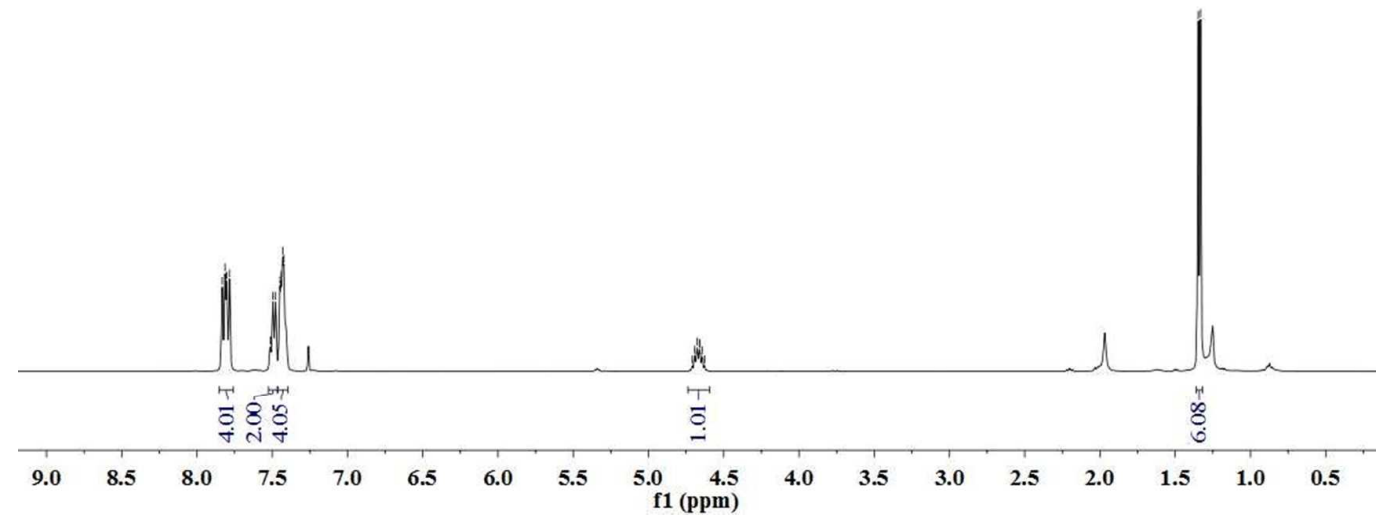

$\stackrel{\text { \$े }}{\text { iे }}$
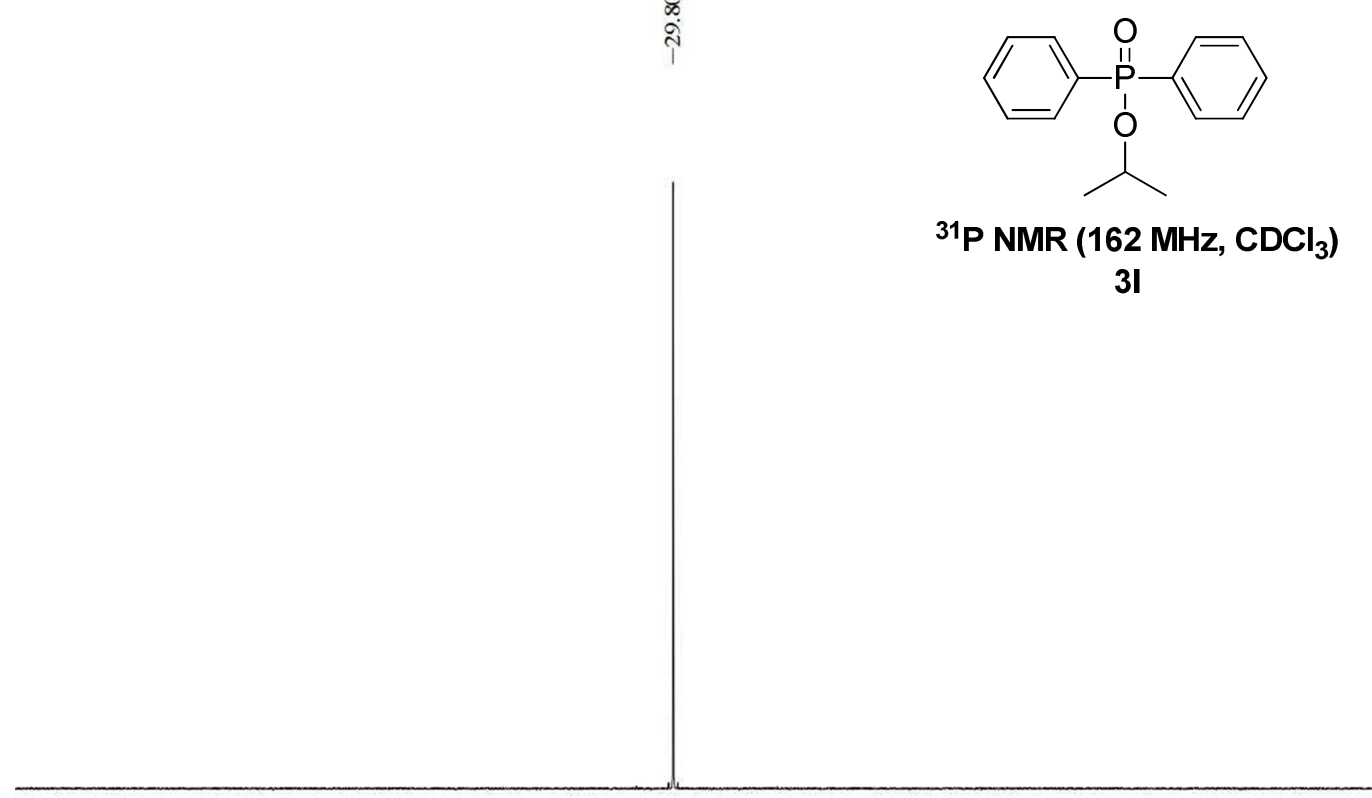

$\begin{array}{llllllllllllllllllllllllllllllll}90 & 85 & 80 & 75 & 70 & 65 & 60 & 55 & 50 & 45 & 40 & 35 & 30 & 25 & 20 & 15 & 10 & 5 & 0 & -5 & -10 & -15 & -20 & -25 & -30 & -3\end{array}$ 

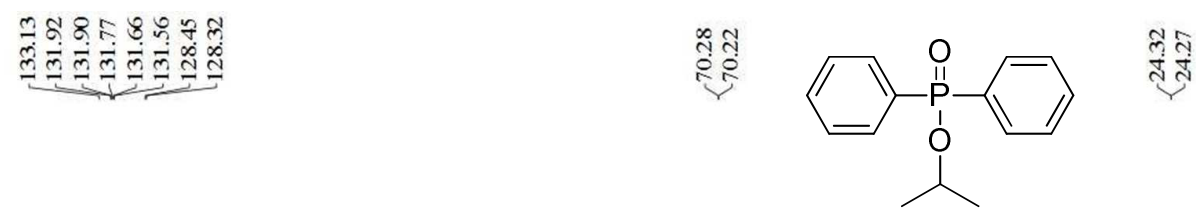

${ }^{13} \mathrm{C}$ NMR (100 MHz, $\mathrm{CDCl}_{3}$ )

3I

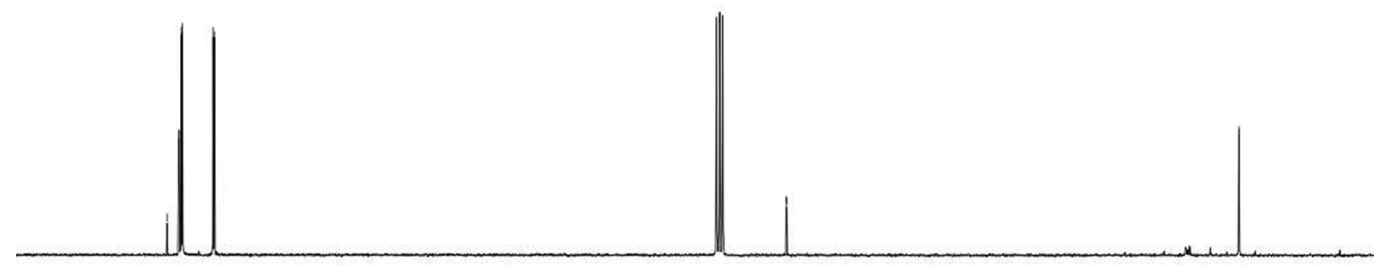

$\begin{array}{llllllllllllllllllllllllllllllllllllll}145 & 140 & 135 & 130 & 125 & 120 & 115 & 110 & 105 & 100 & 95 & 90 & 85 & 80 & 75 & 70 & 65 & 60 & 55 & 50 & 45 & 40 & 35 & 30 & 25 & 20 & 15\end{array}$

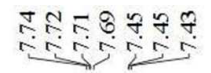

हैं

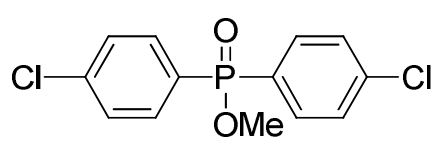

${ }^{1} \mathrm{H}$ NMR (400 MHz, $\left.\mathrm{CDCl}_{3}\right)$

$3 p$

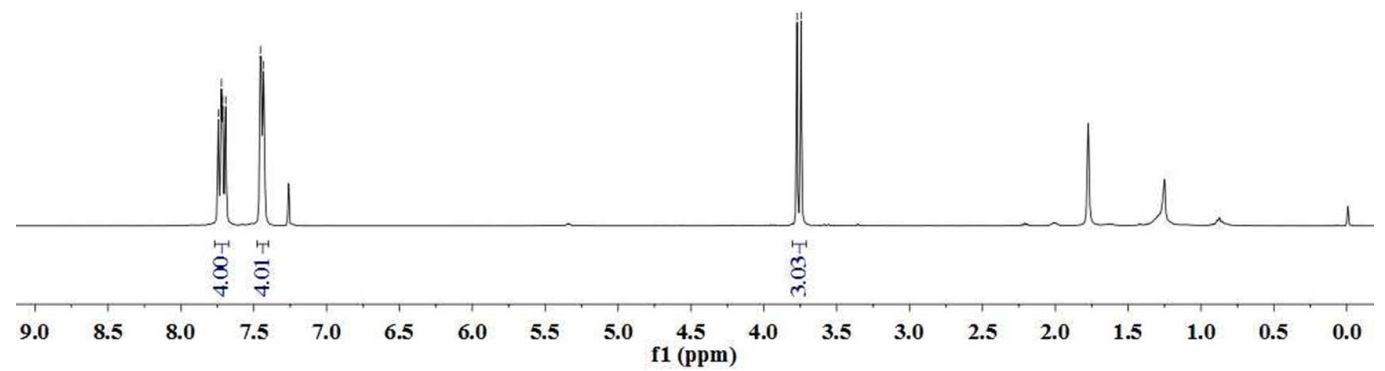




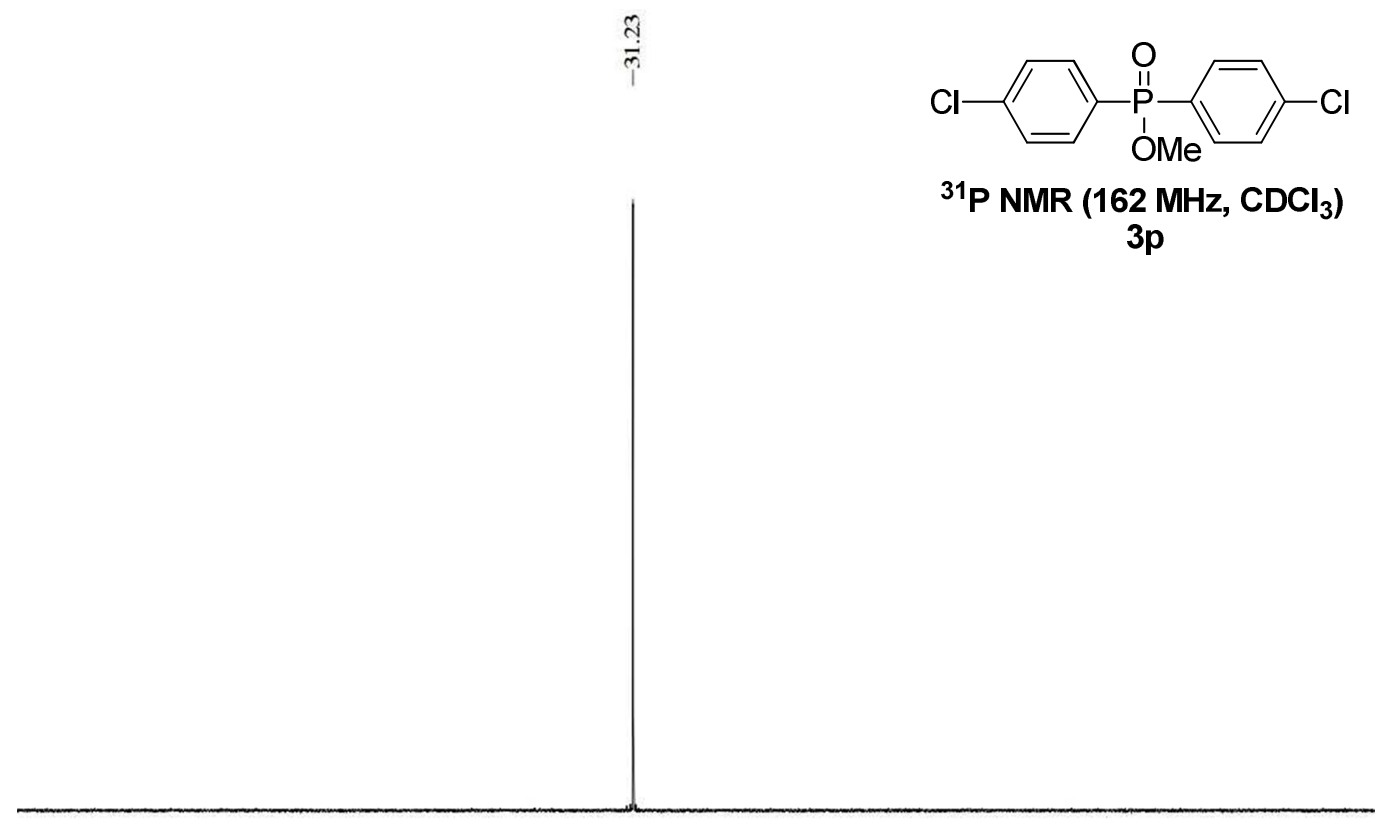

$\begin{array}{lllllllllllllllllllllll}130 & 120 & 110 & 100 & 90 & 80 & 70 & 60 & 50 & 40 & 30 & \underset{f}{20}(\mathrm{ppm}) & 10 & 0 & -10 & -20 & -30 & -40 & -50 & -60 & -70 & -80 & -9\end{array}$
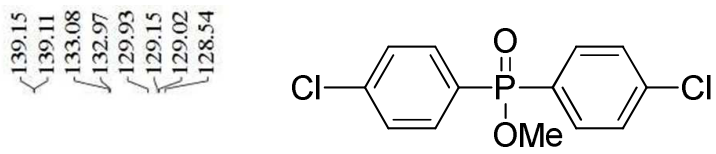

䑰

${ }^{13} \mathrm{C}$ NMR (100 MHz, $\left.\mathrm{CDCl}_{3}\right)$

$3 p$

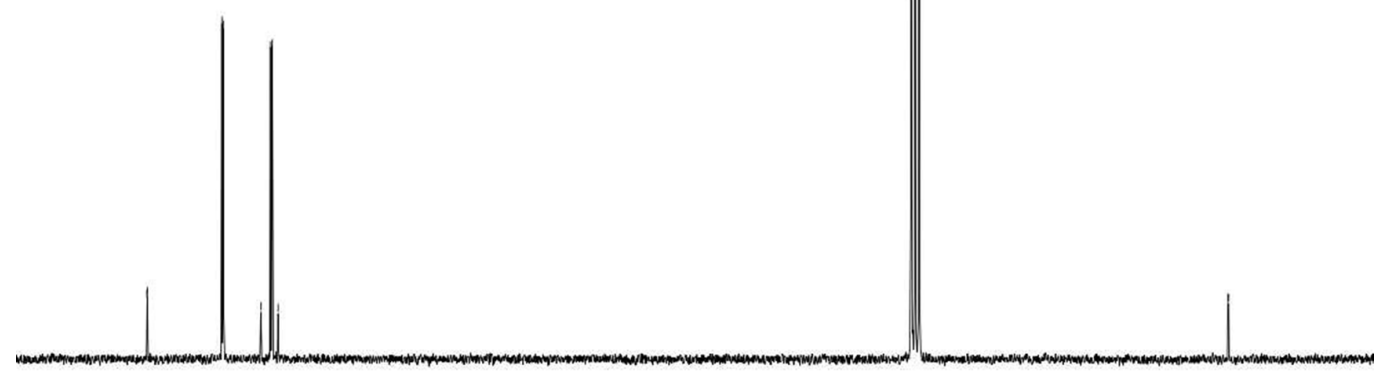

$\begin{array}{lllllllllllllllllllllllll}145 & 140 & 135 & 130 & 125 & 120 & 115 & 110 & 105 & 100 \underset{\mathrm{f} 1(\mathrm{ppm})}{95} & 90 & 85 & 80 & 75 & 70 & 65 & 60 & 55 & 50 & 45 & 4\end{array}$ 

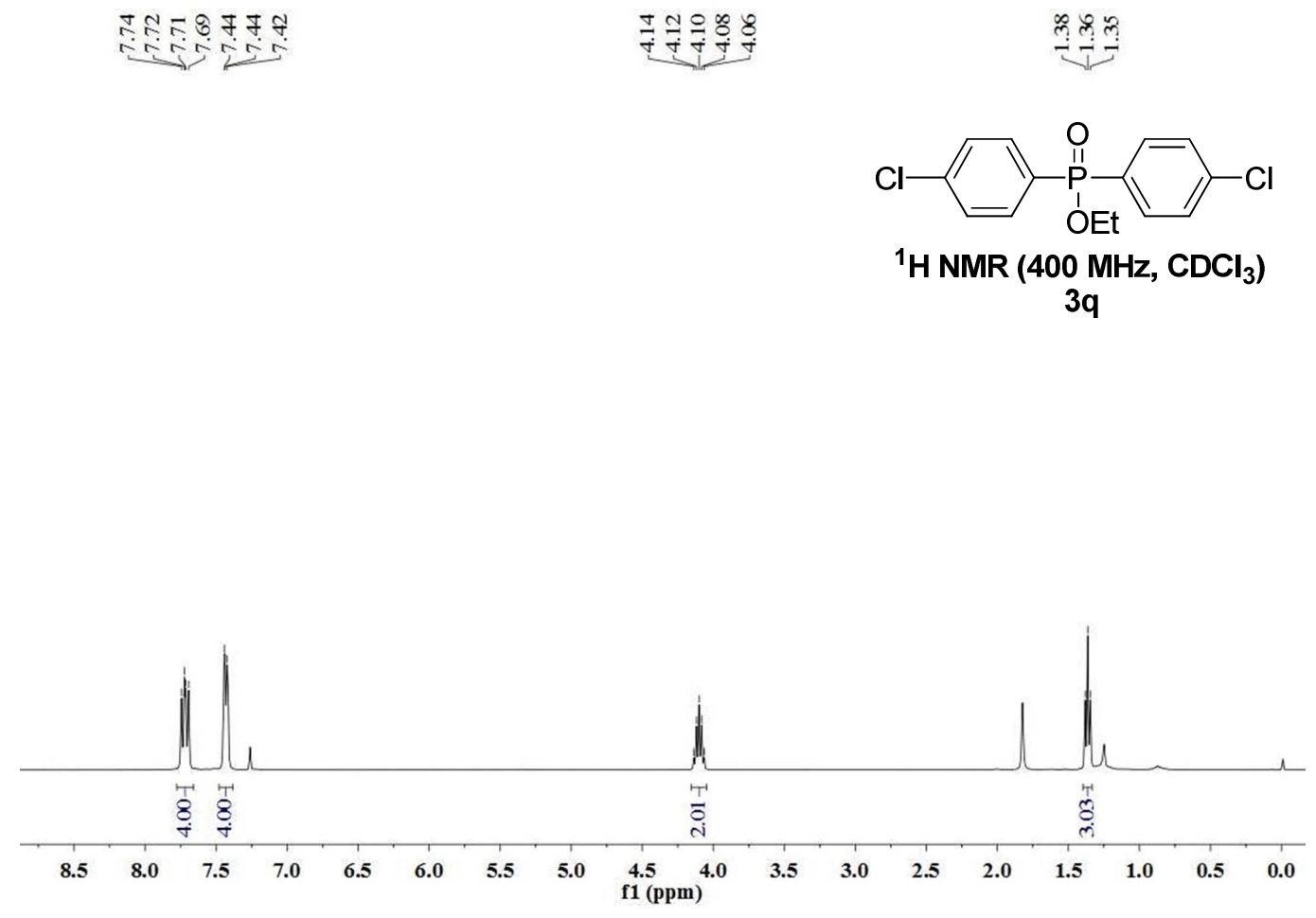

ले
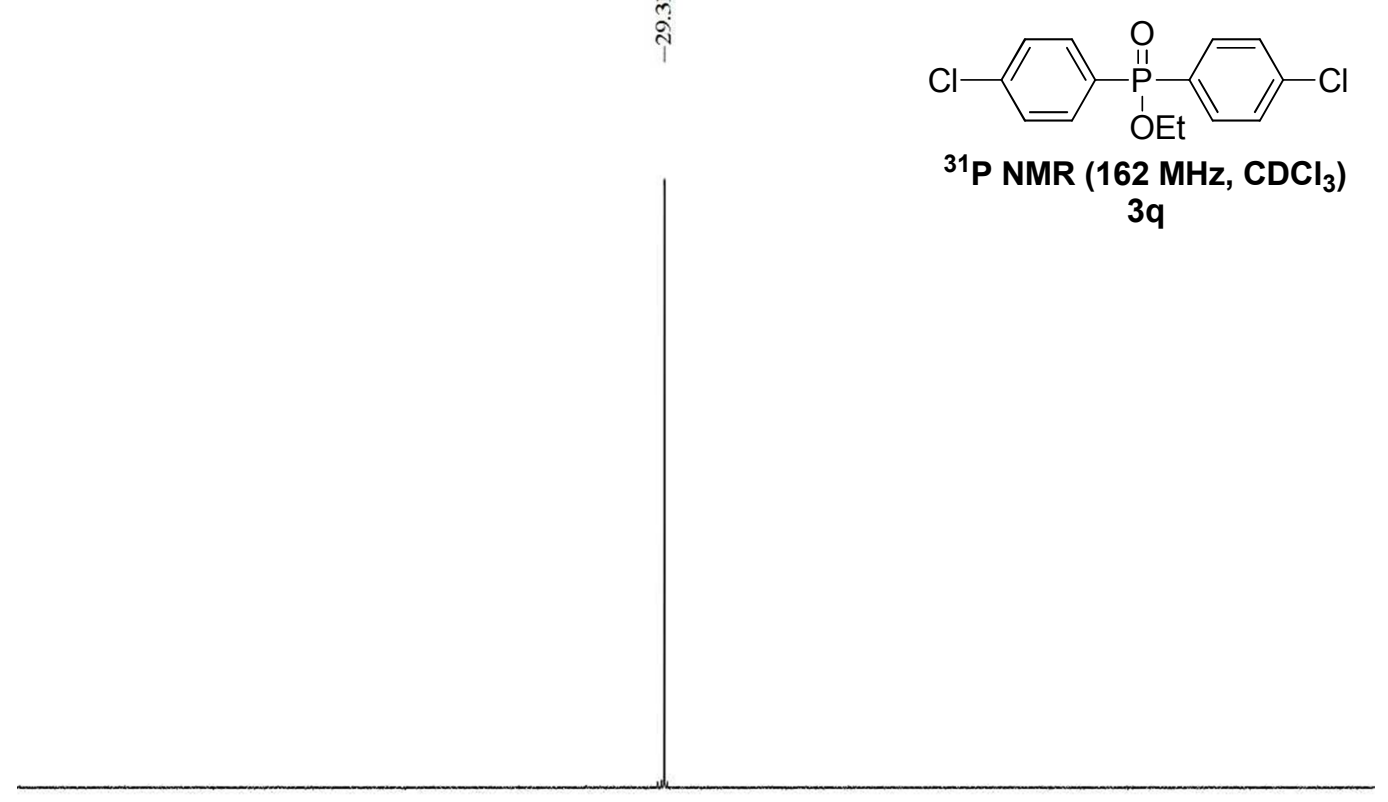

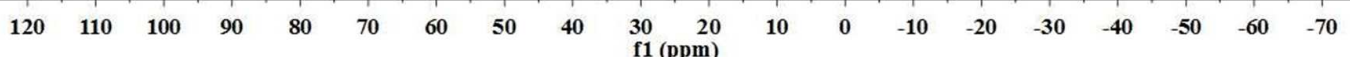




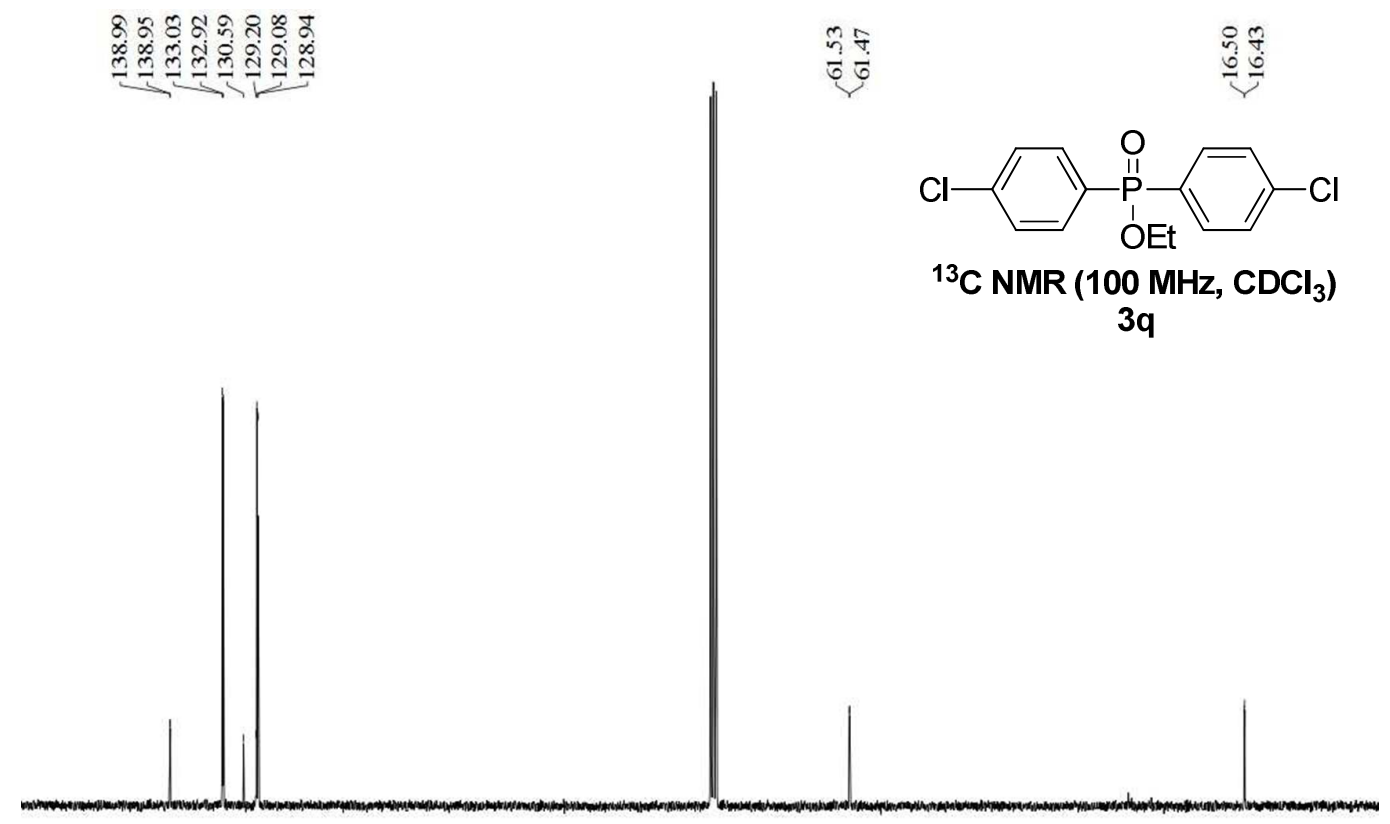

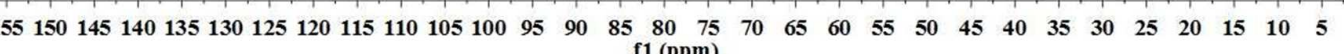
f1 (ppm)
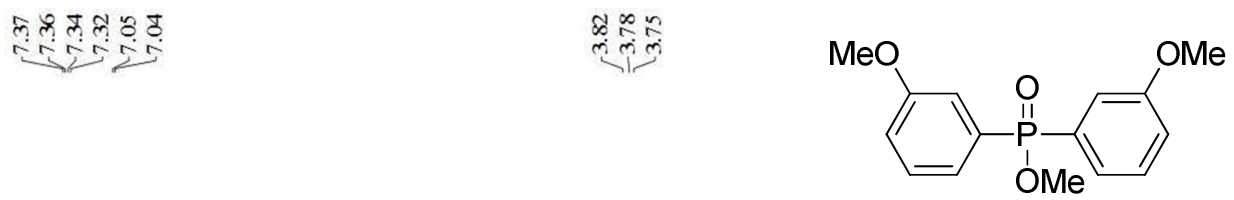

${ }^{1} \mathrm{H}$ NMR (400 MHz, $\mathrm{CDCl}_{3}$ )

$3 r$

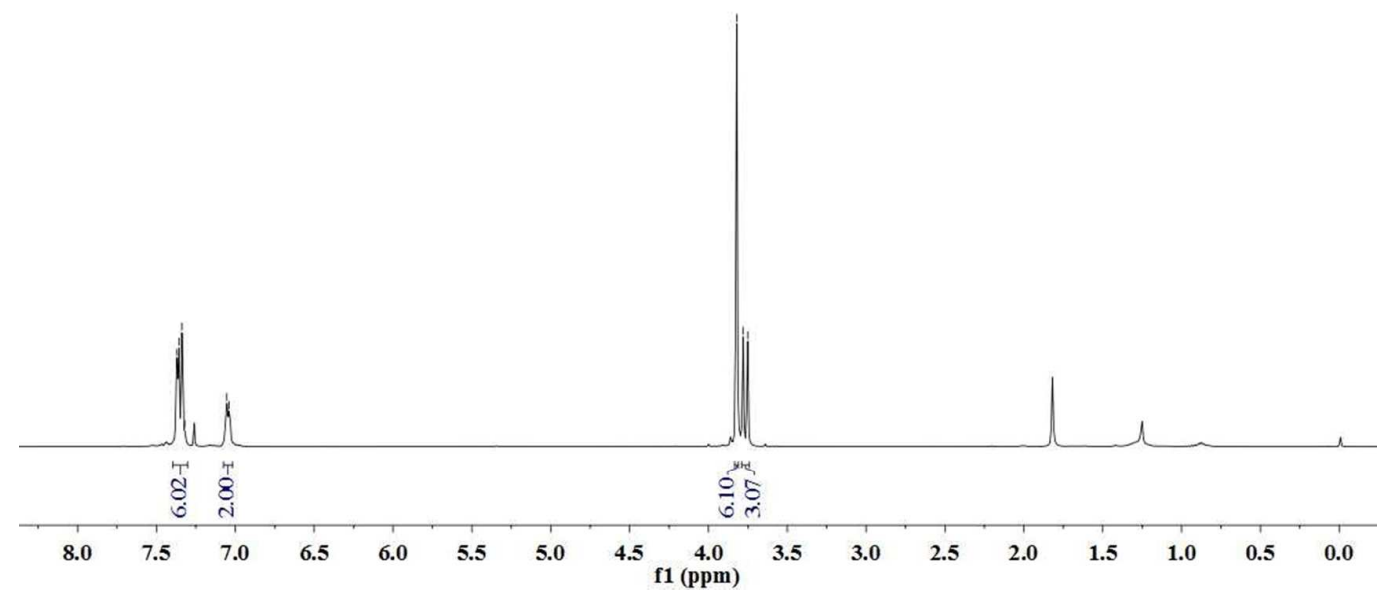



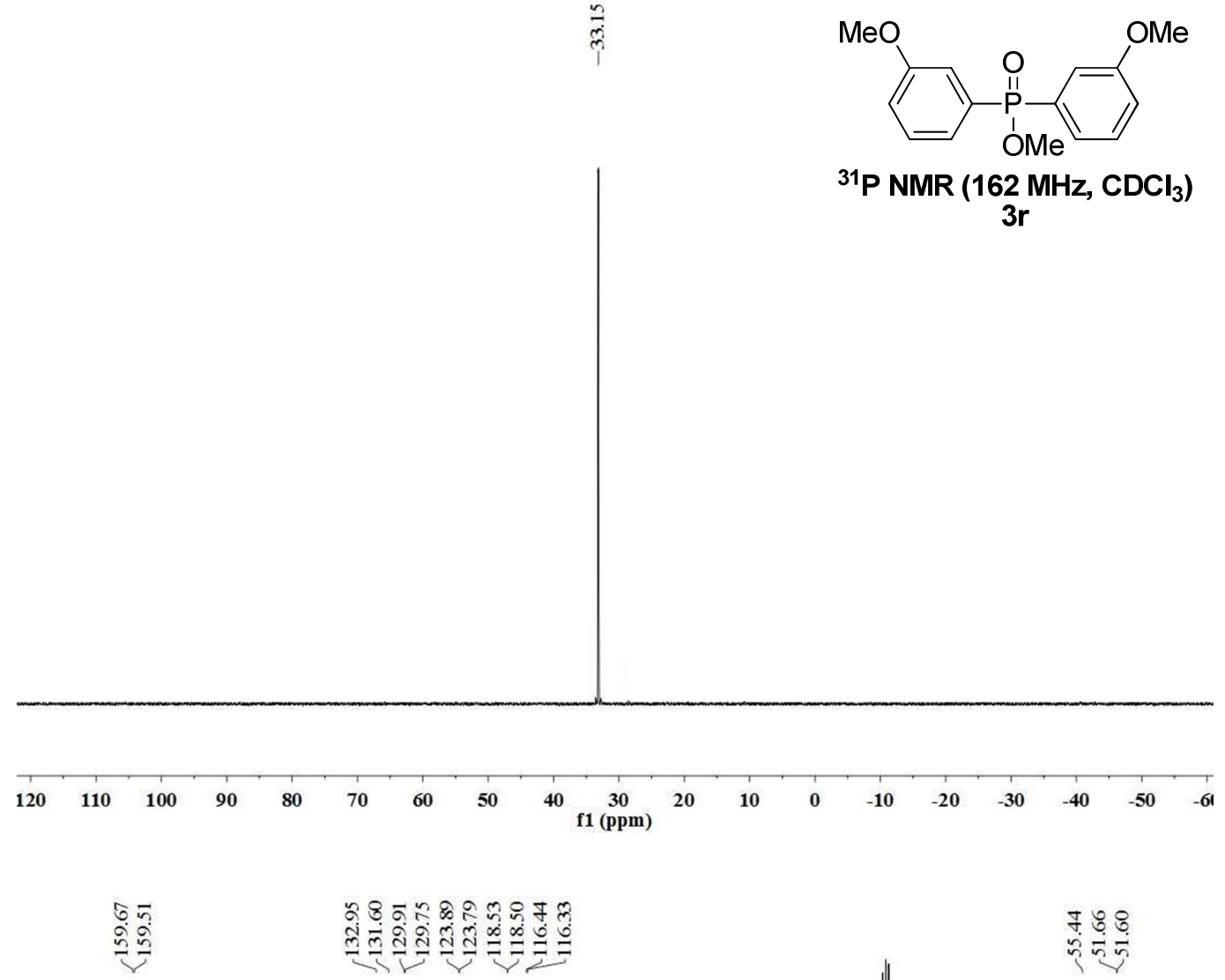

$78:$

$\mathrm{MeO}$

in $\frac{\pi}{2}$
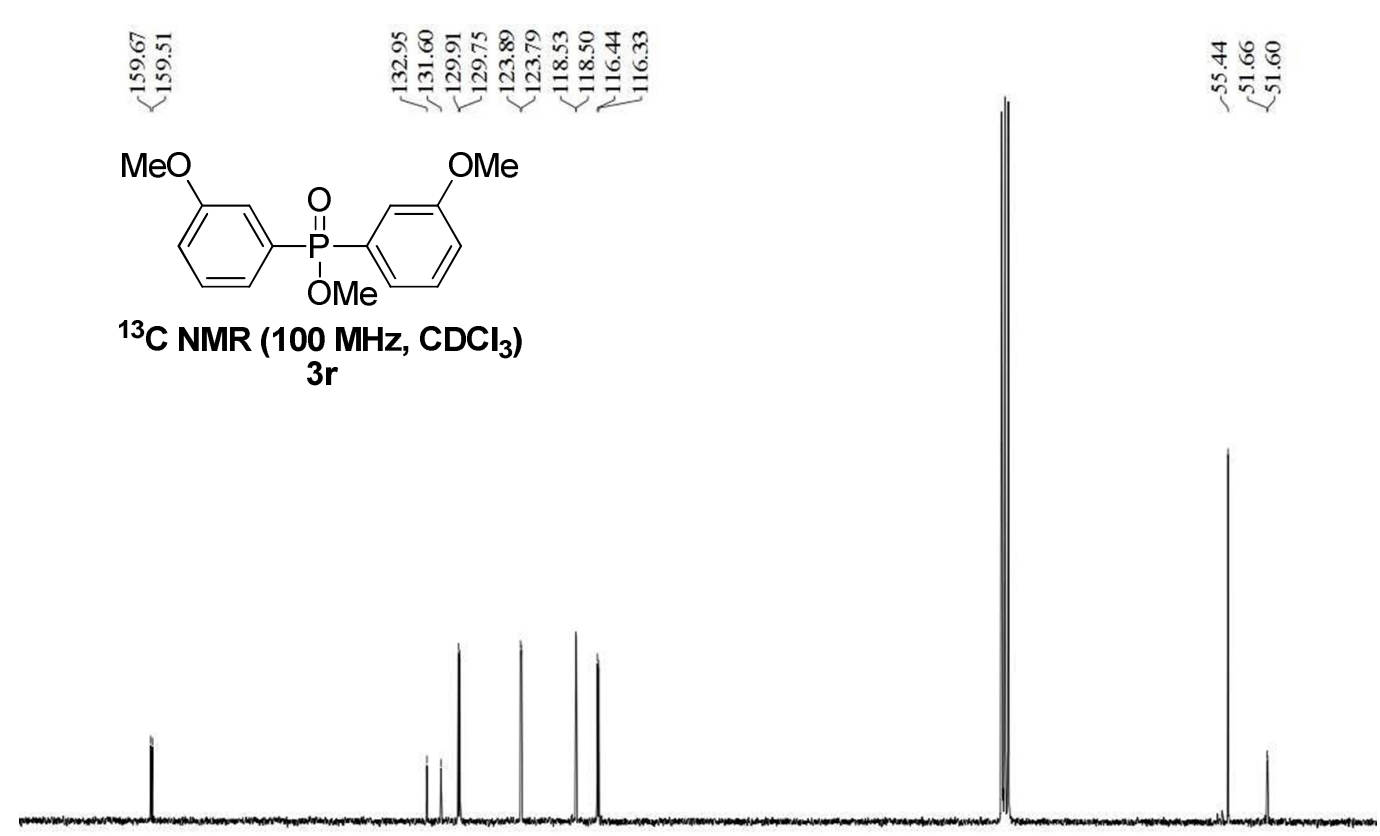

$\begin{array}{lllllllllllllllllllllllllllllllllllll}170 & 165 & 160 & 155 & 150 & 145 & 140 & 135 & 130 & 125 & 120 & 115 & 110 & 105 & 100 & 95 & 90 & 85 & 80 & 75 & 70 & 65 & 60 & 55 & 50 & 45\end{array}$ 11 (ppm) 


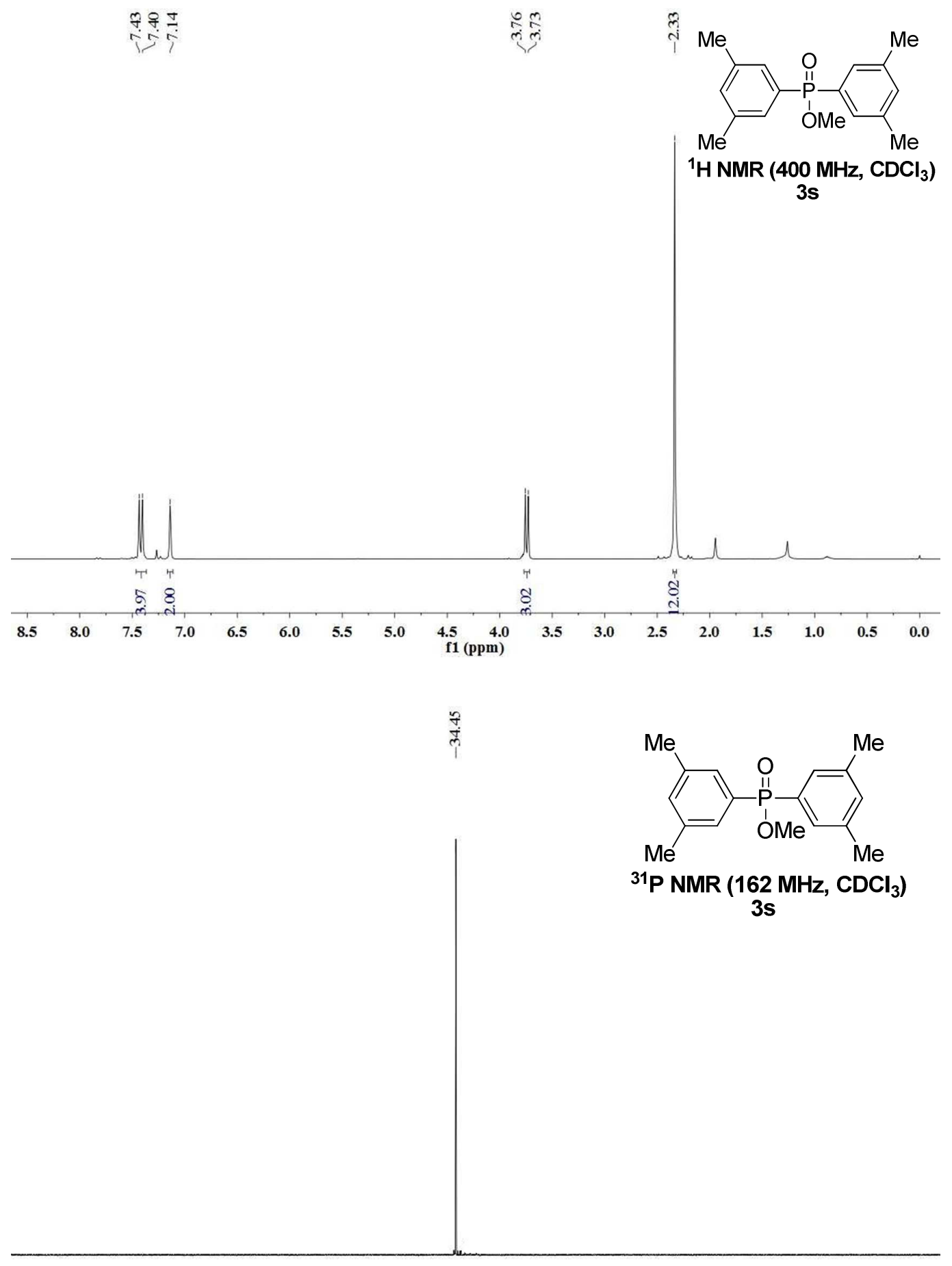

$\begin{array}{llllllllllllllllllll}120 & 110 & 100 & 90 & 80 & 70 & 60 & 50 & 40 & \underset{f 1}{(\mathrm{ppm})} & 20 & 10 & 0 & -10 & -20 & -30 & -40 & -50 & -60\end{array}$ 


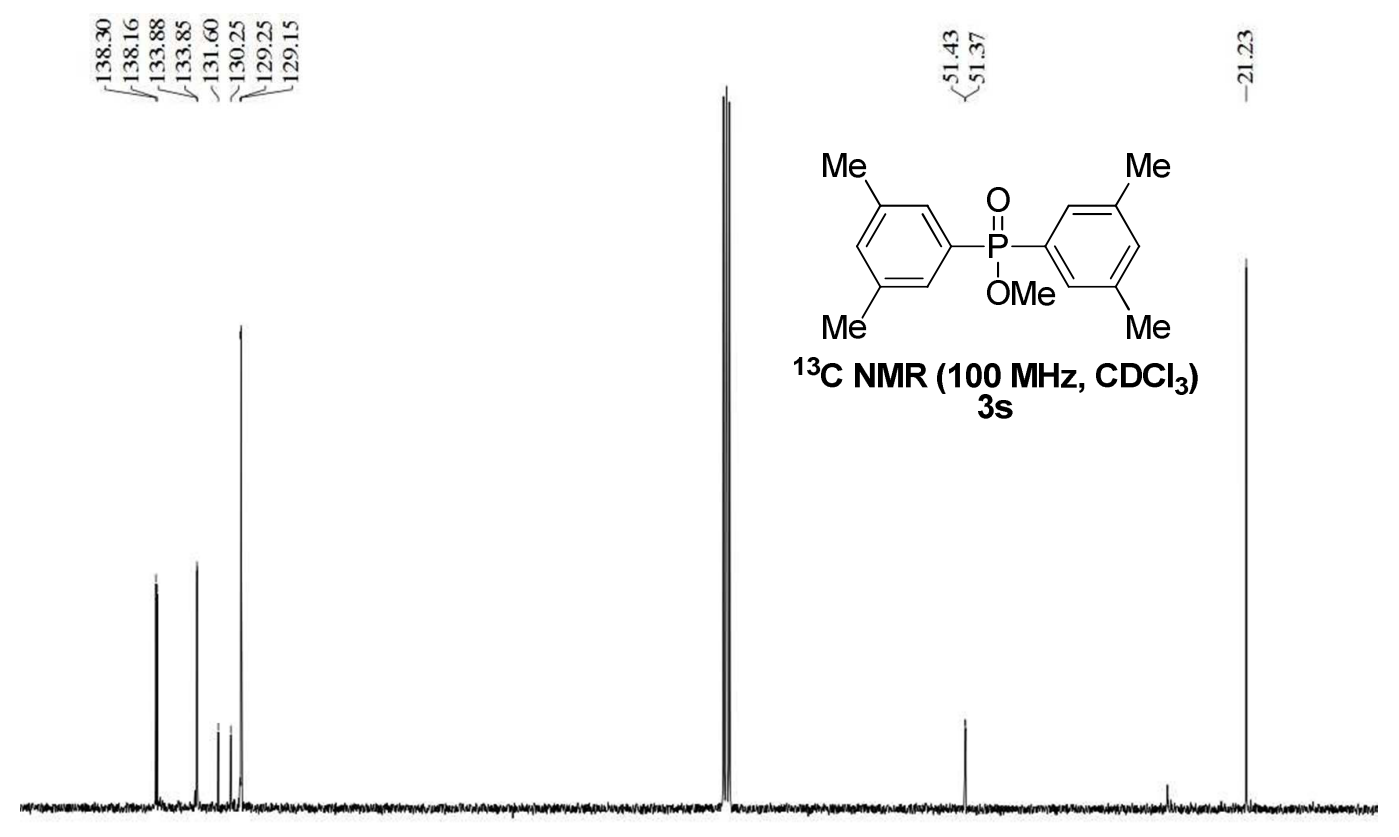

$\begin{array}{lllllllllllllllllllllllllllllllllllllllllll}150 & 145 & 140 & 135 & 130 & 125 & 120 & 115 & 110 & 105 & 100 & 95 & 90 & 85 & 80 & 75 & 70 & 65 & 60 & 55 & 50 & 45 & 40 & 35 & 30 & 25 & 20 & 15 & 10\end{array}$
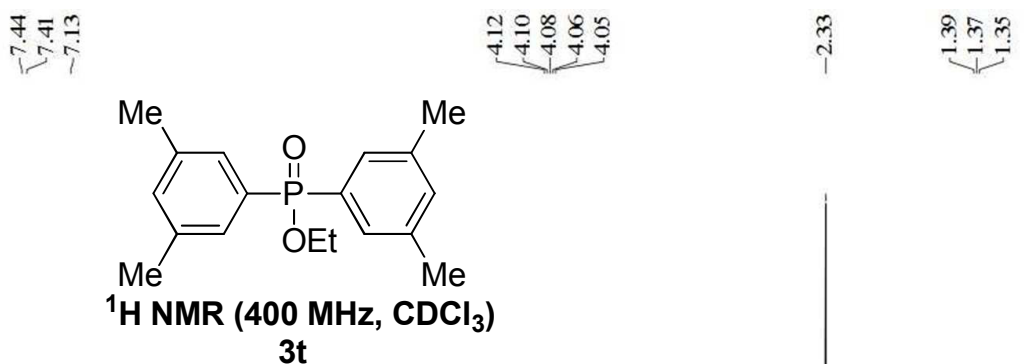

3t

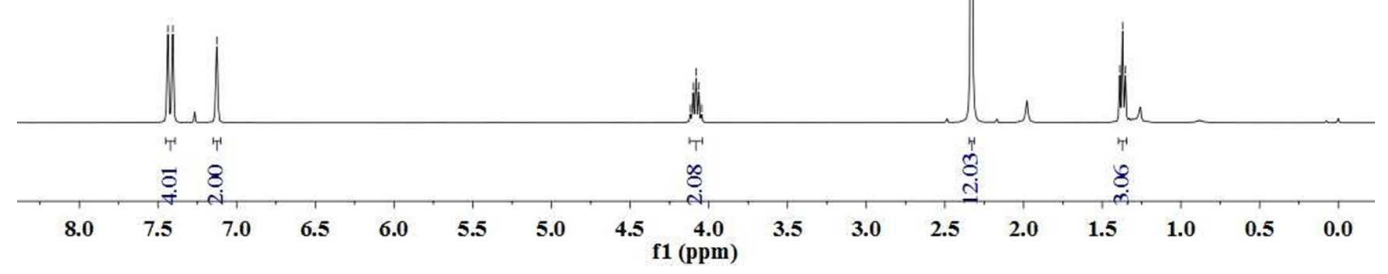




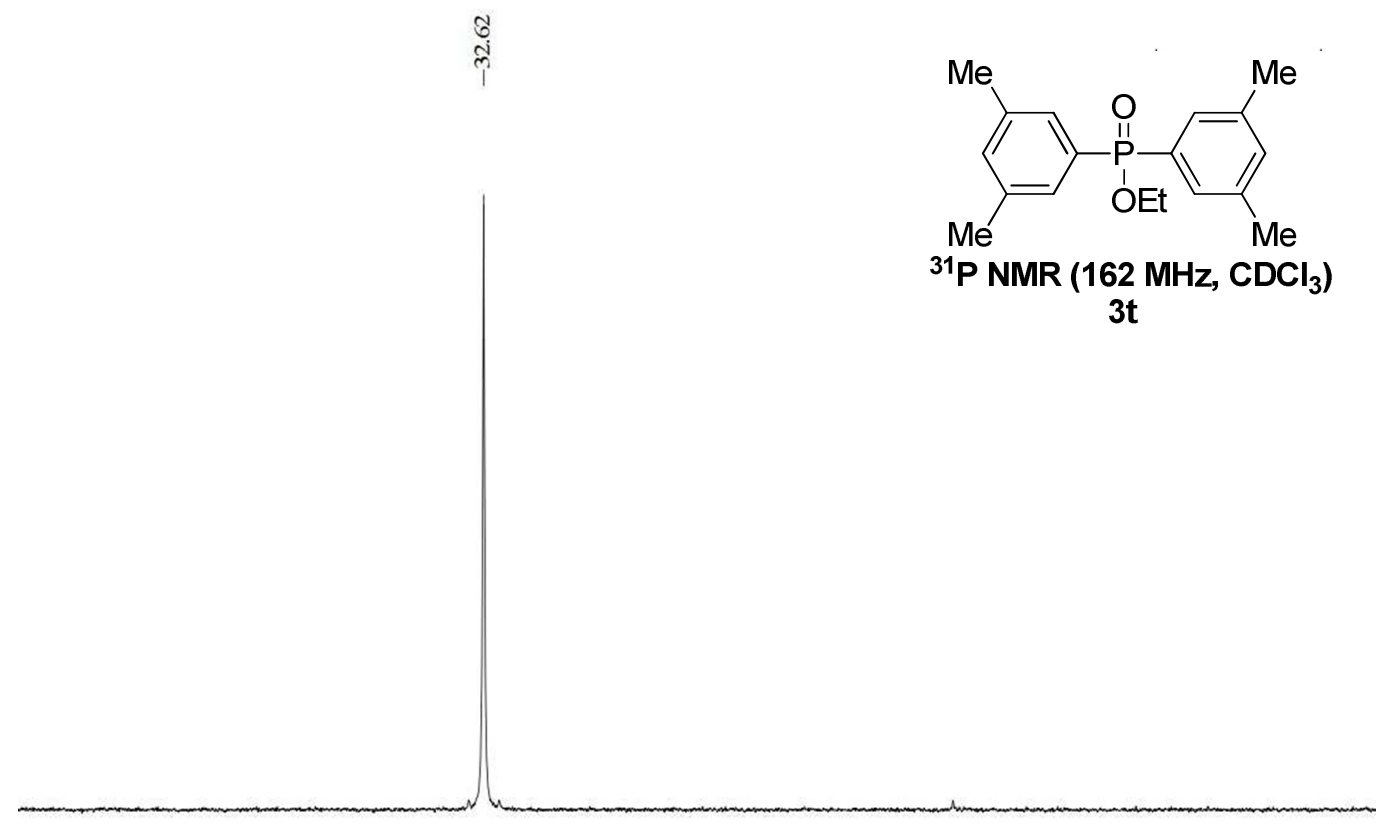

$\begin{array}{lllllllllllllllllllllllllllllllllllllllll}45 & 44 & 43 & 42 & 41 & 40 & 39 & 38 & 37 & 36 & 35 & 34 & 33 & 32 & 31 & 30 & 29 & 28 & 27 & 26 & 25 & 24 & 23 & 22 & 21 & 20 & 19 & 18 & 17 & 16 & 15 & 14 & 13 & 12 & 11 & 10 & 9\end{array}$ f1 (ppm)
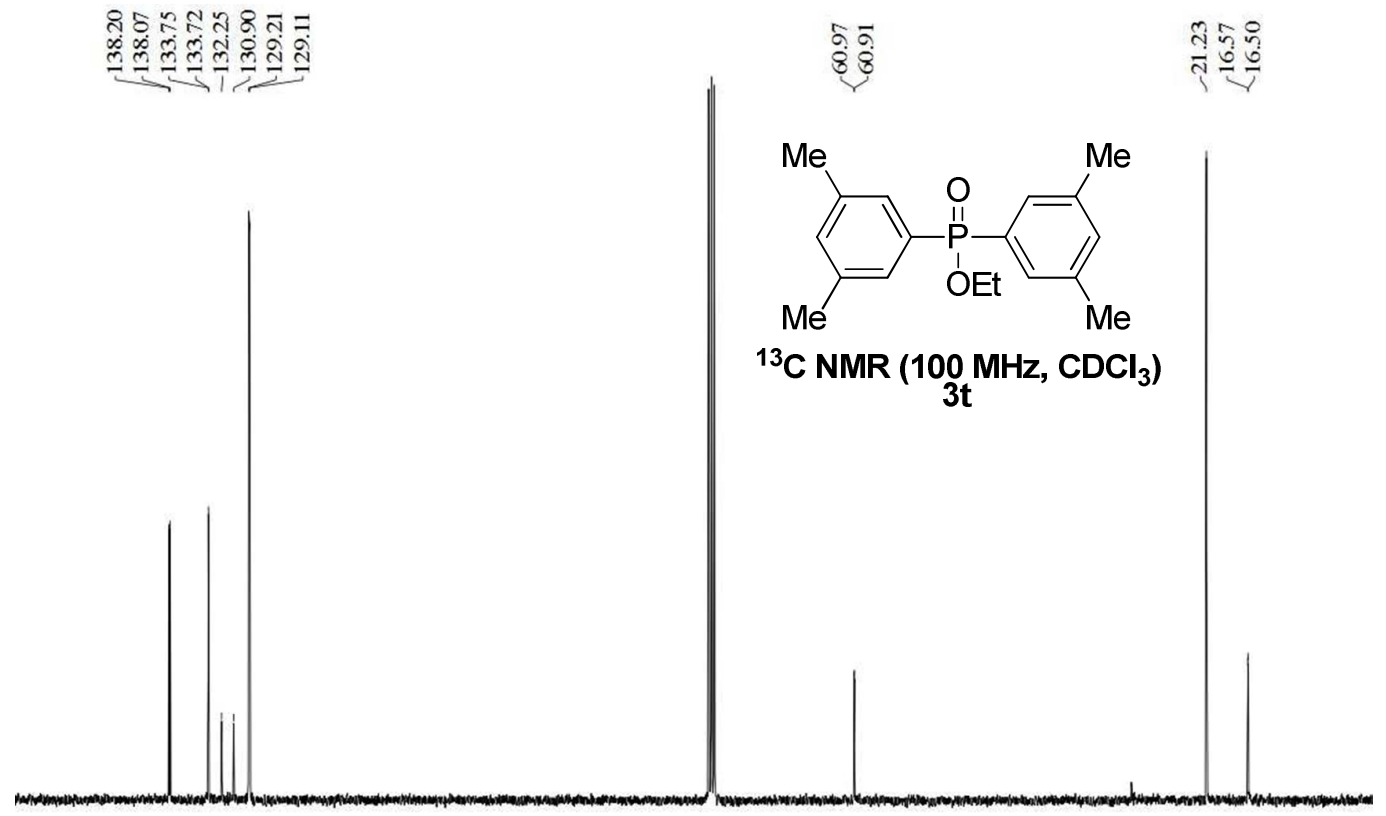

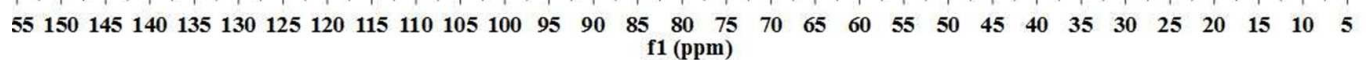

